\author{
UNIVERSIDADE DE SÃO PAULO \\ FACULDADE DE CIÊNCIAS FARMACÊUTICAS \\ Programa de Pós-Graduação em Ciências dos Alimentos \\ Área de Bromatologia
}

\title{
Prevalência e características de Salmonella spp em carne bovina brasileira para exportação: contribuição para uma avaliação de risco
}

Angela Palamin Azevedo

Dissertação para obtenção do grau de MESTRE

Orientadora: Prof. Tit. Dra. Bernadette Dora Gombossy de Melo Franco 


\author{
UNIVERSIDADE DE SÃO PAULO \\ FACULDADE DE CIÊNCIAS FARMACÊUTICAS \\ Programa de Pós-Graduação em Ciências dos Alimentos \\ Área de Bromatologia
}

\title{
Prevalência e características de Salmonella spp em carne bovina brasileira para exportação: contribuição para uma avaliação de risco
}

Angela Palamin Azevedo

Dissertação para obtenção do grau de MESTRE

Orientadora: Prof. Tit. Dra. Bernadette Dora Gombossy de Melo Franco 
Angela Palamin Azevedo

Prevalência e características de Salmonella spp em carne bovina brasileira para exportação: contribuição para uma avaliação de risco

Comissão Julgadora

da

Dissertação para obtenção do grau de Mestre

Profa. Dra. Bernadette Dora Gombossy de Melo Franco orientadora / presidente

$1^{\circ}$. examinador

$2^{\circ}$. examinador

São Paulo, de 


\section{AOS MEUS PAIS}

Obrigada por vocês existirem e por serem quem são: mais que apenas pais biológicos.

Obrigada pela dedicação, pela amizade, pelo companheirismo.

Obrigada pela vida e pelo orgulho que é ter nascido de vocês.

Obrigada pelos ensinamentos, pelos sermões, pelos castigos, pelas palmadas e, principalmente pelos exemplos.

Eles são valiosíssimos.

Obrigada pelos agrados e principalmente pelos desagrados.

Assim, eu pude ver que na vida nem tudo é como a gente quer

Aprendi a ter limites a ser mais “gente”.

Obrigada pelas preocupações sei que muitas vezes fui (e ainda sou) causa de inapetência e insônia.

Obrigada pela caminhada, pela luta, pela lida.

Aprendi com vocês

A ter coragem, a não desanimar, a saborear a vitória.

Obrigada pelas mãos entrelaçadas na minha, doando-me confiança, na certeza de estar indo por caminhos seguros e na certeza de que terei sempre onde amparar caso eu tropece.

Obrigada por tudo que vocês planejaram e fizeram, por tudo que planejaram e não fizeram e pelo o que fizeram sem planejar.

Obrigado pelas renúncias...

Perdão por tudo que fiz, por tudo que não fiz e pelo que pensei em fazer.

Deus abençoe vocês

E me abençoe também

Dando-me a alegria de tê-los por muito tempo ainda.

\section{Amo vocês!}




\section{MEU IRM $\boldsymbol{A} O$}

Você esteve do meu lado durante todo esse tempo, me ajudou a superar tantos medos, a percorrer tantos caminhos, a diminuir a minha dor, a conquistar tantos sorrisos...

Você, por muitas vezes foi o único ombro amigo, a única solução.

E estava sempre com a disposição de ajudar, independente do que tenha sido o meu problema e eu retribuí da mesa forma quando precisou de mim...

Fomos confiando um no outro cada vez mais, fomos nos gostando cada vez mais, e queríamos estar sempre em contato, mesmo que fosse apenas para dizer "oi"...

Trocamos mensagens, confidências, alegrias, tristezas e amizade...

Você e eu, amigos inseparáveis, amigos para qualquer hora e qualquer problema ou qualquer felicidade!

Amigos de verdade...

Amigos que brincam que falam a verdade, que ofendem com carinho, que pedem desculpas, que repreendem sem magoar, que emprestam o ouvido para ouvir, que emprestam as mãos para fazer carinho, que emprestam o próprio tempo para fazer companhia...

Somos amigos, temos muitas coisas em comum, temos tudo o que se espera numa amizade, e nos sentimos felizes em sermos amigos...

Agradeço a Deus por ter você em minha vida, sem a sua amizade, ela não teria o mesmo valor! mundo,

Obrigado pela pessoa amiga que é, obrigado por existir nesse

Obrigado por me deixar lhe chamar de AMIGO, meu

IRMÃO!!!

Autoria: Vilma Galvão

\section{OBRIGADA A TODOS DA MINHA FAMÍLIA!!!!}




\section{Agradecimentos}

À Prof. Dra. Bernadette Dora Gombossy de Melo Franco, pela oportunidade de trabalho, compartilhamento de seus conhecimentos, por acreditar em mim e pela amizade.

À Prof. Dra. Mariza Landgraf pelas sugestões e convívio.

À Prof. Dra. Maria Teresa Destro pelas sugestões e convívio.

À Dra. Tânia Maria Ibele Vaz do Instituto Adolfo Lutz pela imensa contribuição na sorotipificação das cepas.

À Prof. Dra. Elaine Pereira de Martini e ao Prof. Dr. Auro Nomizo, pela grande contribuição na realização dos testes com células Caco-2.

À Bruna Carrer Gomes pela grande contribuição na realização dos testes com células Caco-2.

Aos docentes e funcionários das disciplinas de Microbiologia, Parasitologia e Imunologia do Departamento de Análise Clínicas Toxicológicas e Bromatológicas da FCFRP / USP.

À minha futura companheira de formação Kátia Leani de Oliveira Souza e Silva, técnica do Laboratório de Microbiologia de Alimentos FCF / USP, pela amizade valiosa, força, ajuda nos momentos difíceis e colaboração dedicada em todos os experimentos práticos.

Aos meus verdadeiros anjos da guarda, por quem eu tenho uma admiração e amor enorme (com todo respeito...) Ana Eucares, André, Cecília, Tatiana, Vanessa e Verena, por todos os momentos felizes, difíceis, mas de qualquer forma momentos de muitas risadas. Amo vocês! 
Aos amigos que passaram e que continuam no laboratório, Anderson, Adriana, Carol, Crystina, Danielle, Eb, Graciela, Janaína, Joyce, Kátia Lima, Keila, Lúcia, Maíra, Marildes, Matheus, Mônika Priscila, Verônica e Vinícius pela amizade e colaboração.

Aos novos e eternos amigos da FCFRP/USP, Leo, Fabrícia, Miriam, Bruna, Marina, Lizziane, Fernanda, Beatriz, Fabrício, Otávio e Vanessa, pela amizade, colaboração e mútua orientação.

À Mônica, Cleonice e Edílson da secretaria do departamento, pelos serviços prestados.

À Elaine e Jorge da secretaria de Pós-Graduação, pela atenção dedicada e serviços prestados.

Aos funcionários do Frigorífico, onde foram coletadas as amostras para o desenvolvimento da pesquisa, pois sem a colaboração deles, não seria possível a realização deste trabalho.

Aos meus queridos amigos de Ribeirão Preto, Danielle e Marcelo, Fabiana e Guilherme, Flávia e Guilherme e suas respectivas famílias, que durante toda a minha vida, sempre fizeram presentes em forma de apoio, críticas e incentivos. Amo vocês! 


\section{SUMÁRIO}

Página

SUMÁRIO.

I

LISTA DE FIGURAS........................................................................ III

LISTA DE TABELAS......................................................................... IV

LISTA DE QUADRO......................................................................... $\quad V$

RESUMO.................................................................................................. VI

ABSTRACT ................................................................................... VII

1. REVISÃO DA LITERATURA................................................... 1

1.1 Carne bovina brasileira: importância da exportação............... 2

1.2 Contaminação microbiana da carne bovina........................ 3

1.3 Salmonella spp: características gerais............................ 5

1.3.1 Taxonomia................................................ 5

1.3.2 Fisiologia e Bioquimismo................................ 6

1.3.3 Patogenicidade............................................. 8

1.3.4 Características epidemiológicas............................ 12

1.3.5 Isolamento e identificação................................... 13

1.3.6 Subtipagem molecular................................. 14

1.3.7 Resistência a antimicrobianos............................. 16

1.4 Análise de Risco microbiológico..................................... 18 


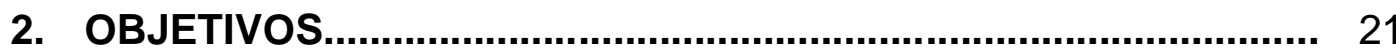

2.1- Geral......................................................................... 22

2.2- Específicos.............................................................. 22

3. MATERIAL E MÉTODOS............................................................ 23

3.1 Origem das amostras bovinas........................................ 24

3.2 Coleta, acondicionamento e transporte das amostras............ 24

3.3 Isolamento e identificação de Salmonella spp...................... 27

3.4 Eletroforese em Gel de Campo Pulsado (PFGE).................. 31

3.5 Teste de invasão a células da linhagem Caco $-2 \ldots \ldots \ldots \ldots \ldots . . . .32$

3.6 Avaliação da resistência a antimicrobianos........................ 34

4. RESULTADOS.................................................................................. 36

5. DISCUSSÃO.............................................................................. 49

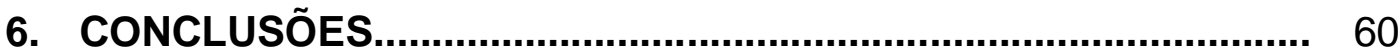

7. REFERÊNCIAS BIBLIOGRÁFICAS.......................................... 62

8. ANEXOS....................................................................................... 79 


\section{LISTA DE FIGURAS}

Figura 1. Esquema de abate de bovinos, com indicação dos três pontos de amostragem.

Figura 2. Pontos de amostragem nas carcaças bovinas

Figura 3. Esquema do procedimento de isolamento de Salmonella spp.

Figura 4. Fitas Etest (AB Biodisk - Suécia), usadas para avaliação da resistência a antimicrobianos.

Figura 5. Positividade para Salmonella spp nos 200 bovinos analisados

Figura 6. Dendograma indicando a relação genética entre as cepas de Salmonella spp isoladas no estudo.

Figura 7. Fotomicrografia (Olympus BX51) mostrando a Eficiência de Invasão de células Caco - 2 - A: Salmonella Typhimurium ATCC 14028 (Controle positivo), B: E.coli K12 (Controle negativo), C e D: Cepa 16 (Salmonella enterica subsp. enterica cepa rugosa - couro do animal 16). Coloração com May Grunwald - Giemsa (aumento 1.000 vezes).

Figura 8. Avaliação da resistência aos antimicrobianos empregando fitas Etest: A: culturas sensíveis, B: culturas resistentes, de acordo com CLSI. 


\section{LISTA DE TABELAS}

Tabela 1. Antimicrobianos utilizados no antibiograma - Etest

Tabela 2. Distribuição da positividade para Salmonella nas amostras analisadas e os sorovares encontrados.

Tabela 3. Resultados da prova de invasão das cepas de Salmonella nas células Caco - 2

Tabela 4. Comportamento das cepas de Salmonella spp, frente aos antimicrobianos determinado pelo Método do Etest.

Tabela 5. Distribuição dos perfis de resistência das cepas de Salmonella spp isoladas.

Tabela 6. Correlação entre origem das cepas de Salmonella spp, perfil genético, perfil de resistência aos antimicrobianos, sorovares e Eficiência de Invasão de células Caco-2 


\section{LISTA DE QUADRO}

Quadro 1. Distribuição de Salmonella spp, nas amostras bovinas, de acordo com a origem dos lotes de animais avaliados 
AZEVEDO, A.P. Prevalência e características de Salmonella spp em carne bovina brasileira para exportação: contribuição para uma avaliação de risco.2009. 84p. Dissertação (Mestrado) - Faculdade de Ciências Farmacêuticas, Universidade de São Paulo, São Paulo, 2009.

\section{Resumo}

O Brasil consolidou-se como o principal produtor e exportador mundial de carne bovina. Estudos microbiológicos, geralmente realizados com amostras de carne coletadas no comércio e não na cadeia produtiva de carne, resultam numa insuficiência de dados a respeito das características fenotípicas e genotípicas das bactérias patogênicas de relevância nos produtos destinados à exportação. Objetivando determinar a prevalência e características de Salmonella spp em carne bovina para exportação, realizou-se a coleta de amostras de superfícies de 200 bovinos adultos, provenientes de 12 fazendas, abatidos em Frigorífico Exportador em São Paulo, Brasil, no ano de 2008. Foram coletadas amostras do couro do animal, logo após a realização da sangria (Co), da carcaça do mesmo animal, após a esfola ( $\mathrm{Ca} \mathrm{I})$ e da carcaça do mesmo animal, após o toalete e antes da refrigeração ( $\mathrm{Ca}$ II). O isolamento e a identificação de Salmonella spp foram realizados de acordo com o método - ISO 6579:2002, com algumas modificações. O patógeno foi detectado em 14 amostras de couro (7,0\%), 5 de carcaça I (2,5\%) e 4 de carcaça II (2,0\%). Verificou-se a prevalência do sorovar S. Give $(52,0 \%)$, seguido de $S$. Abaetetuba (16,0\%), S. Typhimurium (8,0\%), S. Agona (4,0\%) e $S$. Dublin $(4,0 \%)$, e quatro cepas $(16,0 \%)$ não tipáveis. A tipagem molecular, feita por PFGE, mostrou que as salmonelas expressaram 12 perfis genéticos distintos, sendo 10 formados por apenas uma cepa, cada. As demais cepas (15) pertenceram a dois perfis genéticos apenas, que apresentaram $91,7 \%$ de similaridade. De acordo com o teste de infecção de células Caco-2, a maioria das cepas $(92,0 \%)$ apresentou Eficiência de Invasão inferior a 1,0\%, indicando baixo potencial de virulência. Quanto ao perfil de resistência a antibióticos, 68,0\% das cepas analisadas foram multiresistentes, apresentando 12 perfis diferentes. Animais diferentes, provenientes de uma mesma fazenda, apresentaram salmonelas de um mesmo sorovar e com o mesmo perfil genético e de resistência a drogas, comprovando a ocorrência de contaminação cruzada durante o processamento da carne bovina. A multiresistência das salmonelas isoladas e a possibilidade de disseminação desses patógenos denotam a necessidade de se adotar medidas de higiene adequadas e maior prudência no emprego de antimicrobianos, na dieta alimentar e na terapêutica veterinária.

Palavras - chave: Salmonella spp, carne bovina, tipagem molecular, virulência, resistência a antibióticos. 


\title{
Prevalence and characteristics of Salmonella spp in bovine meat for export: contribution for a risk assessment.
}

\begin{abstract}
Brazil is an important bovine meat producer and exporter. Microbiological surveys are generally run with meat samples collected at retail level and not with meat for export, explaining the lack of data on the phenotypic and genotypic characteristics of pathogens of relevance in exported food products. This study aimed to evaluate the prevalence and characteristics of Salmonella spp in bovine meat destined for export, through surface sampling of hides and carcasses of 200 animals, from 12 farms, slaughtered in 2008 in an export slaughterhouse located in São Paulo, Brazil. Sampling was done from the hides right after bleeding (Co) and from carcasses of the same animal after removal of the hide ( $\mathrm{Ca} \mathrm{I}$ ) and after cleaning but before chilling (Ca II). Isolation and identification of Salmonella spp were done according to ISO 6579:2002, with some modifications. The pathogen was detected in 14 samples of hides (7,0\%), 5 of carcasses $\mathrm{Ca}$ I (2,5\%) and 4 of carcasses $\mathrm{Ca}$ II $(2,0 \%)$. The most prevalent serovars were $S$. Give $(52,0 \%)$, followed by $S$. Abaetetuba $(16,0 \%), S$. Typhimurium (8,0\%), S. Agona (4,0\%) and $S$. Dublin (4,0\%). Four isolates $(16,0 \%)$ were not typable. Molecular typing using PFGE indicated that the isolates presented 12 molecular profiles, ten of them containing one single isolate. Fifteen isolates belonged to only two distinct profiles, with $91.7 \%$ similarity. Invasion Efficiency tests, run with Caco- 2 cells, indicated that most isolates (92,0\%) presented low virulence potential. $68,0 \%$ of the isolates were multiresistant to antimicrobial drugs, presenting 12 different resistance profiles. Different animals, coming from the same rearing farm, harbored salmonellae belonging to same serovar and presenting the same genetic and antimicrobial resistance profiles, indicating cross contamination in the slaughterhouse during production of meat. The occurrence of salmonellae that can disseminate in the slaughterhouse and the multiresistance presented by the strains strengthen the need for adoption of proper hygiene control measures and care in the use of antibiotics in human and veterinary therapeutics.
\end{abstract}

Key-words: Salmonella spp, bovine meat, molecular typing, virulence, antimicrobial resistance. 
1. REVISÃO DA LITERATURA 


\subsection{Carne bovina brasileira: importância da exportação}

Em conseqüência ao crescimento da população mundial, o padrão de competitividade entre os países exportadores de alimentos está aumentando, com grande potencial para os produtos do agronegócio. Nesse cenário, o Brasil consolidou-se como o principal produtor e exportador de proteína de origem animal. O Brasil é hoje o maior exportador mundial de carne bovina e de aves e o quarto maior de carne suína, tendo atingido a marca histórica de US\$11 bilhões com exportações de carnes, em 2007 (MDICE, 2008).

De acordo com a Associação Brasileira das Indústrias Exportadoras de Carne (ABIEC, 2008), entre janeiro a outubro de 2008 o Brasil exportou pouco mais de 1,89 milhões de toneladas de carcaças de carne bovina, com faturamento de US\$ 4,67 milhões. Em relação ao mesmo período de 2007, houve um aumento de $26,0 \%$ em receita, com retração de $13,0 \%$ em volume. As exportações de carne in natura caíram 15,0\% em quantidade, com expansão de 21,0\% em receita. Quanto à carne industrializada, houve aumento em valor e volume - 59,0\% e $8,0 \%$, respectivamente.

Entre janeiro a julho de 2009, o Brasil exportou mais de 788 milhões de toneladas de carcaças de carne bovina, com faturamento de US $\$ 1,637$ milhões. Em relação ao mesmo período de 2008 , houve uma queda de $24,0 \%$ em receita, com retração de 13,0\% em volume. As exportações de carne in natura caíram 13,0\% em quantidade, com declínio de 29,0\% em receita. Quanto à carne industrializada, houve queda em valor e volume $-19,0 \%$ e 18,0\%, respectivamente (ABIEC, 2009).

O maior comprador de carne bovina brasileira in natura é a Rússia, com $38,0 \%$ de participação, seguida de Venezuela (9,0\%), Irã (7,0\%), Hong Kong $(5,0 \%)$, Egito $(5,0 \%)$, Argélia $(4,0 \%)$ e Israel $(4,0 \%)$. Outros países, com pouca representatividade individual, ficaram com os $28,0 \%$ restantes. Com relação à carne industrializada, 20,0\% do total exportado vão para os Estados Unidos, seguido do Reino Unido (14,0\%), Itália (6,0\%), Países Baixos (6,0\%), Alemanha (2,0\%), Bélgica $(1,0 \%)$ e Jamaica $(1,0 \%)$. O grupo "outros" fica com os $50,0 \%$ restantes. Portanto, em 2008, com o aumento das restrições européias, a carne in natura do Brasil teve um crescimento mais expressivo em relação à carne industrializada, no entanto, as vendas de carne in natura caíram, inclusive para a própria Europa. No final de 2008 
a crise financeira internacional impactou, negativamente, os embarques, com especial destaque para a Rússia (ABIEC, 2008).

\subsection{Contaminação microbiana da carne bovina}

A contaminação microbiana mais importante da carne bovina é de origem externa, uma vez que a massa interna (músculo) da carne não contém microrganismos, ou estes são muito escassos (XAVIER e JOELE 2004). A contaminação da carne ocorre por contato com a pele, pêlos, patas, conteúdo gastrointestinal e leite do úbere dos animais, bem como através de equipamentos, mãos e roupas de manipuladores, água utilizada para lavagem das carcaças e ar dos locais de abate e armazenamento (ROÇA e SERRANO, 1994 e 1995; ALMEIDA et al., 2002). Devido ao seu elevado valor nutritivo, a carne bovina serve de substrato para a multiplicação destes microrganismos (PARDI et al., 2001; ICMSF, 2005), sendo muitos os fatores que podem favorecer a multiplicação microbiana. Dessa forma, o slogan "animal saudável, carne saudável” nem sempre é verdadeiro, pois a qualidade e segurança da carne dependem da aplicação rigorosa de práticas higiênicas, em todas as etapas da cadeia produtiva (ICMSF, 2005).

Os Pontos Críticos de Controle (PCC) do fluxograma de abate de bovinos são a esfola, a evisceração e o resfriamento. A esfola é uma das etapas mais críticas, pois a superfície do couro dos animais, impregnada de sujidades, pode veicular grande quantidade de microrganismos para a superfície da carcaça (PARDI et al., 2001). O trato gastrointestinal dos bovinos é outra fonte importante de microrganismos, de modo que a evisceração deve ser conduzida cuidadosamente, evitando-se perfurações nos intestinos (ROÇA e SERRANO, 1994). Segundo Sigarini et al. (2006), a redução de contaminação microbiana em toda cadeia produtiva de carne bovina é possível, tomando-se medidas na fase de pré abate, como fechamento dos condutos do reto e esôfago, e na descontaminação das carcaças.

O nível de contaminação encontrado nos estabelecimentos de produção da carne bovina é determinado por uma somatória de fatores relacionados com falhas nas diferentes etapas do processo, como, por exemplo, ausência de esterilizadores de facas e ganchos, condições higiênico-sanitárias insatisfatórias, estrutura física 
precária do ambiente e falta de treinamento dos funcionários envolvidos nessa atividade (ICMSF, 2005; SIGARINI et al., 2006),

A presença de Salmonella spp em carnes bovinas e derivados já foi estudada no Brasil e em outros países. Na cidade de Manaus, AM, Aquino et al. (1991) pesquisaram Salmonella spp em 50 amostras de carne bovina moída comercializadas em mercados e açougues e encontraram $20,0 \%$ de positividade. Os sorovares identificados foram Salmonella Anatum, Salmonella Agona, Salmonella 13,10:-:1,6 e Salmonella London.

Mendes (1996), analisando 30 amostras de carne bovina in natura comercializadas em supermercados, açougues e feiras livres de Belém, PA, verificou que nenhuma das amostras foi positiva para Salmonella spp. Xavier e Joele (2004) analisaram 30 amostras de carne bovina in natura, de diversos cortes comercializados na cidade de Belém, PA, durante o mês de janeiro de 2002, verificando que apenas uma amostra, obtida em feira-livre, apresentou Salmonella spp.

Ainda no Brasil, Almeida et al. (2002) observaram que 20,0\% das 40 amostras de corte de carne bovina (acém inteiro e moído) provenientes de estabelecimentos comerciais da cidade do Rio de Janeiro, RJ, apresentaram positividade para Salmonella spp.

Sigarini et al. (2006), ao avaliarem a influência da desossa feita no estabelecimento comercial em relação a desossa feita no frigorífico na qualidade bacteriológica da carne bovina comercializada em Cuiabá, MT, verificaram que $12,5 \%$ das amostras analisadas antes da desossa encontravam-se contaminadas por Salmonella spp, enquanto nas amostras desossadas no estabelecimento de venda, a porcentagem de positividade foi mais alta, 20,0\%.

Resultados semelhantes aos obtidos no Brasil também foram relatados em outros países. Estudos realizados por Beach et al. (2002) comprovaram que 22,3\% das 538 amostras de carne bovina no Texas, EUA, provenientes de animais tratados com suplemento alimentar, foram positivas para Salmonella spp. Os sorovares mais comumente detectados foram Salmonella Anatum (18,3\%), Salmonella Kentucky (17,5\%), Salmonella Montevideo (9,2\%), Salmonella Senftenberg (8,3\%) e Salmonella Mbandaka (7,5\%). Em relação as 512 amostras provenientes de bovinos alimentados sem suplemento detectou-se $31,4 \%$ positivas para Salmonella spp. Os 
sorovares mais comuns entre as 161 cepas detectadas deste grupo de animais e de seu ambiente foram Salmonella Kentucky (35,4\%), Salmonella Montevideo (21,7\%), Salmonella Cerro (7,5\%), Salmonella Anatum (6,8\%) e Salmonella Mbandaka $(5,0 \%)$.

Ransom et al. (2002), pesquisaram Salmonella spp, em couro (150) e carcaça (120) de 60 bovinos de cinco frigoríficos dos Estados Unidos, verificando que $45,3 \%$ das amostras de couro e $1,7 \%$ de carcaça foram positivas.

Amostras de carne vermelha coletadas do setor de desossa de um grande abatedouro situado na Província Estado Livre, África do Sul foram analisadas por Nel et al. (2004). Dentre as 50 amostras avaliadas, 60,0\% foram positivas para Salmonella spp.

Em estudo realizado em 1997, 1998 e 1999 na Bélgica, Ghafir et al. (2005) observaram que somente um baixo número de amostras carnes de bovinos estavam contaminadas por Salmonella spp (0,0 a 4,2\%).

Na Inglaterra, Small et al. (2006) constataram que a positiva para Salmonella spp em carcaças de cordeiros, novilhos, suínos e bezerros de 14 dias de idade foi de $9,6 \%, 12,7 \%, 31,0 \%$ e $20,0 \%$, respectivamente. Salmonella spp não foi isolada de nenhuma das 330 carcaças de bovinos adultos

\subsection{Salmonella spp: características gerais}

\subsubsection{Taxonomia}

O gênero Salmonella é dividido em duas espécies: Salmonella enterica e Salmonella bongori. Recentemente, foi proposta a inclusão de uma terceira espécie denominada Salmonella subterranea, isolada de sedimento, coletado na região aquífera de Oak Ridge - Estados Unidos, que apresenta 96,4\% de similaridade com Salmonella bongori (D'AOUST e MAURER, 2007), ainda não reconhecida taxonomicamente. A espécie Salmonella enterica é subdividida em seis subespécies, cada uma com vários sorovares, dependendo da composição antigênica da parede celular (antígeno O), dos flagelos (antígenos H) e dos antígenos capsulares (antígenos Vi): Salmonella enterica subsp. enterica (1504 sorovares), Salmonella enterica subsp. salamae (502 sorovares), Salmonella 
enterica subsp. arizonae (95 sorovares), Salmonella enterica subsp. diarizonae (333 sorovares), Salmonella enterica subsp. houtenae (72 sorovares) e Salmonella enterica subsp. indica (13 sorovares), e a espécie Salmonella bongori (22 sorovares), perfazendo um total de 2541 sorovares de Salmonella spp. (HOLT et al., 1994; POPOFF e LE MINOR, 2005; D'AOUST e MAURER, 2007).

A nomenclatura das espécies, subespécies e sorovares de Salmonella spp têm passado por constantes alterações. Atualmente, considera-se internacionalmente aceito o esquema proposto pelo Centro para Controle e Prevenção de Doenças (CDC), dos Estados Unidos, no qual gênero, espécie e subespécie são escritos em letras itálicas, somente com o gênero com letra inicial maiúscula, e o sorovar é escrito em letras ocidentais, e com inicial maiúscula, por exemplo: Salmonella enterica subsp. enterica sorovar Enteritidis. Por conveniência, costuma-se citar apenas o gênero e o sorovar, grafando-se, por exemplo, Salmonella Enteritidis, Salmonella Typhimurium, Salmonella Infantis (HOLT et al., 1994; CDC, 2002).

Com finalidades epidemiológicas, as salmonelas podem ser classificadas em três grupos: (1) as que infectam somente humanos, como Salmonella Typhi, Salmonella Paratyphi A e Salmonella Paratyphi C, agentes das febres tifóides e paratifóides, respectivamente, consideradas as mais graves de todas as enfermidades produzidas por Salmonella spp; (2) os sorovares adaptados a hospedeiros específicos, como Salmonella Gallinarum (aves), Salmonella Dublin (bovinos), Salmonella Abortus-equi (equinos), Salmonella Abortus-ovis (ovinos) e Salmonella Choleraesuis (suínos) e (3) sorovares sem hospedeiro específico, que podem ser patogênicos para o homem e outras espécies animais, que incluem a maioria das sorovares transmitidos por alimentos (POPOFF et al., 2004).

\subsubsection{Fisiologia e bioquimismo}

O gênero Salmonella spp pertencente à família Enterobacteriaceae apresenta as seguintes características: bastonetes retos $(0,7-1,5 \times 2,5 \mu \mathrm{m})$, Gram negativos, não formadores de esporos, geralmente móveis por flagelos peritríquios, com exceção de Salmonella Pullorum e Salmonella Gallinarum, que são imóveis. 
São anaeróbios facultativos, que catabolizam glicose e outros carboidratos, com produção de ácido e, geralmente, gás; muitas espécies são incapazes de metabolizar a lactose e sacarose, característica que pode variar, quando algum sorovar de Salmonella spp adquire plasmídeos, transportadores de genes codificadores de enzimas, para a fermentação de lactose (plasmídeo lac+), desenvolvendo colônias lactose positivas, nos meios de isolamento, semelhantes às de Escherichia coli. As salmonelas são capazes de utilizar o citrato como única fonte de carbono; são oxidase negativa, catalase positiva, indol negativo, VogesProskauer (VP) negativo (não produtores de acetoína); produzem $\mathrm{H}_{2} \mathrm{~S}$, não hidrolisam uréia, mas descarboxilam lisina e ornitina (HOLT et al., 1994).

Este gênero é composto de microrganismos mesófilos; no entanto, alguns sorovares são capazes de multiplicação em temperaturas elevadas $\left(\leq 54{ }^{\circ} \mathrm{C}\right)$, enquanto outros têm propriedades psicrotróficas, podendo multiplicar-se em temperaturas de refrigeração $\left(2^{\circ}\right.$ a $\left.4^{\circ} \mathrm{C}\right)$. São relativamente termos sensíveis, por serem destruídos a $60^{\circ} \mathrm{C}$, em 15-20 minutos; não se multiplicam abaixo de $5^{\circ} \mathrm{C}$, embora sobrevivam bem em temperaturas de refrigeração. O congelamento provoca uma redução significativa do número de células viáveis, mas, nunca a destruição completa. Segundo a literatura, Salmonella Senftenberg $775 \mathrm{~W}$ é a mais termoresistente, inativada em 31 minutos a $57^{\circ} \mathrm{C}$, enquanto que a Salmonella Typhimurium é destruída em 1 a 2 minutos; considera-se que esta espécie seja 10 a 20 vezes mais resistente ao calor que as demais $\left(57^{\circ} \mathrm{C}\right.$ ) (HOLT et al., 1994; D'AOUST e MAURER, 2007; TRABULSI e ALTERTHUM, 2008).

A atividade de água mínima, para multiplicação da Salmonella spp, é de 0,93. O pH ótimo fica entre 6,5 e 7,5; sendo que valores superiores a 9,0 e inferiores a 4,0 são bactericidas. Os efeitos bactericidas ou bacteriostáticos do $\mathrm{pH}$ dependem da natureza química do ácido, utilizado para a acidificação. Entre ácidos orgânicos, os ácidos acético e propiônico são mais inibitórios do que os ácidos lático e cítrico, comumente empregados na acidificação de alimentos. As salmonelas são capazes de se adaptar ao pH ácido, sobrevivendo bem em condições ácidas, como por exemplo, durante o processo de fermentação de alimentos. Estas bactérias não toleram concentrações de sal superiores a 9,0\%. O nitrito é inibitório e seu efeito é acentuado pelo pH ácido (HOLT et al., 1994; D’AOUST e MAURER, 2007). 


\subsubsection{Patogenicidade}

Os processos de adesão, invasão e replicação da Salmonella spp no trato gastrointestinal são complexos e já foram estudados em culturas celulares e em animais experimentalmente infectados. Estes processos são determinados por uma variedade de fatores de virulência, como ilhas de patogenicidade, plasmídeos, fímbrias, toxinas e outros (FLUIT, 2005; D’AOUST e MAURER, 2007).

A maioria dos genes de virulência de Salmonella spp está localizada em regiões especificas do cromossomo, denominadas llhas de Patogenicidade de Salmonella (Salmonella Pathogenicity Island - SPI). São conhecidas cinco SPI, denominadas SPI - 1 a SPI - 5, onde se agrupam genes responsáveis pela adesão e invasão da célula hospedeira, assim como genes relacionados com a produção de toxinas (na SPI-1), além daqueles necessários para a sobrevivência e multiplicação do patógeno no hospedeiro, que são manifestados na fase sistêmica da doença (SPI-2 a SPI-4) (MARCUS et al., 2000; COBURN et al., 2007).

Além dos fatores de virulência cromossomais, alguns podem ser encontrados em plasmídeos de virulência, de diferentes tamanhos e composição genética. A expressão desses genes é importante para a sobrevivência e multiplicação intracelular da Salmonella spp, contribuindo para a fase sistêmica da doença (FLUIT, 2005).

Evidências sugerem que as fímbrias bacterianas podem desempenhar um papel importante no mecanismo de adesão à superfície da célula-alvo, bem como na patogênese das salmonelas. No genoma de Salmonella spp já foram identificados 20 operons distintos, relacionados com produção de fímbrias (COLLIGHAN e WOODWARD, 2001; EDWARDS et al., 2002). O papel da fímbria SEF-14, expressa unicamente por sorovares de Salmonella spp do grupo D, incluindo Salmonella Enteritidis e Salmonella Dublin, na patogênese, está relacionado com etapas da infecção posteriores à colonização do epitélio intestinal do hospedeiro, sendo considerada essencial para a adesão ou sobrevivência da bactéria em macrófagos (EDWARDS et al., 2002).

As endotoxinas correspondem à fração lipídica do lipopolissacarídeo que compõe a membrana celular da Salmonella spp, sendo responsáveis pelo efeito 
tóxico quando a bactéria sofre lise celular. O papel das endotoxinas como agentes causadores de diarréia tem sido bastante questionado (D`AOUST e MAURER, 2007)

Embora uma extensa gama de interações entre hospedeiro e bactéria possa causar a doença, a adesão das células bacterianas ao epitélio intestinal é considerada o primeiro passo na patogênese do processo invasivo de bactérias causadoras de doenças entéricas. No passado, utilizavam-se vários modelos animais para determinar diferenças na virulência e na infectividade de bactérias patogênicas, mas atualmente existem outros métodos que dispensam o uso de modelos animais, como as culturas celulares para os testes de adesão in vitro, e formação de biofilme (XIA et al., 2009).

Culturas de células intestinais são frequentemente usadas nos testes de adesão, como indicação de patogenicidade bacteriana. Variações na capacidade de adesão ao epitélio intestinal podem explicar as diferenças de patogenicidade entre as cepas (HURLEY e McCORMICK, 2003; KIM e WEI. 2007; de LUNA, 2008; MUSKEN, 2008).

Apesar do estudo com cultura de células epiteliais ter sido útil para caracterizar alguns eventos que acontecem durante a infecção por Salmonella spp, os estudos empregando monocamadas de células, em particular de células Caco-2, derivadas de células de adenocarcinoma de coloretal humano (ATCC HTB-37 ${ }^{\mathrm{TM}}$ ) têm fornecido novas informações. Essas monocamadas têm superfície apical e basolateral bem definidas e junções intercelulares funcionais, e correspondem a um modelo semelhante à barreira intestinal. Além das células Caco-2 outras linhagens celulares, como COS-1, HeLa, MDCK, T84, e HEp2, podem ser usadas para esta finalidade (HURLEY e McCORMICK, 2003; KIM e WEI, 2007).

As células T84, Caco-2 e MDCK são capazes de formar monocamadas polarizadas quando se multiplicam em suportes permeáveis, constituindo modelos de culturas celulares similares ao local inicial de ação de Salmonella. Cada linhagem celular tem uma aplicação particular. Por exemplo, linhagens celulares COS-1 e MDCK, derivadas de tecidos de macacos e de cão, respectivamente, são usadas em experimentos que requerem a transferência de material genético. As linhagens celulares HeLa e Hep2 são derivadas de tecidos humanos, podendo fornecer um modelo mais apropriado para doenças humanas, no entanto, nenhuma dessas linhagens é derivada do tecido epitelial intestinal, local onde atuam as salmonelas. 
As células T84 e Caco-2 são células epiteliais humanas e, portanto mais adequada para estes estudos. No entanto, multiplicam-se mais lentamente que as demais células, são de difícil manuseio e mais caras (HUANG et al., 1998; HURLEY e McCORMICK, 2003).

Vários estudos de virulência de Salmonella foram desenvolvidos empregando-se as células Caco-2. Rasmussen et al. (2005) mostraram que S. Typhimurium DT104 multiresistente é mais virulenta do que cepas de $S$. Typhimurium sensíveis a antibióticos, e que certas evoluções genéticas neste sorovar poderiam ter contribuído para essa hipervirulência. Kim e Wei (2007) demonstraram diferenças na capacidade de invadir células epiteliais humanas entre diferentes cepas S. Typhimurium DT104 sugerindo que a multiresistência a antibióticos não tem relação com a hipervirulência. Estes autores demonstraram também que cepas de $S$. Typhimurium DT104, isoladas de diferentes fontes (carne moída, animais e humanos) apresentaram diferentes capacidades de invadir células Caco-2.

A simples presença de Salmonella spp no alimento não é suficiente para causar a doença, sendo necessário que sua concentração seja superior à dose infectante, que depende da virulência do sorovar envolvido e dos fatores ligados ao hospedeiro como espécie, raça, idade e condições imunológicas e nutricionais. A dose infectante capaz de causar doença pode ser de apenas uma célula, como ocorre com Salmonella Typhi, ou de milhões de células, como por exemplo, $10^{5} \mathrm{a}$ $10^{6}$ para Salmonella Bareilly e Salmonella Newport, e $10^{9}$ a $10^{10}$ para Salmonella Pullorum, adaptada às aves (JAY, 2005; FDA / CFSAN, 2008).

As doenças causadas por Salmonella spp podem ser subdivididas em três grupos: febre tifóide, causada por Salmonella Typhi; febres entéricas, causadas por Salmonella Paratyphi (A, B, C) e enterocolites (ou salmoneloses), causadas pelas demais salmonelas. A febre tifóide só acomete o homem e, normalmente, é transmitida por água e alimentos contaminados com material fecal humano. As febres entéricas são bastante semelhantes à febre tifóide, mas os sintomas clínicos são mais brandos. As salmoneloses e/ou enterocolites caracterizam-se por sintomas que incluem diarréia, febre, dores abdominais e vômitos. O período de incubação da salmonelose é de 8 a 22 horas, com diarréia, mal estar e cólicas, com ou sem febre. Já na febre tifóide, o período de incubação varia de 7 a 28 dias. A manifestação 
clinica é traduzida por cólicas abdominais, náuseas, vômitos, calafrios, febre, cefaléia e diarréia, muitas vezes sanguinolentas. Normalmente, esses sintomas são acompanhados de abatimento, debilidade muscular, cansaço, febre moderada e sonolência. O quadro clínico pode persistir por um a dois dias e a recuperação dáse, na maioria dos casos, após três dias do início da infecção. Estes prazos dependem da quantidade de células viáveis ingerida, do sorovar envolvido e das condições do próprio hospedeiro (FRANCO e LANDGRAF, 2005; D’AOUST e MAURER, 2007).

Nas crianças pequenas e recém-nascidas, a salmonelose pode ser bastante grave, já que a Salmonella spp pode atingir a corrente circulatória e provocar lesões em outros órgãos. No adulto, algumas patologias pré-existentes, como a Acquired Immune Deficiency Syndrome (AIDS) e a esquistossomose, podem agravar a doença. Existem relatos de meningites, osteomielites e problemas renais, decorrentes de infecções por Salmonella spp. Nestes casos, a antibioticoterapia é indispensável. Pacientes imunocomprometidos, principalmente com AIDS, apresentam 20 vezes mais bacteremia e gastroenterites por Salmonella spp, além das demais complicações mencionadas (KONEMAN et al., 2001; FRANCO e LANDGRAF, 2005; DFBMD, 2008).

De um modo geral, a salmonelose é uma infecção de baixa mortalidade, porém de alta morbidade, resultando em perdas econômicas elevadas, devido à necessidade de cuidados médicos, hospitalizações e queda de produtividade do indivíduo acometido por esta enfermidade. Segundo Jay (2005), o índice de mortalidade está diretamente relacionado com a idade do indivíduo infectado: 5,8\% no primeiro ano de idade, 2,0\% entre 1 a 50 anos e 15,0\% entre pessoas com mais de 50 anos. Em média 4,1\% dos indivíduos envolvidos vão a óbito. Dados do FDA / CFSAN (2008) referem que o grau de mortalidade da febre tifóide é de 10,0\%, comparado com menos de $1,0 \%$ com as demais salmoneloses. O grau de mortalidade da Salmonella Dublin é de 15,0\%, quando associado à septicemia em idosos; a Salmonella Enteritidis tem demonstrado, aproximadamente, um grau de mortalidade em torno de $3,6 \%$, em surtos ocasionados em hospitais e enfermarias, particularmente envolvendo idosos.

$\mathrm{Na}$ fase aguda da salmonelose, o microrganismo pode ser detectado em material fecal. No entanto, sua presença nas fezes diminui gradualmente, com 
redução de mais ou menos $50,0 \%$ na segunda semana; cerca de 15,0\% na quarta semana e raramente perdura por mais de seis a oito meses. Os indivíduos que continuam excretando Salmonella spp são tidos como portadores. As bactérias restantes se localizam em certos locais dos intestinos, na vesícula biliar, no fígado e até nos rins, sendo excretadas continuamente. Esta eliminação permanente de microrganismos pode perdurar por semanas, meses e mesmo por anos (FRANCO e LANDGRAF, 2005).

\subsubsection{Características epidemiológicas}

Salmonella spp estão amplamente distribuídas na natureza, sendo o trato intestinal do homem e de animais o principal reservatório. O estado de portador de Salmonella spp é esporádico, mas alguns animais podem ter o papel de carreadores do microrganismo, mantendo a infecção no rebanho (SMALL et al., 2006). Vários fatores estão relacionados com a ocorrência de animais portadores, tais como dieta, stress durante o transporte, estação do ano em que as amostras são coletadas e áreas geográficas em que se localizam os bovinos (FEDORKA-CRAY et al., 1998; BARHAM et al., 2002; BEACH et al., 2002; SORENSEN et al., 2002; FLUCKEY et al., 2007). Temperaturas mais frias contribuem para a sobrevivência de salmonelas no adubo ou esterco (PLACHÁ et al., 2001), permitindo ao patógeno reinfectar os animais quando a temperatura for mais quente.

Os alimentos à base de carne e ovos são os principais veiculadores de salmonelas para os humanos, embora muitos outros alimentos possam ser contaminados secundariamente. Em função da sua capacidade de disseminação no meio ambiente, esta bactéria pode ser isolada de diferentes locais (águas doces superficiais, costa marítima, carnes de animais, pescados, verduras, ovos) e, consequentemente, de diversas matérias-primas alimentares. Podem ainda ser veiculadas pelo próprio homem, quando portador assintomático. Hábitos alimentares podem influenciar, consideravelmente, a epidemiologia das salmonelas, como o hábito de ingestão de alimentos crus ou insuficientemente aquecidos (JAKABI et al., 1999; PARDI et al., 2001; FRANCO e LANDGRAF, 2005).

A distribuição geográfica dos diferentes sorovares é variável, não sendo ainda bem definida. Alguns sorovares apresentam uma distribuição regional, como a 
verificada para Salmonella Derby no México, Salmonella Panama na Europa, Salmonella Weltewreden na Ásia e Salmonella Virchow no Reino Unido e ex-União Soviética (CDC, 2006a).

Conforme relatado no Centro de Vigilância Epidemiológica do Estado de São Paulo (CVE - SP, 2008), no período de janeiro de 2006 a julho de 2008 ocorreu 700 surtos de DTA, acometendo 17.699 pessoas. Constatou-se que 4,7\% (33) foram provocados por Salmonella spp. No ano de 2006 ocorreram 16 surtos, sendo 7 por Salmonella Enteritidis, 7 Salmonella spp, 1 Salmonella Typhi e 1 Salmonella Brandenburg, totalizando 740 casos e 2 óbitos. Em 2007 ocorreram 14 surtos sendo 10 por Salmonella spp, 3 Salmonella Enteritidis e 1 Salmonella Typhi, totalizando 741 casos e 2 óbitos. No decorrer de 2008 ocorreram 3 surtos sendo 2 por Salmonella spp e 1 Salmonella Enteritidis, totalizando 53 casos sem óbito.

Apesar das informações disponíveis sobre etiologia da doença transmitida por alimentos serem incompletas, uma parcela importante dos surtos de toxinfecções alimentares ocorridas no Brasil tem origem domiciliar. No ano de 2000, $16,0 \%$ dos surtos notificados em São Paulo tiveram origem no ambiente domiciliar, sendo 23,0\% causadas por Salmonella spp (CVE - SP, 2008). No Rio de Janeiro, no mesmo período, Fernandes et al. (2003), confirmaram a ocorrência de 53 surtos de DTA, com, $24,5 \%$ de origem domiciliar, sendo 7,0\% causadas por Salmonella spp. As carnes vermelhas foram responsáveis por $11,6 \%$ dos surtos de origem alimentar, ocorridos no Brasil entre 1999 e 2004 (BRASIL, 2005).

\subsubsection{Isolamento e identificação}

A busca de uma metodologia adequada e eficiente para detectar Salmonella spp em alimentos tem sido uma constante. Apesar de alguns métodos com tecnologias avançadas terem surgido (MALORNY et al., 2003), o método cultural clássico continua sendo o método de referência e amplamente utilizado em laboratórios de monitoramento de Salmonella spp nas indústrias de alimentos (BRASIL, 2001; SILVA et al., 2007). No entanto, muitos estudos têm revelado diferenças significativas entre resultados obtidos com este método, principalmente no que se refere aos meios de cultura e às temperaturas de incubação, aplicadas nas diferentes etapas de seu procedimento (MAIJALA et al., 1992; BERCHIERI et 
al., 1993; GIOMBELLI e LOPES DA SILVA, 2001; RANSOM et al., 2002; XAVIER e JOELE, 2004).

O método cultural clássico tem várias etapas, iniciando-se por um préenriquecimento não seletivo, feito em meio líquido não seletivo para Salmonella spp. Segue-se um enriquecimento seletivo, em meio de cultura líquido inibitório para a maioria dos microrganismos presentes, favorecendo a multiplicação de Salmonella spp. No passo seguinte, este caldo de enriquecimento seletivo é transferido para meios seletivos sólidos diferenciais, que permitem o isolamento de colônias típicas. As colônias suspeitas de Salmonella spp são então submetidas a testes fenotípicos, imunológicos e moleculares para sua completa identificação.

\subsubsection{Subtipagem molecular}

A utilização de técnicas moleculares para subtipagem de microrganismos é cada vez mais comum nos Laboratórios de Saúde Pública, sendo ferramentas úteis para investigações epidemiológicas de surtos e para o controle e monitoramento da disseminação de potenciais patógenos (HUNTER et al., 2005; SMALL et al., 2006; KÉROUANTON et al., 2007; FOLEY et al., 2007; STEVENS et al., 2008).

Das diversas técnicas de tipagem molecular existentes, a eletroforese em gel de campo pulsado (PFGE, em inglês) é bastante utilizada para agrupar patógenos, sendo considerada padrão ouro para a subtipagem de patógenos de alimentos, devido ao seu alto poder de discriminação e reprodutibilidade (HUNTER et al., 2005; KÉROUANTON et al., 2007). A PFGE é uma variação da eletroforese em gel, onde a orientação do campo elétrico aplicado ao gel varia de forma pulsada (FOLEY et al., 2007).

A principal vantagem da PFGE em relação aos demais métodos de tipagem molecular é a alta reprodutibilidade do método. Esta reprodutibilidade é atribuída à imobilização do DNA dentro do plug de agarose, o que o protege de danos mecânicos na pipetagem, de modo que as bandas geradas são decorrentes da atividade da restrição enzimática, e não causadas por outros fatores. Com isso, o perfil genético obtido é baseado no genoma inteiro e não em fragmentos gerados artificialmente. Uma desvantagem da PFGE é que exige um trabalho intenso na realização e na interpretação dos resultados. Além disso, a PFGE não é capaz de 
detectar uma variação genética que não cause um impacto significativo na mobilidade eletroforética do fragmento de restrição (FOLEY et al., 2007).

Desde 1996, a técnica de PFGE é indicada pelo CDC dos Estados Unidos para tipagem molecular de microrganismos patogênicos em estudos epidemiológicos de casos e surtos de doenças de origem alimentar, constituindo uma rede nacional denominada PulseNet. Para que os dados enviados pelos laboratórios participantes da rede sejam totalmente confiáveis e reprodutíveis, padronizou-se um protocolo de procedimento laboratorial denominado protocolo PulseNet (CDC, 2000).

Com a técnica de PFGE é possível avaliar a relação genética entre os diferentes isolados envolvidos em uma investigação epidemiológica (WOO e LEE, 2006), assim como rastrear contaminação na cadeia de produção de alimentos. O banco de dados gerados pela PFGE pode ser utilizado por veterinários, produtores de alimentos e analistas de riscos, para determinação das possíveis fontes de contaminação na fazenda e nas plantas de processamento das indústrias alimentícias (KÉROUANTON et al., 2007).

Diferentes cepas apresentando o mesmo perfil genético de PFGE podem ser classificadas como epidemiologicamente relacionadas, com um alto grau de confiabilidade. Vale ressaltar, no entanto, que existem limitações, pois é necessário também realizar a caracterização fenotípica dessas cepas, visto que podem ocorrer mutações que podem alterar o seu perfil genético (HUNTER et al., 2005).

A técnica de PFGE tem sido bastante utilizada no estudo de Salmonella spp em alimentos. Kérouanton et al. (2007) empregaram a técnica de PFGE para a caracterização dos sorovares de Salmonella mais frequentemente detectados em alimentos na França. Foram estudadas 1128 cepas, e de acordo com o protocolo do PulseNet, foram identificados 452 perfis de PFGE distintos, sendo que 305 perfis (67,5\%) eram constituídos por uma única cepa e 54 (11,9\%) por somente duas cepas. Para um mesmo sorovar foi possível obter de 4 até 46 perfis de PFGE diferentes, dependendo do sorovar. Por exemplo, 26 cepas de S. Agona foram agrupadas em 17 perfis diferentes, 27 cepas de $S$. Dublin pertenceram a 10 perfis e 17 cepas de $S$. Give foram agrupadas em 8 perfis, enquanto 135 cepas de $S$. Typhimurium foram agrupadas em 46 perfis diferentes.

Stevens et al. (2008) realizaram uma análise epidemiológica de Salmonella spp na cadeia produtiva de carne bovina no Senegal, utilizando a PFGE com a 
enzima de restrição Xbal para identificar as relações clonais e a sua potencial transmissão na cadeia produtiva. Foram analisadas cepas isoladas de amostras de bovinos de abatedouros oficiais e do varejo, pertencentes a diferentes sorovares. A combinação entre os perfis genético e de resistência aos antimicrobianos permitiu concluir que $56,0 \%$ das cepas testadas estavam nos abatedouros, enquanto $44,0 \%$ estavam no varejo, evidenciando que a tipagem molecular permitiu avaliar o risco potencial de salmoneloses associadas com consumo de carne no Senegal.

\subsubsection{Resistência a antimicrobianos}

A emergência de Salmonella spp resistentes a antimicrobianos é considerada, mundialmente, um problema sério de Saúde Pública, pois o uso generalizado de antibióticos em humanos e na medicina veterinária provoca um aumento na multiresistência dessas bactérias (HELMS et al., 2002; TRAVERS e BARZA, 2002; VARMA et al., 2002; CHEN et al., 2004; VALDEZATE et al., 2005; SKOV et al., 2007; GRAZIANI et al., 2008).

O uso contínuo de antibióticos para o controle e tratamento de infecção por Salmonella, em animais de fazenda, e nas práticas médicas, é considerado o principal fator para o surgimento de cepas multiresistentes (TANCREDI, 1990; WHITE et al., 2001). Infecções causadas por cepas antibiótico resistentes são de tratamento mais difícil devido à ineficácia do tratamento inicial e à necessidade de usar opções de tratamento menos desejáveis. Além disso, a associação de infecções por Salmonella multiresistente com o aumento da taxa de hospitalização, morbidade e mortalidade, sugere que a resistência antimicrobiana tem um papel importante na alteração da virulência destas cepas (TRAVERS e BARZA, 2002; VARMA et al., 2002; CIPARS, 2005; CDC, 2006b; THRELFALL et al., 2006).

Os alimentos de origem animal tornam-se potencialmente transmissores de agentes etiológicos de infecções de difícil tratamento, uma vez que, no Brasil, apesar da legislação brasileira proibir a utilização de antibióticos, em animais produtores de alimentos, tal prática é comum, o que favorece a presença de resíduos, nestes alimentos, e, conseqüentemente, a seleção de bactérias resistentes (BRASIL, 1998 e 1999). 
Entretanto, alguns estudos mostram que não há correlação entre o uso de drogas na medicina veterinária e o aumento do número de cepas resistentes. Estudo realizado por Threlfall et al. (2006) demonstrou que o aumento do uso veterinário de tetraciclina e ampicilina não teve impacto na incidência de Salmonella Enteritidis e Salmonella Typhimurium resistentes a estas drogas. Da mesma forma, a redução no uso de trimetoprim não provocou queda acentuada de resistência a este antimicrobiano, nos dois sorovares estudados.

Embora não haja consenso sobre o verdadeiro impacto do uso de agentes antimicrobianos na produção animal, o seu emprego neste segmento vem sendo discutido, sendo que alguns países adotaram novas regulamentações quanto ao seu uso, para reduzir a emergência de cepas resistentes (SARMAH et al., 2006; FLUKEY et al., 2007).

$\mathrm{Na}$ União Européia, o uso de qualquer antimicrobiano como promotor de crescimento, na produção animal, está proibido desde 2006 (CASTANON, 2007). Por outro lado, nos Estados Unidos, há poucas regulamentações sobre o uso de antimicrobianos como promotores de crescimento. Recentemente, o uso de fluoroquinolonas como agente terapêutico em animais foi suspenso, devido à similaridade com antibióticos utilizados para tratamento de infecções em humanos (FDA, 2005). Entretanto, outras drogas como tetraciclinas, penicilinas, macrolídeos e lincomicina ainda são aprovadas, para uso como promotores de crescimento (SARMAH et al., 2006).

No Brasil, o uso de clortetraciclina, oxitetraciclina, penicilinas e sulfonamidas sistêmicas, na veterinária, está proibido, de acordo com a Portaria Ministerial $n^{\circ} 193$, de 12 de maio de 1998 (BRASIL, 1998). A Instrução Normativa n 9, de 27 de junho de 2003 (BRASIL, 2003), proíbe fabricação, manipulação, fracionamento, comercialização, importação e uso de cloranfenicol, nitrofuranos e produtos que contenham estes princípios ativos, para uso veterinário e na alimentação de animais.

$\mathrm{Na}$ Europa, o monitoramento da resistência antimicrobiana em 10 países, durante cinco anos, revelou um aumento na ocorrência de resistência em Salmonella não-tifóides, isoladas de casos de infecção em humanos. A incidência de cepas resistentes às sulfonamidas, tetraciclina, ampicilina e estreptomicina passou de $57,0 \%$ em 2000 para 66,0\% em 2004, enquanto que ocorreu uma redução de $18,0 \%$ para $15,0 \%$, no número de cepas multiresistentes. Foi observado um 
aumento significativo no número de cepas resistentes ao ácido nalidíxico (GRAZIANI et al., 2008; MEAKINS et al., 2008).

No Canadá, o Canadian Integrated Program for Antimicrobial Resistance Surveillance (CIPARS) realiza o monitoramento de resistência antimicrobiana em bactérias entéricas, isoladas em diferentes pontos da cadeia alimentar, e de casos de doença em humanos. No período de 2003 a 2005, entre salmonelas isoladas de amostras clínicas, houve um aumento significativo nas taxas de resistência à ampicilina (35,0\% a 47,0\%) em Salmonella Heidelberg; ácido nalidíxico (44,0\% a $72,0 \%)$, ampicilina (10,0\% a $26,0 \%)$, tetraciclina $(9,0 \%$ a $24,0 \%)$ e trimetoprimsulfametoxazol (9,0\% a 26,0\%) em Salmonella Typhi; ceftiofur (2,0\% a 4,0\%) e ácido nalidíxico (1,0\% a 3,0\%) em Salmonella Typhimurium (CIPARS, 2005).

No Brasil, embora não haja um programa de monitoramento com abrangência nacional, estudos relataram a ocorrência de cepas resistentes e multiresistentes em Salmonella Enteritidis (FERNANDES et al., 2003; OLIVEIRA et al., 2005; CARDOSO et al., 2006); Salmonella Infantis (FONSECA et al., 2006), Salmonella Hadar (RIBEIRO et al., 2006); Salmonella Typhimurium (GHILARDI et al., 2006; BESSA et al., 2007); Salmonella Agona (MICHAEL et al., 2005) e Salmonella Derby (MICHAEL et al., 2006), isoladas de diferentes fontes.

\subsection{Análise de Risco microbiológico}

Segundo FAO (2006), a Análise de Risco Microbiológica em alimentos é a estratégia mais apropriada para se estimar, de forma adequada, o impacto potencial da segurança dos alimentos na Saúde Pública e os custos econômicos associados às Doenças Transmitidas por Alimentos.

A Análise de Risco é um processo formado por três componentes: Avaliação do Risco, Gestão do Risco e Comunicação do Risco (FAO, 2006).

Q A Avaliação de Risco envolve quatro etapas: Identificação do Perigo; Avaliação da Exposição; Caracterização do Perigo; Caracterização do Risco.

A Identificação do Perigo é a etapa baseada na disponibilidade de dados sobre a existência de um perigo. No que se refere aos agentes microbianos, o propósito desta etapa é obter o maior número possível de informações sobre os microrganismos ou toxinas microbianas de interesse em um determinado alimento. Estas informações sobre 
os perigos podem ser obtidas a partir da literatura científica, bases de dados como as das indústrias de alimentos, agências governamentais e organizações internacionais relevantes e, também, por meio de especialistas (FAO, 2006).

Uma vez identificado o microrganismo considerado na Avaliação de Risco, a Avaliação da Exposição corresponde à avaliação qualitativa e/ou quantitativa da presença deste microrganismo (FAO, 2006). Na avaliação da exposição, estima-se a prevalência e os níveis de contaminação microbiana no alimento no momento do consumo e a quantidade de produto consumido a cada refeição, por diferentes categorias de consumidores (ICMSF, 2005).

Uma Avaliação da Exposição necessita de três diferentes tipos de informação: (1) presença do patógeno na matéria-prima; (2) os efeitos das etapas de processamento, distribuição, manuseio e preparação do alimento sobre o patógeno e (3) formas de consumo do alimento considerado. De posse destes dados, é possível estimar com diferentes níveis de incertezas, a probabilidade de ocorrência do microrganismo patogênico ou de suas toxinas, bem como sua quantidade no momento do consumo.

A Caracterização do Perigo, também denominada avaliação dose-resposta, mensura a relação entre dose do patógeno e resposta do hospedeiro, ou seja, estima a relação entre o número de células do patógeno ingeridas e a probabilidade de uma população específica apresentar uma resposta a esta ingestão (FAO, 2006). Nesta etapa, leva-se em conta que a severidade e a duração dos efeitos adversos à saúde, resultantes da ingestão de um microrganismo ou sua toxina, presentes num alimento, bem como as consequências desta exposição. É preciso lembrar que a presença destes perigos em um alimento pode ter conseqüências de diferentes gravidades como infecção assintomática, doença aguda, doença crônica ou ainda morte do hospedeiro (ICMSF, 2005).

A Caracterização do Risco consiste no processo de estimar, qualitativa ou quantitativamente (incluindo-se as incertezas), a probabilidade de ocorrência e a severidade dos efeitos adversos à saúde, em uma determinada população, causados pelo perigo microbiológico considerado. Esta etapa é também chamada Estimativa de Risco, que deve ser baseado nos dados gerados nas etapas anteriores da Avaliação de Risco, ou seja, Identificação do Perigo, Caracterização do Perigo e Avaliação da Exposição (FAO, 2006). A caracterização do risco combina as informações geradas na Identificação do Perigo, na Avaliação da Exposição e na Caracterização do Perigo, com o objetivo de produzir um quadro completo do risco, 
levando em conta não apenas o lado científico, mas também social ético e econômico. O resultado é o risco estimado, que é uma identificação do nível de enfermidade e de suas consequências (por exemplo, número de casos por 100.000 habitantes por ano), resultantes de uma dada exposição (ICMSF, 2005).

To Gestão de Risco é o processo por meio do qual se faz a seleção e a implementação de medidas apropriadas para proteger a saúde do consumidor, sem, necessariamente, eliminar os riscos, mas atingir o nível tolerável, já que risco zero não existe. Entre as medidas a serem implementadas podem ser citadas: implementação de práticas seguras de manuseio de alimentos, controle de qualidade de processo e estabelecimento de padrões de qualidade e segurança.

\$ Comunicação de Risco é a troca interativa de informações a respeito do risco e de sua gestão, feita entre os profissionais responsáveis pela Avaliação e Gestão dos Riscos, consumidores e demais partes interessadas (FAO, 2006). Um dos problemas mais críticos da Comunicação de Risco é a compreensão inadequada do seu significado em termos científicos, fundamental tanto para avaliadores como para os gestores de risco (SCHLUNDT, 2002). A fim de se maximizar o impacto da comunicação do risco, seu conteúdo deve ser chamativo, compreensível e ter o poder de influenciar decisões, além de ser claro e facilmente interpretável (BREAKWELL, 2000).

Avaliações de Riscos são difíceis de serem realizadas no Brasil devido à precariedade das informações necessárias para a sua realização. Os dados epidemiológicos disponíveis sobre as enfermidades transmitidas pelos alimentos são insuficientes e inadequados, assim como não há informações suficientes sobre a exposição do consumidor aos patógenos de maior relevância nos diferentes alimentos. No caso da carne bovina, dados sobre prevalência e características dos patógenos de maior relevância são limitados a estudos desenvolvidos com carne coletada no comércio e não diretamente nos abatedouros ou frigoríficos. Considerando que Salmonella spp é um dos patógenos mais importantes em produtos de origem animal, e que a carne bovina é um dos componentes mais importantes do agronegócio brasileiro, esse projeto foi idealizado para contribuir com dados que permitam avaliar a exposição à Salmonella spp em carne bovina coletada diretamente em estabelecimentos produtores de carne bovina destinada à exportação. 
2. OBJETIVOS 


\title{
2.1 Geral
}

\begin{abstract}
$\checkmark \quad$ No contexto da Avaliação de Risco Microbiológico em alimentos, o objetivo deste estudo foi contribuir com resultados sobre prevalência e características de Salmonella spp na cadeia produtiva da carne bovina destinada à exportação.
\end{abstract}

\subsection{Específicos}

$\checkmark \quad$ Detectar a incidência de Salmonella spp, na cadeia produtiva de carne bovina pela amostragem em três pontos da cadeia: 1: couro do animal abatido, depois da sangria; 2: carcaça, após a esfola e 3: carcaça, após a toalete, antes da refrigeração;

$\checkmark \quad$ Identificar a prevalência dos diferentes sorovares de Salmonella spp nas amostras estudadas;

$\checkmark \quad$ Avaliar possíveis relações genéticas entre as cepas de Salmonella spp isoladas, por meio da técnica de subtipagem molecular por PFGE.

$\checkmark \quad$ Avaliar o potencial de virulência das cepas de Salmonella spp isoladas, por meio do teste de infecção de células epiteliais intestinais humanas da linhagem Caco-2;

$\checkmark \quad$ Determinar o perfil de resistência a antibióticos e quimioterápicos das cepas de Salmonella spp isoladas. 
3. MATERIAL $\mathcal{E}$ MÉTODOS 


\subsection{Origem das amostras bovinas}

O estudo foi realizado com amostras coletadas de 200 bovinos adultos, 198 machos e 2 fêmeas, abatidos em Frigorífico Exportador, situado no Estado de São Paulo - Brasil.

Os animais analisados foram provenientes de 12 fazendas, localizadas em diferentes municípios, dos Estados de Goiás, Mato Grosso do Sul, Paraná e São Paulo. A coleta das amostras foi realizada durante 0 ano de 2008 (janeiro a dezembro), compreendendo as quatro estações do ano (verão, outono, primavera e inverno), sempre no período da manhã.

\subsection{Coleta, acondicionamento e transporte das amostras}

A amostragem, coleta, acondicionamento, transporte e preparo das amostras foram realizadas de acordo com Midura e Bryant (2001).

Para a identificação dos animais, afixou-se uma placa de plástico colorido na pata traseira de cada animal no início do processo de abate, após a suspensão do animal no trilho. Essa placa continuou afixada no animal até a coleta de todas as amostras daquele animal.

As amostras foram coletadas em três pontos do processo de abate, conforme indicado no esquema representado na Figura 1:

Ponto 1 - No couro do animal, logo após a realização da sangria (Co);

Ponto 2 - Na carcaça do mesmo animal, após a esfola (Ca I);

Ponto 3 - Na carcaça do mesmo animal, após o toalete e antes da refrigeração (Ca II). 


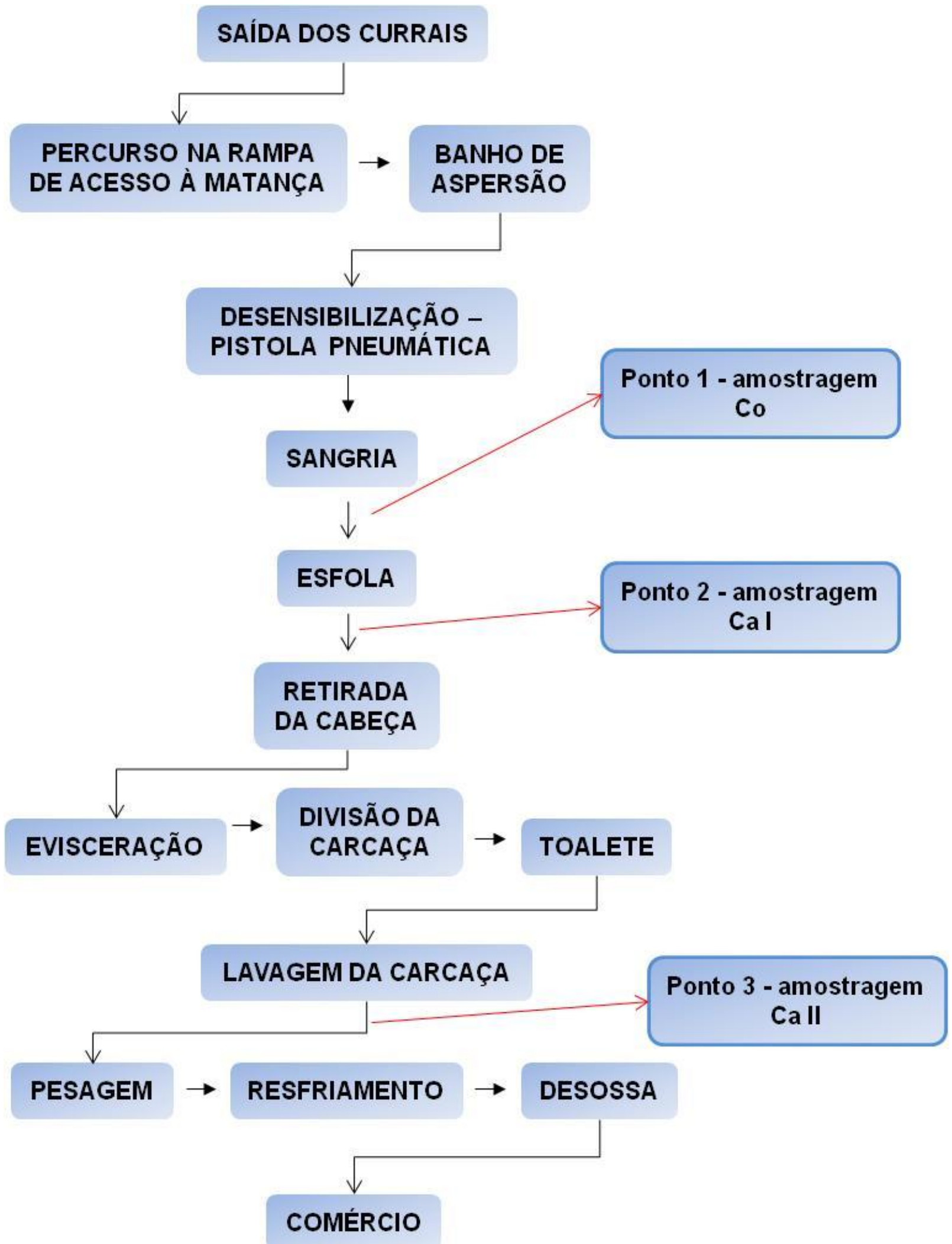

Figura 1. Esquema de abate de bovinos, com indicação dos três pontos de amostragem. 
Para a coleta de todas as amostras, utilizou-se a técnica do Esfregaço de Superfície, empregando-se as esponjas esterilizadas de $11,5 \times 23,0 \mathrm{~cm}$ (SpeciSponge ${ }^{\Theta}$ - Nasco, EUA), mantidas nas respectivas bolsas plásticas umedecidas com $10,0 \mathrm{~mL}$ de salina peptonada - SP $(0,1 \%$ de peptona e $0,85 \%$ de $\mathrm{NaCl})$ e refrigeradas.

Com as mãos enluvadas, duas esponjas foram friccionadas em duas áreas de $10 \times 10 \mathrm{~cm}$ do lado direto do peito do animal, e outras duas do lado esquerdo do mesmo animal (Figura 2), perfazendo um total de quatro esponjas. Este procedimento foi adotado para a coleta das amostras Co, Ca I e Ca II. As quatro esponjas para cada amostra Co foram transferidas para uma única bolsa plástica de capacidade de $720 \mathrm{~mL}$ (Nasco, EUA), o mesmo sendo feito para as quatro esponjas para cada amostra $\mathrm{Ca} I$ e para cada amostra Ca II. As bolsas plásticas foram transferidas para uma caixa isotérmica contendo gelo reutilizável e transportadas por via rodoviária até o Laboratório de Microbiologia de Alimentos, da Faculdade de Ciências Farmacêuticas - USP / SP.

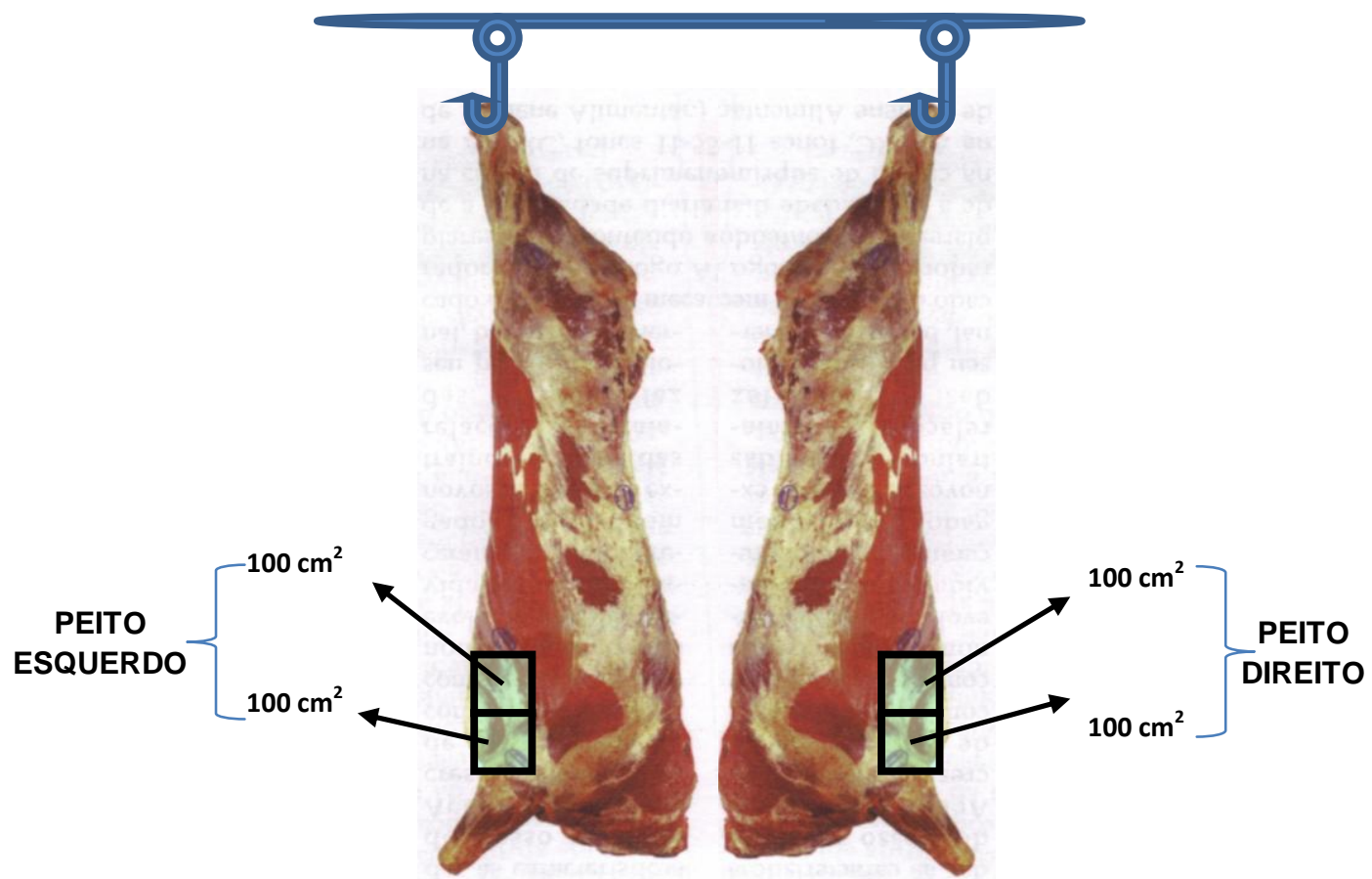

Figura 2 - Pontos de amostragem nas carcaças bovinas.

Na chegada ao laboratório, adicionou-se $200 \mathrm{~mL}$ de SP a cada bolsa plástica e agitou-se em um Stomacher (Lab Blender - Inglaterra) por um minuto. As esponjas foram 
descartadas e o material restante foi refrigerado a $8{ }^{\circ} \mathrm{C}$ até a manhã seguinte, para 0 início das análises.

\subsection{Isolamento e identificação de Salmonella spp}

A pesquisa de Salmonella spp nas amostras bovinas foi fundamentada na metodologia ISO 6579:2002 (ISO, 2002), empregando-se meios de cultura Merck (Alemanha), exceto quando especificado. A Figura 3 apresenta um esquema do procedimento adotado.

Para a análise, uma alíquota de $40 \mathrm{~mL}$ do material de cada bolsa plástica foi transferida para um frasco Nalgene esterilizado, e centrifugada a $1000 \times \mathrm{g} \mathrm{a} 5^{\circ} \mathrm{C}$, por 15 minutos (centrífuga RC5C Sorvall Instruments Du Point - Brasil). O sobrenadante foi descartado e o sedimento resuspenso em 100,0 $\mathrm{mL}$ de água peptonada tamponada (APT) e incubados a $37^{\circ} \mathrm{C} \pm 1$ por $18 \mathrm{~h}$.

Após esse período, transferiu-se $0,1 \mathrm{~mL}$ dessa suspensão para tubos contendo 10,0 mL de caldo Rappaport-Vassilidis com soja (RVS) e 1,0 mL para tubos com 10,0 mL de caldo Muller Kauffmann tetrationato com novobiocina (MKTTn), previamente acrescentado de 0,2 $\mathrm{mL}$ da solução de iodo (20,0 g de iodo + $25,0 \mathrm{~g}$ de iodide de potássio $-\mathrm{KI}+100,0 \mathrm{~mL}$ de água). Os dois caldos foram homogeneizados utilizando um agitador Vortex (Mixtron - Toptronix) e incubados por $24 \mathrm{~h}$ a $41,5^{\circ} \mathrm{C} \pm 1$ e a $37^{\circ} \mathrm{C} \pm 1$, respectivamente. A incubação a $41,5^{\circ} \mathrm{C} \pm 1$ foi feita em banho-maria e a $37^{\circ} \mathrm{C} \pm 1$ em estufa. A suspensão em APT (antes da incubação) foi também inoculada em placas de agar bismuto sulfito (BS) para isolamento direto de Salmonella spp, empregando-se semeadura em superfície.

Uma alíquota dos caldos RVS e MKTTn foi transferida para placas de agar xilose lisina desoxicolato (XLD) e BS, empregando-se uma alça plástica de $1 \mu \mathrm{L}$ (Copan Diagnostics - EUA) e a técnica de esgotamento (estrias). As placas foram incubadas a $37^{\circ} \mathrm{C} \pm 1$ por 24 horas.

A partir das placas de agar XLD e BS, colônias suspeitas de pertencerem ao gênero Salmonella foram estriadas em placas contendo agar nutriente (AN), incubadas a $37^{\circ} \mathrm{C} \pm 1$ por 24 horas, para a realização das provas subsequentes. Para cada placa, trabalhou-se com um máximo de dez colônias. 
As culturas em AN foram submetidas ao teste de aglutinação em lâmina com soro polivalente anti-Salmonella (Probac do Brasil Produtos Bacteriológicos Ltda., Brasil), utilizando o seguinte protocolo recomendado pelo fabricante:

Transferir uma pequena porção da cultura bacteriana para duas cavidades da lâmina de sorologia e adicionar uma gota de solução fisiológica esterilizada, em uma das cavidades, homogeneizar bem o inóculo bacteriano; em seguida, adicionar uma gota de soro polivalente antiSalmonella na outra cavidade, emulsionar bem o inóculo e observar se ocorre aglutinação. Comparar com a aparência da emulsão com solução salina mais o inóculo, para confirmar se ocorreu ou não auto-aglutinação. Em caso de auto-aglutinação, os isolados deverão ser semeados em agar seletivo para a detecção da provável contaminação.

As culturas que apresentaram aglutinação com o soro polivalente antiSalmonella foram transferidas novamente para tubos com $\mathrm{AN}$ e incubadas a $37^{\circ} \mathrm{C} \pm 1$ por 24 horas, para a realização das provas bioquímicas. Parte das culturas foi analisada pelo método convencional em tubos e parte foi analisada empregando-se o Painel para Enterobactérias (Probac do Brasil Produtos Bacteriológicos Ltda., Brasil), seguindo-se as recomendações do fabricante. Em ambos os testes, empregou-se Salmonella Typhimurium ATCC 14028 como controle.

As provas bioquímicas realizadas pelo método convencional em tubos foram:

\footnotetext{
$\checkmark$ TSI - Teste do metabolismo de carboidratos;

$\checkmark \quad$ Teste de hidrólise da uréia;

$\checkmark \quad$ Teste de produção de lisina descarboxilase;

$\checkmark \quad$ Teste de produção de $\beta$-galactosidase;

$\checkmark \quad$ Teste de Voges-Proskauer para detecção de acetoína;

$\checkmark \quad$ Teste de produção de indol.
} 
O Painel para Enterobactérias (Probac do Brasil Produtos Bacteriológicos Ltda., Brasil) é constituído de 23 testes:

\footnotetext{
$\checkmark \quad$ Teste de produção de Indol; acetoína; $\mathrm{H}_{2} \mathrm{~S}$; triptofano desaminase;

$\checkmark \quad$ Teste de hidrólise da uréia; citrato de Simmons; esculina

$\checkmark \quad$ Teste de controle de descarboxilação;

$\checkmark$ Teste de descarboxilação de lisina; arginina; ornitina;

$\checkmark \quad$ Teste de degradação de malonato;

$\checkmark \quad$ Teste de oxidação de glicose;

$\checkmark \quad$ Teste de fermentação de glicose; lactose; manitol; adonitol; mioinositol; sorbitol; rafinose; ramnose; maltose; melobiose;

$\checkmark \quad$ Teste de produção de $\beta$-galactosidase.
}

As culturas com resultados típicos de Salmonella spp foram testadas também ao Kit API-20E (bioMérieux - França), seguindo as instruções do fabricante, e enviadas à seção de Bacteriologia Médica do Instituto Adolfo Lutz, São Paulo - SP, para sorotipagem completa. 


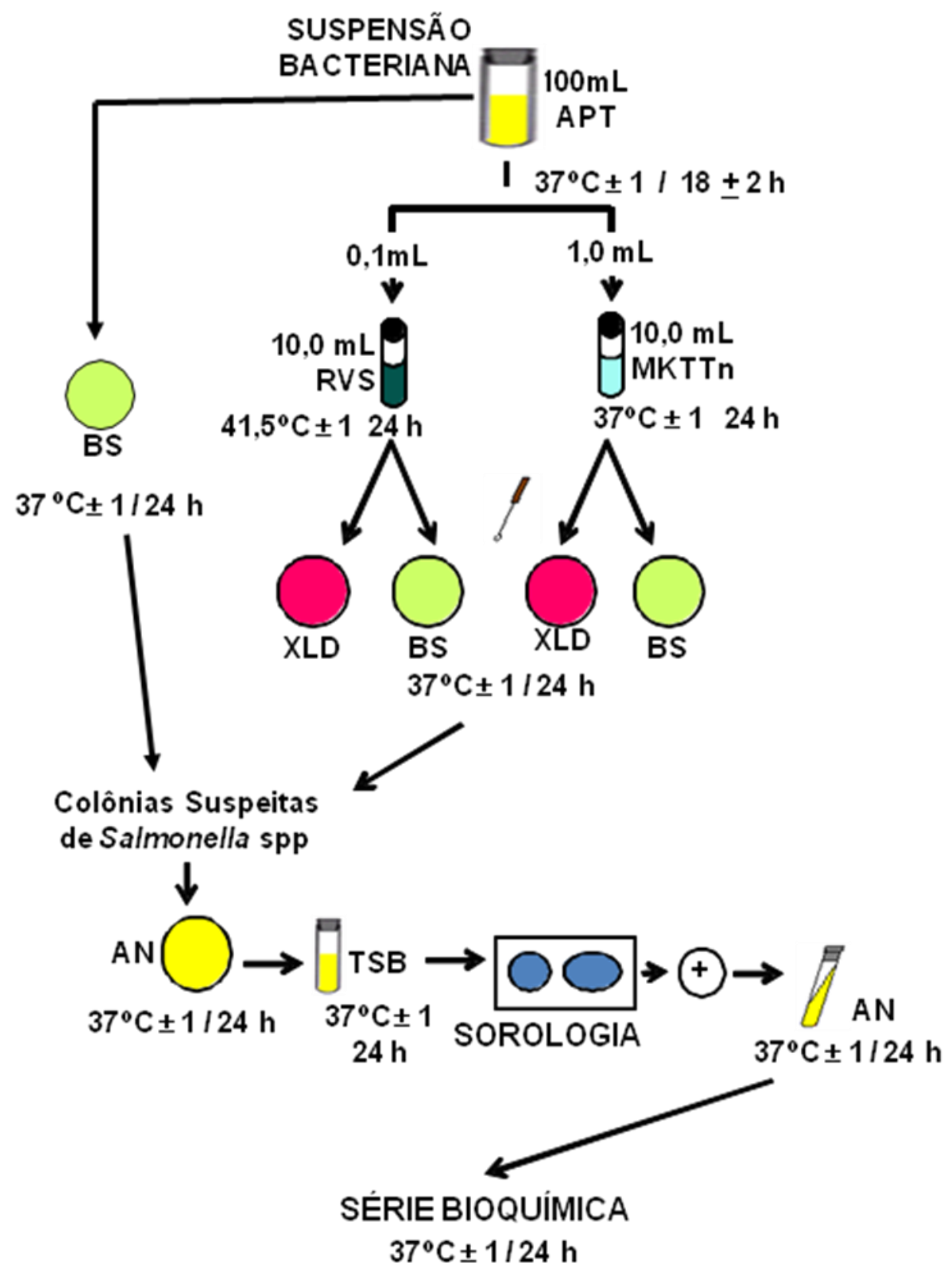

Figura 3 - Esquema do procedimento de isolamento de Salmonella spp.

Legenda: APT - água peptonada tamponada; RVS - Rappaport - Vassiliadis com soja; MKTTn Muller Kauffmann tetrationato com novobiocina; BS - agar bismuto sulfito; XLD - agar xilose lisina desoxicolato; AN - agar nutriente; TSB - caldo triptona soja. 


\subsection{Eletroforese em Gel de Campo Pulsado (PFGE)}

A PFGE foi executada conforme protocolo para subtipagem dos sorovares de Salmonella (não Tifoidal), preconizado pelo PulseNet - CDC (2000).

Para a preparação da suspensão celular das cepas testes e de Salmonella Braenderup, utilizada como marcador de peso molecular (HUNTER et al., 2005), as bactérias foram reativadas em Caldo Tripticaseína de soja - TSB ( $37^{\circ} \mathrm{C} \pm 1$ por $24 \mathrm{~h}$ ), seguida de inoculação por esgotamento, em placa de $\mathrm{AN}\left(37^{\circ} \mathrm{C} \pm 1\right.$ por $\left.24 \mathrm{~h}\right)$. Após a incubação, uma colônia isolada foi repicada para uma nova placa de AN, para a obtenção de crescimento confluente ( $3^{\circ}{ }^{\circ} \mathrm{C} \pm 1$ por $\left.18 \mathrm{~h}\right)$.

Uma porção da cultura em AN foi transferida para tubos com 3,0 mL de tampão de suspensão celular - CSB [100,0 mM Tris-HCl (Pharmacia); 100,0 mM EDTA pH 8,0], para determinar a absorbância a 610 nm (Ultrospec 2000 - Pharmacia); com densidade óptica corrigida para 1,3 a 1,4, obtendo-se uma suspensão celular adequada.

Uma alíquota de 400,0 $\mu \mathrm{L}$ dessa suspensão celular foi transferida para tubos tipo Eppendorf, onde foram adicionados $20,0 \mu \mathrm{L}$ de proteinase $\mathrm{K}\left(20,0 \mathrm{mg} \cdot \mathrm{mL}^{-1}\right)$ (Sigma - EUA), agitando-se vagarosamente.

Para o preparo dos blocos de agarose (plugs), aos tubos contendo a suspensão celular e proteinase $\mathrm{K}$ foram adicionados de 400,0 $\mu \mathrm{L}$ de solução de agarose [Seakem Gold Agarose (Cambrex, Nova Jersey, EUA)] 1,0\% em solução de dodecil sulfato de sódio (USB, Ohio, EUA) 1,0\% em TE (10,0 mM Tris-HCl; 1,0 mM EDTA, pH 8,0). Após a homogeneização, aproximadamente $300 \mu \mathrm{L}$ dessa mistura foram distribuídos nos moldes (BioRad, Califórnia, EUA), e mantidos à temperatura ambiente, até a formação dos plugs.

Após a solidificação, os plugs foram transferidos para tubos tipo Falcon $(50,0$ $\mathrm{mL}$ ) contendo 5,0 mL de solução de lise [50,0 mM Tris-HCl; 50,0 mM EDTA pH 8,0; $1,0 \%$ Sarcosina (Sigma); $0,1 \mathrm{mg} \cdot \mathrm{mL}^{-1}$ de Proteinase $\mathrm{K}$ ], que foram incubados a $54^{\circ} \mathrm{C}$ \pm 1 por 2 horas, sob agitação de 150 rpm. Em seguida, os blocos foram submetidos a 2 lavagens de 10 min cada com água Milli-Q esterilizada pré-aquecida a $50^{\circ} \mathrm{C} \pm 1$, e 4 lavagens de 15 min cada com tampão TE esterilizado, também pré-aquecido a $50^{\circ} \mathrm{C} \pm 1$, durante o tempo das lavagens os tubos falcon com plugs, permaneceram 
incubados a $50^{\circ} \mathrm{C} \pm 1$, sob agitação de $150 \mathrm{rpm}$. Estes plugs foram armazenados em tubos tipo Eppendorf com 1,0 mL de tampão TE, sob refrigeração, até a execução da restrição enzimática.

Para efetuar a restrição enzimática, duas pequenas porções dos plugs (aproximadamente 2,0 2,5 mm) foram transferidas para tubos com tampão $1 \mathrm{X}$ Tango (Fermentas Life Sciences - Canadá). O tampão foi retirado, acrescentando-se 200,0 $\mu \mathrm{L}$ da solução de restrição [1X Tango; 0,25U. $\mu \mathrm{L}^{-1}$ Xbal (Fermentas)]. Os tubos foram levemente agitados e incubados a $37^{\circ} \mathrm{C} \pm 1$ por $2 \mathrm{~h}$.

Os produtos da digestão enzimática do DNA foram separados por meio de eletroforese em gel de agarose (1,0\% Seakem Gold Agarose), em tampão TBE 0,5 $\mathrm{X}$, empregando-se o aparelho Gene Navigator System (Pharmacia) com os seguintes parâmetros: tempo de corrida - 20 h, 200 v, ângulo - 120ํ, gradiente - 6 v.cm ${ }^{-1}$, temperatura do tampão - $12^{\circ} \mathrm{C}$, tempo inicial - 2,16 seg e tempo final - 63,8 seg. Após a eletroforese, o gel foi corado em solução aquosa de brometo de etídio $\left(1,0 \mu \mathrm{g} \cdot \mathrm{mL}^{-1}\right)$, durante 30 minutos, seguido de análise sob transiluminação UV 302 $\mathrm{nm}$, com imagem registrada com o auxílio do sistema EDAS120.

Os padrões de bandas gerados foram comparados visualmente e agrupados em perfis genéticos. A correlação entre os perfis obtidos foi avaliada com o auxílio do programa BioNumerics 5.1 (Applied Maths, Kortrijk, Bélgica) utilizando-se o coeficiente de Dice (Dice, 1945) e análise de "clusters" UPGMA (Unweighed Pair Group Method Using Arithmetic Average) (SNEATH e SOKAL, 1973), para gerar o dendrograma, com valor de tolerância de 1,0\%.

Para interpretação dos resultados, perfis com similaridade $\geq 80,0 \%$ foram considerados semelhantes, e aqueles com similaridade de 100,0\% foram considerados perfis clonais.

\subsection{Teste de invasão de células da linhagem Caco-2}

O teste de invasão de células Caco-2 foi realizado de acordo com Huang et al. (1998) e Xia et al. (2009), com modificações. As células da linhagem Caco-2 obtidas da American Type Culture Collection - ATCC (Manassas, EUA), foram cultivadas em frascos de cultura de células (TPP - Suíça) contendo meio RPMIc, constituído pelo meio RPMI 1640 - Glutamax I (Gibco - EUA), suplementado com 
$10,0 \%$ de soro fetal bovino - SFB (Invitrogen - EUA) e 100 unidades / mL de estreptomicina e penicilina (Sigma - EUA), incubados a $37^{\circ} \mathrm{C}$ em atmosfera com $5,0 \% \mathrm{CO}_{2}$ (Forma Scientific - EUA), até a obtenção de crescimento confluente, aderido ao fundo dos frascos.

Para o teste, a superfície das células foi lavada duas vezes com o próprio meio RPIMc, que foi em seguida descartado. Efetuou uma última lavagem com 13 $\mathrm{mL}$ de solução salina esterilizada, agitando-se os fracos levemente entre as lavagens. Após a última lavagem, adicionou-se $27 \mathrm{~mL}$ de solução salina esterilizada e $3 \mathrm{~mL}$ de Tripsina - 10X (Sigma - EUA), agitando-se vigorosamente até formação de suspensão turva, indicativa do desprendimento das células do fundo do frasco. Em seguida, foram acrescentados $60 \mathrm{~mL}$ de RPMlc, com nova agitação, dividindo-se a solução em tubos tipo Falcon, que foram centrifugados (Beckman, EUA) a $1000 \mathrm{~g}$ $10^{\circ} \mathrm{C}$, por $15 \mathrm{~min}$. Descartou-se o sobrenadante e resuspendeu-se o sedimento com $10 \mathrm{~mL}$ de RPMlc, agitando-se o tubo. A contagem de células Caco-2 nessa suspensão foi feita em câmaras de Newbauer, empregando-se um microscópico óptico comum. A concentração de células na suspensão foi ajustada para $10^{5}$ $\mathrm{cel} / \mathrm{mL}$, adicionando o volume necessário de RPMlc.

Para o teste de invasão, transferiu-se $1 \mathrm{~mL}$ da suspensão de células Caco-2 para os poços de uma placa de 24 poços (TPP - Suíça), incubando-se por $24 \mathrm{~h}$ a $37^{\circ} \mathrm{C} \pm 1$ em atmosfera com $5,0 \%$ de $\mathrm{CO}_{2}$. O meio de cultura foi então removido, e os poços lavados duas vezes com meio RMPI. Em seguida adicionou-se aos poços 900 $\mu \mathrm{L}$ de RPMI e $100 \mu \mathrm{L}$ da cultura de Salmonella spp em teste, obtida em caldo TSB a $37^{\circ} \mathrm{C} \pm 1$ por $24 \mathrm{~h}$ e diluída em solução salina de forma a conter $10^{7} \mathrm{ufc} / \mathrm{mL}$, resultando em uma concentração de $10^{6} \mathrm{ufc} / \mathrm{mL}$ em cada poço. As placas foram incubadas $3 \mathrm{~h}$ a $37^{\circ} \mathrm{C} \pm 1$ em atmosfera com $5,0 \%$ de $\mathrm{CO}_{2}$. O meio de cultura foi então removido com o auxílio de uma pipeta e os poços lavados, duas vezes, com RPMI. Após a última lavagem, adicionou-se a cada poço $1 \mathrm{~mL}$ de uma solução de RPMI com Gentamicina (100 ug/mL, Sigma, EUA), e incubou-se as placas a $3^{\circ} \mathrm{C} \pm 1$ em atmosfera com 5,0\% de $\mathrm{CO}_{2}$, para eliminar bactérias extracelulares eventualmente presentes no meio Após nova lavagem dos poços com RPMI (duas vezes), efetuou-se a lise por meio da adição de $1 \mathrm{~mL}$ de salina fosfatada tamponada - PBS contendo 0,1\% de Triton X-100 (Sigma - EUA) a cada poço, com incubação por 10 min a $37^{\circ} \mathrm{C} \pm 1$ em atmosfera com $5,0 \%$ de $\mathrm{CO}_{2}$. 
Após o período de incubação, uma alíquota de 100,0 uL de cada poço foi submetida à diluição decimal seriada $\left(10^{-1}, 10^{-2}, 10^{-3}\right)$, em solução salina. Em seguida, transferiu-se 100,0 uL de cada diluição para a superfície de placas contendo agar triptona soja - TSA (Oxoid, Inglaterra), com auxílio da alça de Drigalski, esterilizada. Após a incubação a $37^{\circ} \mathrm{C} \pm 1$ por $24 \mathrm{~h}$, realizou-se a contagem de Salmonella spp (ufc / $\mathrm{mL}$ ).

Em todos os testes, foram incluídos um controle positivo (Salmonella Typhimurium ATCC 14028), um controle negativo (Escherichia coli K12) e um controle da cultura de células Caco-2, ao qual não se adicionou cultura bacteriana. A concentração do inoculo bacteriano, adicionado a cada poço, foi monitorada por meio de semeadura e contagem em agar TSA.

Os experimentos foram realizados em duplicata e repetidos, 3 vezes, de forma independente.

Os resultados foram expressos como Eficiência de Invasão (EI), calculada correlacionando-se a contagem de bactérias interiorizadas nas células Caco-2 com a contagem de bactérias no inóculo inicial aderidas às células Caco-2. A correlação foi apresentada em porcentagem.

\subsection{Avaliação da resistência a antimicrobianos}

O teste de resistência a antibióticos e quimioterápicos (Tabela 1), com determinação da Concentração Inibitória Mínima, foi realizado empregando-se o Etest (AB Biodisk - Suécia) (Figura 4), seguindo-se as recomendações do fabricante. Para cada droga testada, empregou-se um controle positivo, conforme recomendação da CLSI (CLSI, 2005). 


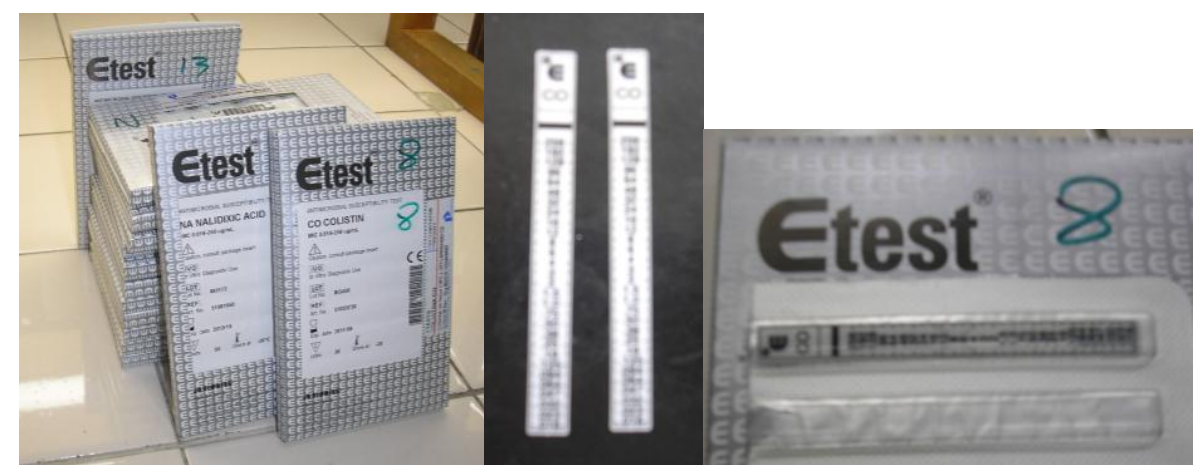

Figura 4 - Fitas Etest (AB Biodisk - Suécia), usadas para avaliação da resistência a antimicrobianos.

Tabela 1 - Antimicrobianos utilizados no antibiograma - Etest.

\begin{tabular}{llllrr}
\hline \multirow{2}{*}{ Grupo } & \multirow{2}{*}{ Classe } & \multirow{2}{*}{ Componentes } & \multirow{2}{*}{ Códigos } & Break point \\
& & & $\mathbf{S}$ & $\mathbf{R}$ \\
\hline B-Lactâmicos & Penicilina & Ampicilina & AMP & $\leq 8$ & $\geq 32$ \\
& Cefalosporina & Cefalotina & CEP & $\leq 8$ & $\geq 32$ \\
& & Cefuroxima & CFX & $\leq 4$ & $\geq 32$ \\
Aminoglicosídeos & & Estreptomicina & EST & $\leq 32$ & $\geq 64$ \\
& & Gentamicina & GEN & $\leq 4$ & $\geq 8$ \\
& & Kanamicina & KAN & $\leq 6$ & $\geq 25$ \\
Tetraciclina & Tetraciclina & TET & $\leq 4$ & $\geq 16$ \\
Quinolona & Ácido nalidíxico & NAL & $\leq 8$ & $\geq 32$ \\
Outros & Cloranfenicol & CLO & $\leq 8$ & $\geq 32$ \\
& & Colistina & CL & $\leq 2$ & $\geq 4$ \\
& & Trimetoprim & TR & $\leq 4$ & $\geq 16$ \\
& & Sulfametoxazol & SX & $\leq 100$ & $\geq 350$ \\
\hline
\end{tabular}

Legenda: S - sensível; R - resistente. 
4. RESULTADOS 
Conforme apresentado no Quadro 1 quatorze dos 200 bovinos analisados foram positivos para Salmonella spp no couro - Co (animais 5, 6, 7, 8, 9 e 10 da fazenda $B$, animais 14,16 e 17 da fazenda $C$, animal 34 da fazenda $G$, animal 84 da fazenda $\mathrm{K}$ e animais 98, 103 e 107 da fazenda L). Cinco animais foram positivos na Carcaça I - Ca I (animais 8, 9 e 10 da fazenda B, animais 17 da fazenda C e animal 90 da fazenda $L$ ) e quatro animais foram positivos na Carcaça II - Ca II (animais 3 e 8 da fazenda B e animais 11 e 19 da fazenda C) (Figura 5)

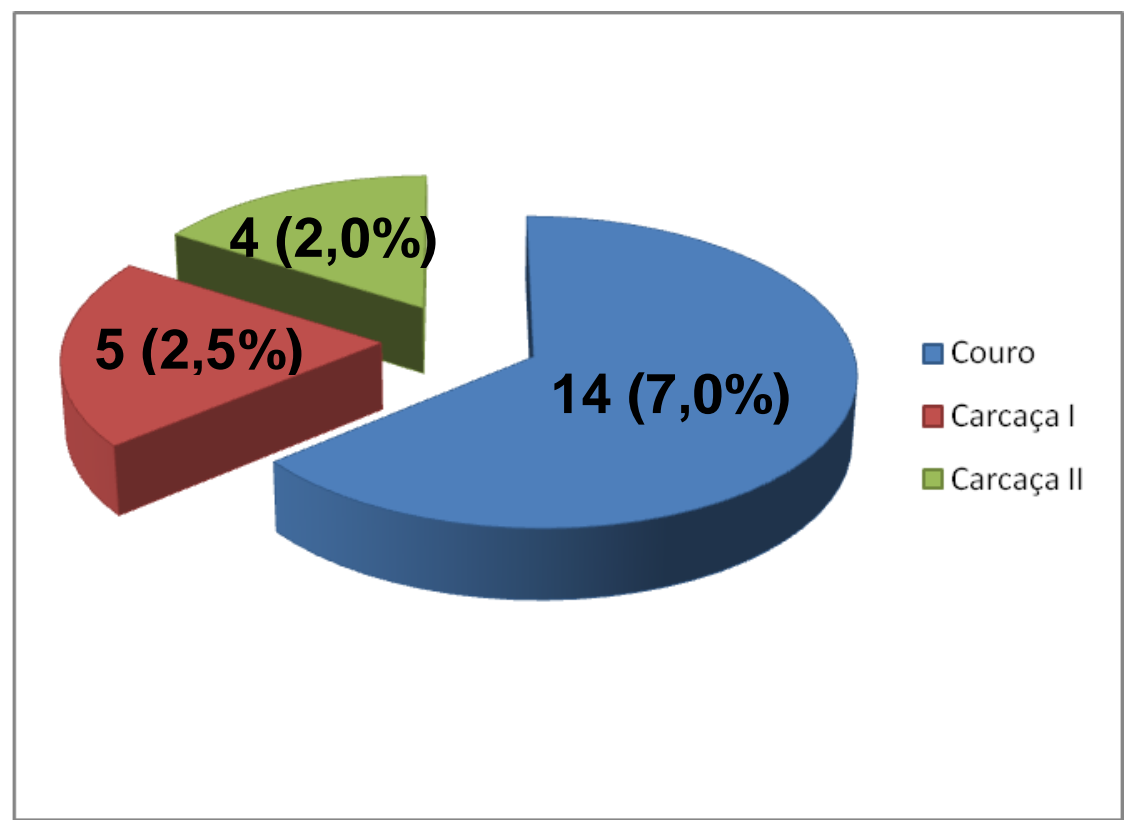

Figura 5 - Positividade para Salmonella spp nos 200 bovinos analisados.

Foi verificado que somente o animal 8 da fazenda $B$, apresentou positividade para Salmonella spp nos três pontos amostrados. Três animais (animais 9 e 10 da fazenda $B$ e animal 17 da fazenda C) foram positivos no couro e na carcaça I simultaneamente. Nenhum animal foi positivo no couro e na carcaça II simultaneamente e nenhum na carcaça I, assim como nenhum animal foi positivo nas carcaças I e II simultaneamente e negativos no couro. Dez animais foram positivos somente no couro, um somente na carcaça I e três somente na carcaça II. 
Quadro1 - Distribuição de Salmonella spp, nas amostras bovinas, de acordo com a origem dos lotes de animais avaliados.

\begin{tabular}{|c|c|c|c|c|c|c|c|c|c|c|c|}
\hline Data & Animal & $\begin{array}{l}\text { Fazenda } \\
\text { Estado }\end{array}$ & Co & Ca I & Ca II & Data & Animal & $\begin{array}{c}\text { Fazenda } \\
\text { Estado }\end{array}$ & Co & Ca I & Ca II \\
\hline \multirow{10}{*}{ 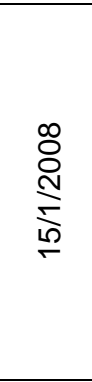 } & 1 & $A-M S$ & & & & \multirow{15}{*}{ 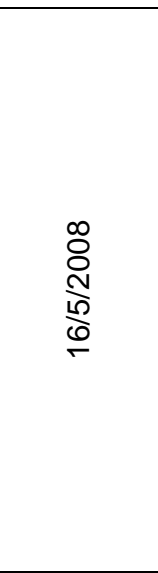 } & 56 & $I-S P$ & & & \\
\hline & 2 & $A-M S$ & & & & & 57 & $I-S P$ & & & \\
\hline & 3 & $A-M S$ & & & & & 58 & $I-S P$ & & & \\
\hline & 4 & $B-M S$ & & & & & 59 & $\mathrm{I}-\mathrm{SP}$ & & & \\
\hline & 5 & $B-M S$ & & & & & 60 & $1-S P$ & & & \\
\hline & 6 & $B-M S$ & & & & & 61 & $I-S P$ & & & \\
\hline & 7 & $B-M S$ & & & & & 62 & $I-S P$ & & & \\
\hline & 8 & $B-M S$ & & & & & 63 & $I-S P$ & & & \\
\hline & 9 & $B-M S$ & & & & & 64 & I-SP & & & \\
\hline & 10 & $B-M S$ & & & & & 65 & I-SP & & & \\
\hline \multirow{10}{*}{ 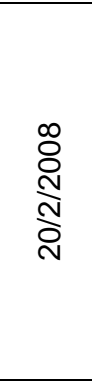 } & 11 & $C-M S$ & & & & & 66 & I-SP & & & \\
\hline & 12 & $C-M S$ & & & & & 67 & I-SP & & & \\
\hline & 13 & $C-M S$ & & & & & 68 & I-SP & & & \\
\hline & 14 & $C-M S$ & & & & & 69 & $J-M S$ & & & \\
\hline & 15 & $C-M S$ & & & & & 70 & $J-M S$ & & & \\
\hline & 16 & $C-M S$ & & & & \multirow{15}{*}{ 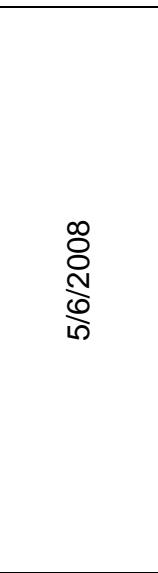 } & 71 & $\mathrm{~K}-\mathrm{GO}$ & & & \\
\hline & 17 & $C-M S$ & & & & & 72 & $\mathrm{~K}-\mathrm{GO}$ & & & \\
\hline & 18 & $C-M S$ & & & & & 73 & $\mathrm{~K}-\mathrm{GO}$ & & & \\
\hline & 19 & C-MS & & & & & 74 & $\mathrm{~K}-\mathrm{GO}$ & & & \\
\hline & 20 & $C-M S$ & & & & & 75 & $\mathrm{~K}-\mathrm{GO}$ & & & \\
\hline \multirow{10}{*}{ 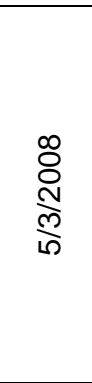 } & 21 & $D-M S$ & & & & & 76 & $\mathrm{~K}-\mathrm{GO}$ & & & \\
\hline & 22 & $D-M S$ & & & & & 77 & $\mathrm{~K}-\mathrm{GO}$ & & & \\
\hline & 23 & $D-M S$ & & & & & 78 & $\mathrm{~K}-\mathrm{GO}$ & & & \\
\hline & 24 & $D-M S$ & & & & & 79 & $\mathrm{~K}-\mathrm{GO}$ & & & \\
\hline & 25 & $D-M S$ & & & & & 80 & $\mathrm{~K}-\mathrm{GO}$ & & & \\
\hline & 26 & $E-P R$ & & & & & 81 & $\mathrm{~K}-\mathrm{GO}$ & & & \\
\hline & 27 & $E-P R$ & & & & & 82 & $\mathrm{~K}-\mathrm{GO}$ & & & \\
\hline & 28 & $E-P R$ & & & & & 83 & $\mathrm{~K}-\mathrm{GO}$ & & & \\
\hline & 29 & $F-M S$ & & & & & 84 & $\mathrm{~K}-\mathrm{GO}$ & & & \\
\hline & 30 & $F-M S$ & & & & & 85 & $\mathrm{~K}-\mathrm{GO}$ & & & \\
\hline \multirow{10}{*}{ 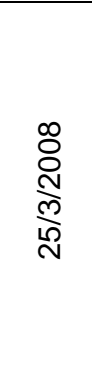 } & 31 & $G-M S$ & & & & \multirow{23}{*}{$\begin{array}{l}\stackrel{\infty}{\circ} \\
\stackrel{N}{\infty} \\
\frac{\infty}{m} \\
\stackrel{m}{\longrightarrow}\end{array}$} & 86 & $L-S P$ & & & \\
\hline & 32 & $G-M S$ & & & & & 87 & $L-S P$ & & & \\
\hline & 33 & $G-M S$ & & & & & 88 & $L-S P$ & & & \\
\hline & 34 & G-MS & & & & & 89 & $L-S P$ & & & \\
\hline & 35 & $G-M S$ & & & & & 90 & $L-S P$ & & & \\
\hline & 36 & G-MS & & & & & 91 & $L-S P$ & & & \\
\hline & 37 & $G-M S$ & & & & & 92 & $L-S P$ & & & \\
\hline & 38 & $G-M S$ & & & & & 93 & $L-S P$ & & & \\
\hline & 39 & $G-M S$ & & & & & 94 & $L-S P$ & & & \\
\hline & 40 & G-MS & & & & & 95 & $L-S P$ & & & \\
\hline \multirow{15}{*}{ 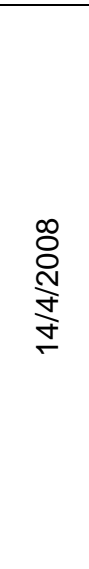 } & 41 & $\mathrm{H}-\mathrm{MS}$ & & & & & 96 & $L-S P$ & & & \\
\hline & 42 & $\mathrm{H}-\mathrm{MS}$ & & & & & 97 & $L-S P$ & & & \\
\hline & 43 & $\mathrm{H}-\mathrm{MS}$ & & & & & 98 & $L-S P$ & & & \\
\hline & 44 & $\mathrm{H}-\mathrm{MS}$ & & & & & 99 & $L-S P$ & & & \\
\hline & 45 & $\mathrm{H}-\mathrm{MS}$ & & & & & 100 & $L-S P$ & & & \\
\hline & 46 & $\mathrm{H}-\mathrm{MS}$ & & & & & 101 & $L-S P$ & & & \\
\hline & 47 & $\mathrm{H}-\mathrm{MS}$ & & & & & 102 & $L-S P$ & & & \\
\hline & 48 & $\mathrm{H}-\mathrm{MS}$ & & & & & 103 & $L-S P$ & & & \\
\hline & 49 & $\mathrm{H}-\mathrm{MS}$ & & & & & 104 & $L-S P$ & & & \\
\hline & 50 & $\mathrm{H}-\mathrm{MS}$ & & & & & 105 & $L-S P$ & & & \\
\hline & 51 & $H-M S$ & & & & & 106 & $L-S P$ & & & \\
\hline & 52 & $\mathrm{H}-\mathrm{MS}$ & & & & & 107 & $L-S P$ & & & \\
\hline & 53 & $\mathrm{H}-\mathrm{MS}$ & & & & & 108 & $L-S P$ & & & \\
\hline & 54 & $\mathrm{H}-\mathrm{MS}$ & & & & \multirow{2}{*}{$24 / 9 / 2008$} & 109 & $M-S P$ & & & \\
\hline & 55 & $\mathrm{H}-\mathrm{MS}$ & & & & & 110 & $M-S P$ & & & \\
\hline
\end{tabular}


Quadro 1 - Distribuição de Salmonella spp, nas amostras bovinas, de acordo com a origem dos lotes de animais avaliados (cont.).

\begin{tabular}{|c|c|c|c|c|c|c|c|c|c|c|c|}
\hline Data & Animal & $\begin{array}{c}\text { Fazenda } \\
\text { Estado }\end{array}$ & Co & Ca I & Ca II & Data & Animal & $\begin{array}{l}\text { Fazenda } \\
\text { Estado }\end{array}$ & Co & Ca I & Ca II \\
\hline \multirow{21}{*}{ 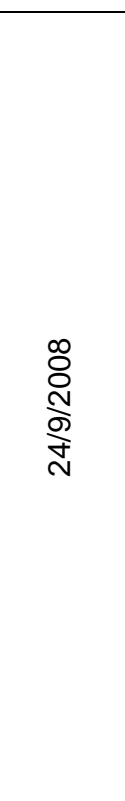 } & 111 & $M-S P$ & & & & \multirow{22}{*}{$\frac{\infty}{\stackrel{\infty}{=}} \frac{\Gamma}{f}$} & 156 & $P-S P$ & & & \\
\hline & 112 & $M-S P$ & & & & & 157 & $P-S P$ & & & \\
\hline & 113 & $M-S P$ & & & & & 158 & $P-S P$ & & & \\
\hline & 114 & $M-S P$ & & & & & 159 & $P-S P$ & & & \\
\hline & 115 & $M-S P$ & & & & & 160 & $P-S P$ & & & \\
\hline & 116 & $M-S P$ & & & & & 161 & $P-S P$ & & & \\
\hline & 117 & $M-S P$ & & & & & 162 & $P-S P$ & & & \\
\hline & 118 & $M-S P$ & & & & & 163 & $P-S P$ & & & \\
\hline & 119 & $\mathrm{M}-\mathrm{SP}$ & & & & & 164 & $P-S P$ & & & \\
\hline & 120 & $M-S P$ & & & & & 165 & $P-S P$ & & & \\
\hline & 121 & $M-S P$ & & & & & 166 & $P-S P$ & & & \\
\hline & 122 & $M-S P$ & & & & & 167 & $P-S P$ & & & \\
\hline & 123 & $M-S P$ & & & & & 168 & $P-S P$ & & & \\
\hline & 124 & $M-S P$ & & & & & 169 & $P-S P$ & & & \\
\hline & 125 & $M-S P$ & & & & & 170 & $P-S P$ & & & \\
\hline & 126 & $\mathrm{M}-\mathrm{SP}$ & & & & & 171 & $P-S P$ & & & \\
\hline & 127 & $M-S P$ & & & & & 172 & $P-S P$ & & & \\
\hline & 128 & $M-S P$ & & & & & 173 & $P-S P$ & & & \\
\hline & 129 & $M-S P$ & & & & & 174 & $P-S P$ & & & \\
\hline & 130 & $M-S P$ & & & & & 175 & $P-S P$ & & & \\
\hline & 131 & $\mathrm{M}-\mathrm{SP}$ & & & & & 176 & $P-S P$ & & & \\
\hline \multirow{23}{*}{$\frac{\infty}{\frac{\infty}{\sigma}}$} & 132 & $\mathrm{~N}-\mathrm{SP}$ & & & & & 177 & $P-S P$ & & & \\
\hline & 133 & $\mathrm{~N}-\mathrm{SP}$ & & & & \multirow{21}{*}{ 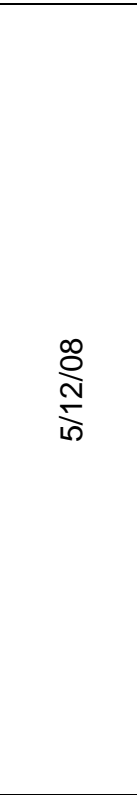 } & 178 & $Q-S P$ & & & \\
\hline & 134 & $\mathrm{~N}-\mathrm{SP}$ & & & & & 179 & $Q-S P$ & & & \\
\hline & 135 & $\mathrm{~N}-\mathrm{SP}$ & & & & & 180 & $Q-S P$ & & & \\
\hline & 136 & $\mathrm{~N}-\mathrm{SP}$ & & & & & 181 & $Q-S P$ & & & \\
\hline & 137 & $N-S P$ & & & & & 182 & $Q-S P$ & & & \\
\hline & 138 & $\mathrm{~N}-\mathrm{SP}$ & & & & & 183 & $Q-S P$ & & & \\
\hline & 139 & $\mathrm{~N}-\mathrm{SP}$ & & & & & 184 & $Q-S P$ & & & \\
\hline & 140 & $\mathrm{~N}-\mathrm{SP}$ & & & & & 185 & $Q-S P$ & & & \\
\hline & 141 & $\mathrm{~N}-\mathrm{SP}$ & & & & & 186 & $Q-S P$ & & & \\
\hline & 142 & $\mathrm{~N}-\mathrm{SP}$ & & & & & 187 & $Q-S P$ & & & \\
\hline & 143 & $\mathrm{~N}-\mathrm{SP}$ & & & & & 188 & $Q-S P$ & & & \\
\hline & 144 & $\mathrm{~N}-\mathrm{SP}$ & & & & & 189 & $Q-S P$ & & & \\
\hline & 145 & $\mathrm{~N}-\mathrm{SP}$ & & & & & 190 & $Q-S P$ & & & \\
\hline & 146 & $\mathrm{~N}-\mathrm{SP}$ & & & & & 191 & $Q-S P$ & & & \\
\hline & 147 & $\mathrm{~N}-\mathrm{SP}$ & & & & & 192 & $Q-S P$ & & & \\
\hline & 148 & $N-S P$ & & & & & 193 & $Q-S P$ & & & \\
\hline & 149 & $\mathrm{O}-\mathrm{GO}$ & & & & & 194 & $Q-S P$ & & & \\
\hline & 150 & $\mathrm{O}-\mathrm{GO}$ & & & & & 195 & $Q-S P$ & & & \\
\hline & 151 & $\mathrm{O}-\mathrm{GO}$ & & & & & 196 & $Q-S P$ & & & \\
\hline & 152 & $\mathrm{O}-\mathrm{GO}$ & & & & & 197 & $Q-S P$ & & & \\
\hline & 153 & $\mathrm{O}-\mathrm{GO}$ & & & & & 198 & $Q-S P$ & & & \\
\hline & 154 & $\mathrm{O}-\mathrm{GO}$ & & & & \multirow{2}{*}{$5 / 1 / 2009$} & 199 & $\mathrm{R}-\mathrm{MS}$ & & & \\
\hline $4 / 11 / 2008$ & 155 & $P-S P$ & & & & & 200 & $\mathrm{R}-\mathrm{MS}$ & & & \\
\hline
\end{tabular}

Legenda: Co - Couro; Ca I - Carcaça I; Ca II - Carcaça II; MS - Mato Grosso; PR - Paraná; GO - Goiás; SP - São Paulo; Quadros amarelos - positividade para Salmonella spp; Quadros em branco negatividade para Salmonella spp.

Os sorovares das cepas de Salmonella spp detectadas nas amostras analisadas estão apresentados na Tabela 2. Entre as 25 cepas testadas, verificou-se uma prevalência do sorovar $S$. Give, com $13(52,0 \%)$ cepas, seguido de $S$. Abaetetuba, com $4(16,0 \%)$ cepas e de $S$. Typhimurium com $2(8,0 \%)$ cepas. Foi ainda detectada uma cepa pertencente ao sorovar $S$. Agona $(4,0 \%)$ e uma pertencente ao sorovar Dublin (4,0\%). Quatro das 25 cepas eram rugosas e, 
portanto, não tipadas, sendo classificadas como Salmonella enterica subespécie enterica cepa rugosa.

Tabela 2 - Distribuição da positividade para Salmonella nas amostras analisadas e os sorovares encontrados.

\begin{tabular}{|c|c|c|c|c|c|c|}
\hline \multirow{2}{*}{ Animal } & \multicolumn{2}{|c|}{ Couro } & \multicolumn{2}{|c|}{ Carcaça I } & \multicolumn{2}{|c|}{ Carcaça II } \\
\hline & Resultado & Sorovar & Resultado & Sorovar & Resultado & Sorovar \\
\hline 3 & - & - & - & - & + & Give \\
\hline 5 & + & Give & - & - & - & - \\
\hline 6 & + & Give & - & - & - & - \\
\hline \multirow{2}{*}{7} & + & Give & - & - & - & - \\
\hline & + & enterica * & - & - & - & - \\
\hline 8 & $\begin{array}{l}+ \\
+\end{array}$ & $\begin{array}{c}\text { Give } \\
\text { enterica * }\end{array}$ & + & Give & + & Give \\
\hline 9 & + & Give & + & enterica * & - & - \\
\hline 10 & + & Give & + & Give & - & - \\
\hline 11 & - & - & - & - & + & Typhimurium \\
\hline 14 & + & Give & - & - & - & - \\
\hline 16 & + & enterica * & - & - & - & - \\
\hline 17 & + & Typhimurium & + & Give & - & - \\
\hline 19 & - & - & - & - & + & Give \\
\hline 34 & + & Agona & - & - & - & - \\
\hline 84 & + & Dublin & - & - & - & - \\
\hline 90 & - & - & + & Abaetetuba & - & - \\
\hline 98 & + & Abaetetuba & - & - & - & - \\
\hline 103 & + & Abaetetuba & - & - & - & - \\
\hline 107 & + & Abaetetuba & - & - & - & - \\
\hline Total & 16 & 16 & 5 & 5 & 4 & 4 \\
\hline
\end{tabular}

Legenda: *- S. enterica subsp. enterica cepa rugosa

De acordo com os resultados do PFGE (Figura 6), as 25 cepas de Salmonella isoladas apresentaram 12 perfis genéticos distintos, sendo que 10 deles foram formados por apenas uma cepa. Verificou-se que 19 das 25 cepas (76,0\%) apresentaram uma grande similaridade entre si, superior a 80,0\%. O perfil 1 (p1) apresentou 7 cepas, 5 das quais foram do sorovar $S$. Give e duas não tipadas ( $S$. enterica subsp. enterica cepa rugosa). O perfil 2 (p2) apresentou 8 cepas, sendo 6 do sorovar S. Give, 1 S. Abaetetuba e 1 não tipada (S. enterica subsp. enterica cepa rugosa). 
DICE (Tol 2,0\%-2,0\%) (H>0,0\% S>0,0\%) [0,0\%-100,0\%]

PFGE - Xbal

\section{Cepa-Animal - Amostra - Perfil}
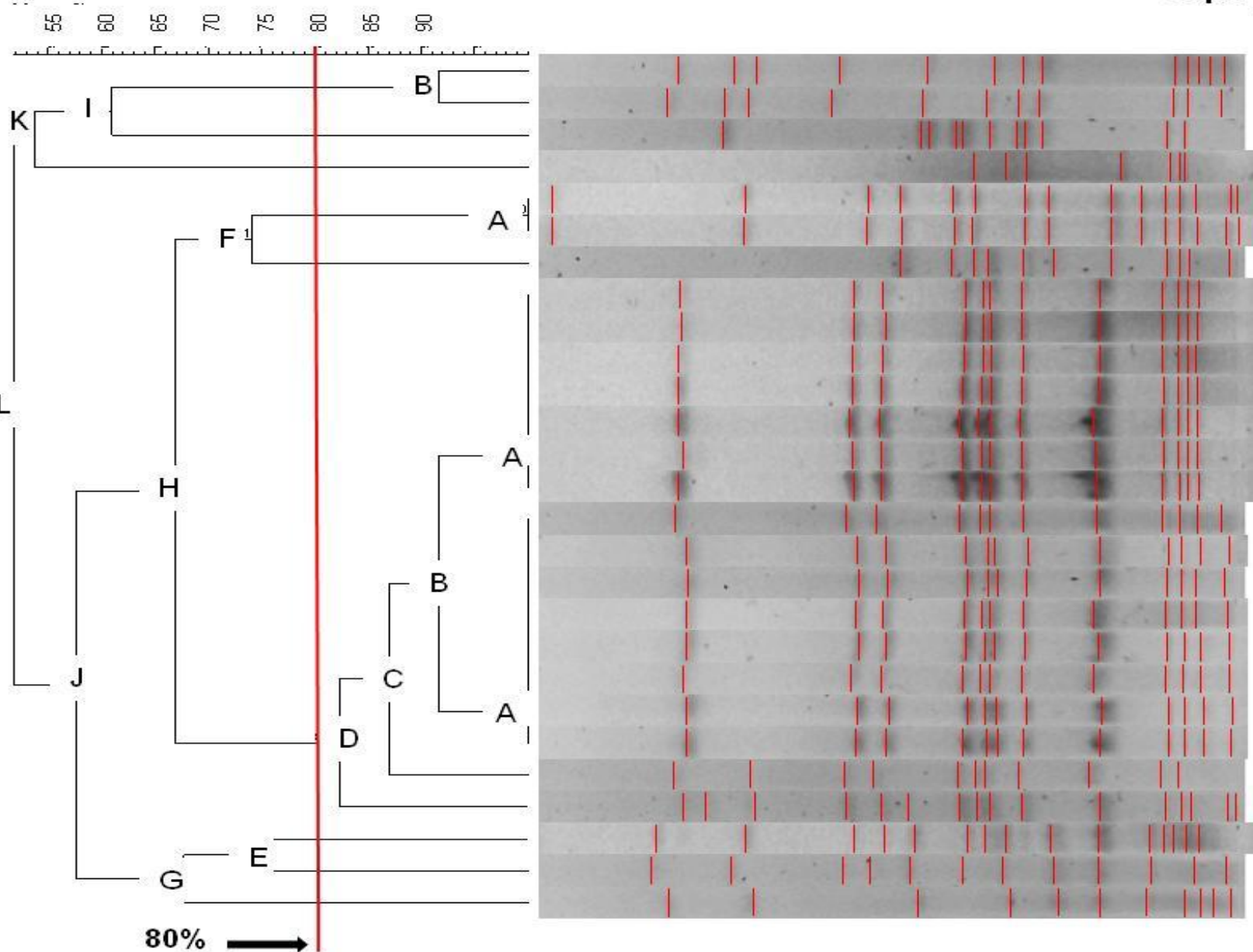

Typhimurium - 11 call _p3

Typhimurium - $17 \mathrm{co}$

Agona - $34 \mathrm{co}-\mathrm{p} 5$

enterica* $-16 \mathrm{co}-\mathrm{p} 6$

Braenderup - $4>$

Braenderup-3

Abaetetuba - $90 \mathrm{cal}-\mathrm{p} 7$

enterica* $-7 c 0$

enterica ${ }^{*}-8 \mathrm{co}$

Give - $10 \mathrm{cal}$

Give - $17 \mathrm{cal}$

Give - 8cal

Give - 8call

Give - 9co

Abaetetuba - 98

enterica* - 9ca

Give - 10 co

Give - 3call

Give - $5 c 0$

Give - 6co

Give $-7 c 0$

Give - 8co

Give - 19call

p8

Dublin - 84c

$\mathrm{p} 9 \mathrm{p} 10$

Abaetetuba-107co $\mathrm{p} 11$

Give - $14 \mathrm{co}-\mathrm{p} 12$

Figura 6 - Dendrograma indicando a relação genética entre as cepas de Salmonella spp isoladas no estudo.

Legenda: A - 100,0\% de similaridade; B - 91,7\%; C - 87\%; D - 82,3\%; E - 75,9\%; F - 74,1\%; G - 67,7\%; H - 66,9\%; I - 61,0\%; J $57,6 \% ; \mathrm{K}-53,7 \%$; L -51,7\%; S. Braenderup - cepa padrão; * Salmonella enterica subsp enterica cepa rugosa. 
Em relação à patogenicidade das cepas isoladas, os resultados de Eficiência de Invasão (IE) das células Caco-2 estão apresentadas na Tabela 3. Com exceção da cepa obtida do couro do animal 16, da fazenda C (Figura 7), que apresentou IE similar ao do controle positivo usado no teste (7,31\%), e da cepa obtida do animal 90, da fazenda L, que apresentou IE de 1,99\%, todas as demais cepas apresentaram IE inferior a 1,0\%, sendo inferior também ao controle negativo.

Tabela 3 - Resultados da prova de invasão das cepas de Salmonella nas células Caco - 2.

\begin{tabular}{ccclccc}
\hline CEPAS ANIMAL AMOSTRA & SOROVAR & INP & $\begin{array}{c}\text { MÉDIA ufC/mL } \\
\text { INTERNALIZADA }\end{array}$ & $\begin{array}{c}\text { IE } \\
\text { (\%) }\end{array}$ \\
\hline C+ & & & Typhimurium & $1,16 \times 10^{6}$ & $8,40 \times 10^{4}$ & 7,31 \\
C - & & & E.coli K12 & $1,23 \times 10^{6}$ & $3,20 \times 10^{4}$ & 2,60 \\
1 & 3 & Ca II & Give & $3,25 \times 10^{6}$ & $2,21 \times 10^{3}$ & 0,07 \\
2 & 5 & Co & Give & $1,14 \times 10^{6}$ & $2,59 \times 10^{3}$ & 0,23 \\
3 & 6 & Co & Give & $9,10 \times 10^{5}$ & $1,75 \times 10^{3}$ & 0,19 \\
4 & 7 & Co & Give & $1,03 \times 10^{6}$ & $3,66 \times 10^{3}$ & 0,60 \\
5 & & Co & enterica * & $1,40 \times 10^{6}$ & $3,45 \times 10^{3}$ & 0,25 \\
6 & 8 & Co & Give & $1,53 \times 10^{6}$ & $4,08 \times 10^{3}$ & 0,27 \\
7 & & Co & enterica * & $2,31 \times 10^{6}$ & $3,80 \times 10^{3}$ & 0,16 \\
8 & & Ca I & Give & $1,44 \times 10^{6}$ & $7,32 \times 10^{3}$ & 0,51 \\
9 & & Ca II & Give & $1,05 \times 10^{6}$ & $6,00 \times 10^{3}$ & 0,57 \\
10 & 9 & Co & Give & $3,46 \times 10^{6}$ & $6,80 \times 10^{3}$ & 0,20 \\
11 & & Ca I & enterica * & $1,84 \times 10^{6}$ & $2,48 \times 10^{3}$ & 0,13 \\
12 & 10 & Co & Give & $1,82 \times 10^{6}$ & $6,34 \times 10^{3}$ & 0,35 \\
13 & & Ca I & Give & $4,07 \times 10^{6}$ & $1,03 \times 10^{4}$ & 0,25 \\
14 & 11 & Ca II & Typhimurium & $3,57 \times 10^{6}$ & $1,15 \times 10^{4}$ & 0,32 \\
15 & 14 & Co & Give & $1,41 \times 10^{6}$ & $1,22 \times 10^{4}$ & 0,87 \\
16 & 16 & Co & enterica * & $6,00 \times 10^{5}$ & $3,64 \times 10^{4}$ & 6,09 \\
17 & 17 & Co & Typhimurium & $2,15 \times 10^{6}$ & $7,81 \times 10^{3}$ & 0,36 \\
18 & & Ca I & Give & $5,90 \times 10^{6}$ & $1,19 \times 10^{4}$ & 0,20 \\
19 & 19 & Ca II & Give & $2,50 \times 10^{6}$ & $1,59 \times 10^{4}$ & 0,64 \\
20 & 34 & Co & Agona & $2,58 \times 10^{6}$ & $1,94 \times 10^{4}$ & 0,75 \\
21 & 84 & Co & Dublin & $2,42 \times 10^{6}$ & $1,27 \times 10^{4}$ & 0,53 \\
22 & 90 & Ca I & Abaetetuba & $3,00 \times 10^{6}$ & $6,00 \times 10^{4}$ & 1,99 \\
23 & 98 & Co & Abaetetuba & $1,75 \times 10^{6}$ & $1,21 \times 10^{4}$ & 0,47 \\
24 & 103 & Co & Abaetetuba & $1,33 \times 10^{6}$ & $7,85 \times 10^{3}$ & 0,59 \\
25 & 107 & Co & Abaetetuba & $6,77 \times 10^{6}$ & $3,52 \times 10^{4}$ & 0,52 \\
\hline
\end{tabular}

Legenda: C+ Typhimurium ATCC14028; C- Escherichia coli K12; Co - Couro; Ca I - Carcaça I; Ca II - Carcaça II; * Salmonella enterica subsp. enterica cepa rugosa; INP - inóculo inicial em cada poço; IE - eficiência de invasão 


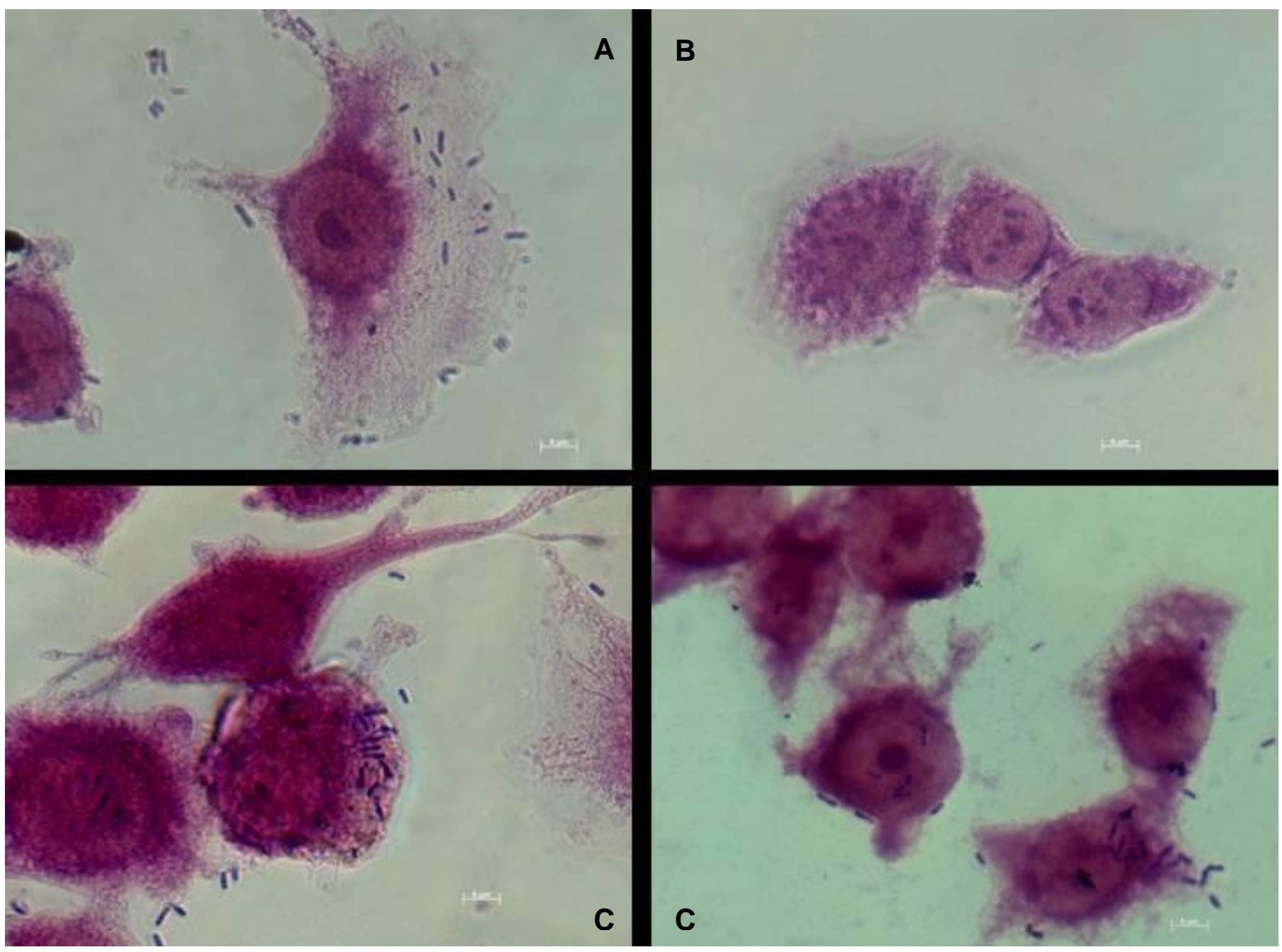

Figura 7 - Fotomicrografia (Olympus BX51) mostrando a Eficiência de Invasão de células Caco - 2 - A: Salmonella Typhimurium ATCC 14028 (Controle positivo), B: E.coli K12 (Controle negativo), C: Cepa 16 (Salmonella enterica subsp. enterica cepa rugosa - couro do animal 16). Coloração com May Grunwald - Giemsa (aumento 1.000 vezes). 
Em relação à resistência aos antimicrobianos (Tabela 4), verificou-se que as 25 cepas de Salmonella spp foram sensíveis à gentamicina e tetraciclina. No entanto, 96,0\% delas $(n=24)$ foram resistentes ao sulfametoxazol, 92,0\% ( $n=23)$ à colistina e $64,0 \%(n=16)$ à cefalotina. Além disso, foram detectadas 5 cepas $(20,0 \%)$ resistentes à trimetoprim, 4 (16,0\%) à estreptomicina e ao ácido nalidíxico e $1(4,0 \%)$ ao cloranfenicol, ampicilina e kanamicina.
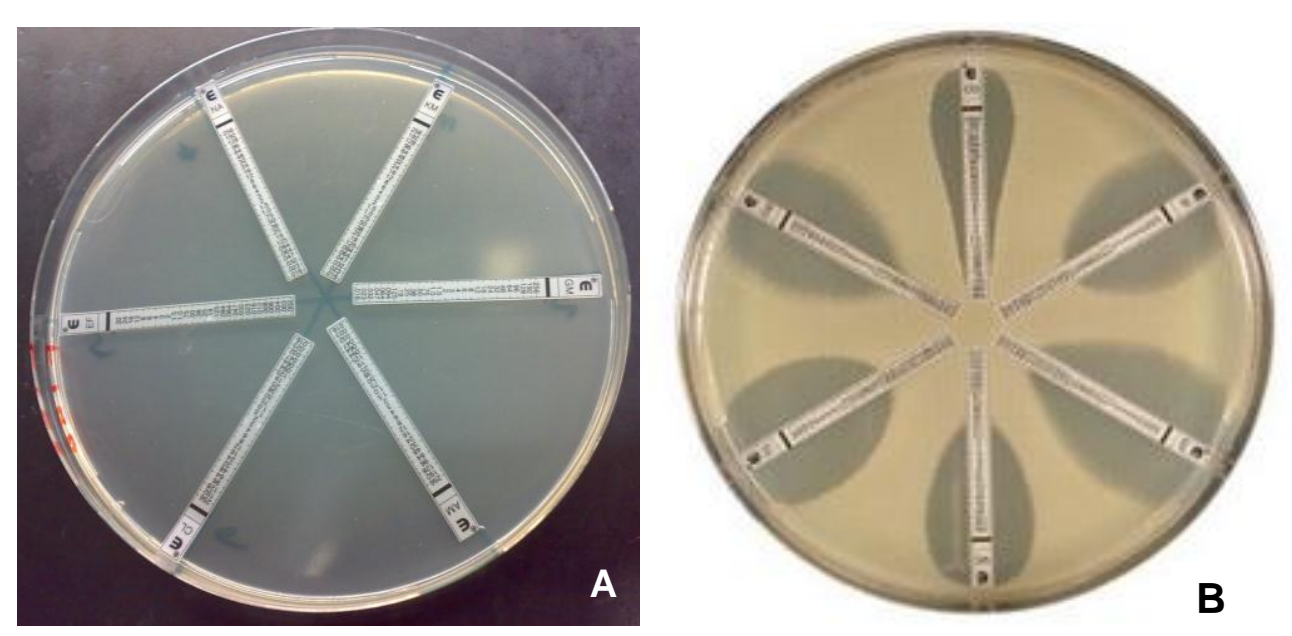

Figura 8 - Avaliação da resistência aos antimicrobianos empregando fitas Etest: A: culturas sensíveis, B: culturas resistentes, de acordo com CLSI.

Avaliando a resistência das cepas aos antimicrobianos, foram observados 12 perfis de resistência diferentes (Tabela 5), com a maioria delas denotando multiresistência, tais como o perfil CEP-CFX-EST-NAL-CL-SX-TMP-AMP (S. Give Ca I - animal 10); CEP-CFX-EST-NAL-CL-SX-TMP (S. Give - Co - 9); CEP-CFXKAN-NAL-CL-SX-TMP (S. Abaetetuba - Co - 98); CEP-CL-SX-TMP-CLO ( $S$. Typhimurium - Co - 17); CEP-CFX-CL-SX (S. Give - Co - 8, S. Give - Ca II - 8, S. Give - Co - 10, S. enterica subsp. enterica cepa rugosa - Ca I - 9); CEP-CL-SXTMP (S. Typhimurium - Ca II - 11); CFX-EST-CL-SX (S. Give - Ca II - 19); CEPCL-SX (S. Give - Ca I - 17, S.Give - Co - 5-6 - 7; S. Abaetetuba - Co - 107); CEP-CFX-EST-CL-SX (S. Give - Ca I - 8); CL-SX (S. Give - Ca II - 3, $S$. 
Abaetetuba Ca I - 90, S. Agona Co - 34, S. enterica subsp.enterica cepa rugosa Co - 7 - 8 e 16); CFX-NAL (S. Dublin - Co - 84) e SX (S. Abaetetuba - Co - 103).

Ressaltamos que $17(68,0 \%)$ cepas de Salmonella multiresistentes apresentaram resistência frente 3 a 8 antimicrobianos, de classes diferentes.

Os 4 animais portadores de Salmonella em 2 (Co e Ca I dos animais 9, 10 e 17) ou 3 pontos de amostragem (Co, Ca I e Ca II - animal 8), albergavam cepas com diferentes perfis de multiresistência.

As 25 cepas de Salmonella compuseram 12 modelos de antibiograma ou perfis de resistência, de acordo com a resistência a dois ou mais antimicrobianos.

Os 4 animais portadores de Salmonella em 2 (Co e Ca I dos animais 9, 10 e 17) ou 3 pontos de amostragem (Co, Ca I e Ca II - animal 8), com sorovares iguais ou diferentes, apresentaram perfis de resistência distintos entre as amostras de um mesmo animal.

A correlação entre origem das cepas de Salmonella analisadas, perfil genético, perfil de resistência aos antimicrobianos, sorovares e Eficiência de Invasão de células Caco-2, está apresentada na Tabela 6. 
Tabela 4 - Comportamento das cepas de Salmonella spp, frente aos antimicrobianos determinado pelo Método do Etest.

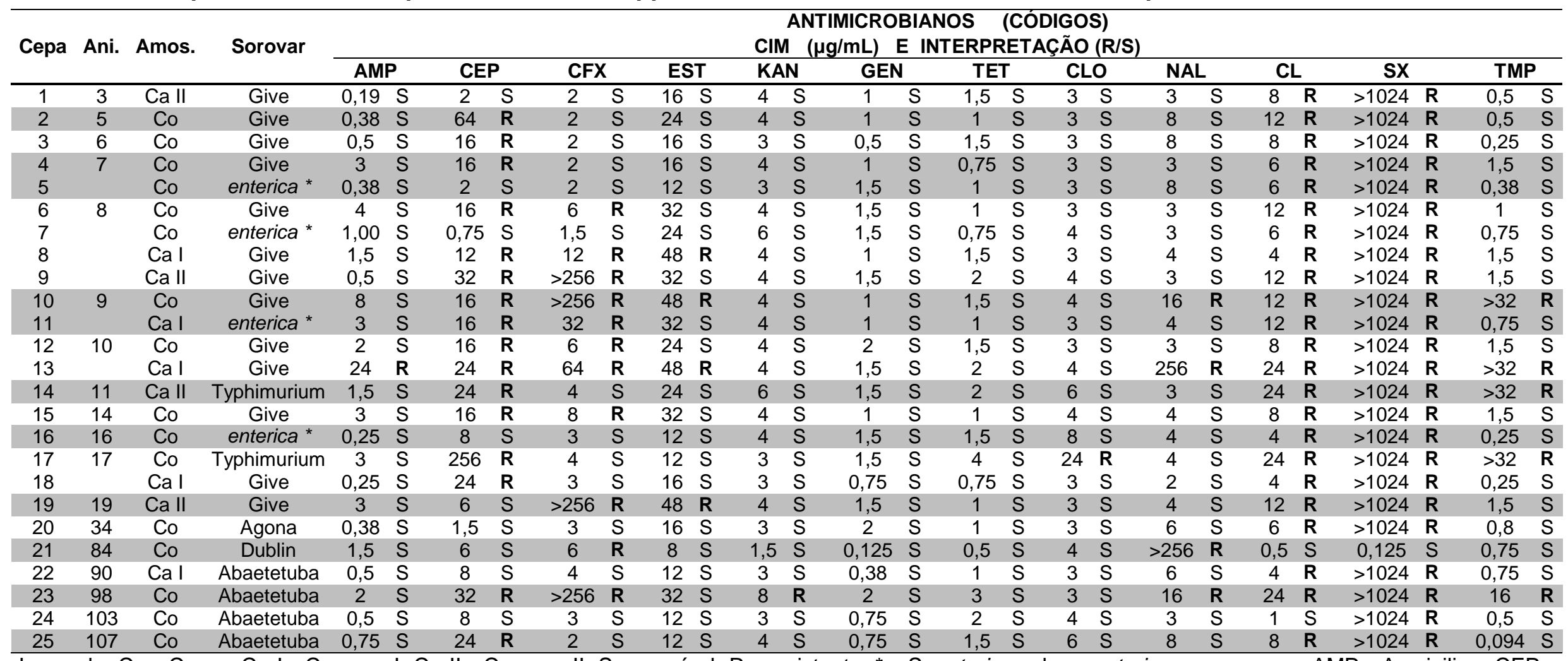

Legenda: Co - Couro; Ca I - Carcaça I; Ca II - Carcaça II; S - sensível; R - resistente; * - S. enterica subsp. enterica cepa rugosa; AMP - Ampicilina; CEP Cefalotina CFX - Cefuroxima; EST - Estreptomicina de acordo com NARMS (2006); KAN - Kanamicina; GEN - Gentamicina; TET - Tetraciclina; CLO - Cloranfenicol; NAL - Ácido Nalidíxico; CL - Colistina; SX - Sulfametoxazol; TMP - Trimetoprim 
Tabela 5 - Distribuição dos perfis de resistência das cepas de Salmonella spp isoladas.

\begin{tabular}{|c|c|c|c|c|c|c|c|c|}
\hline \multicolumn{6}{|c|}{ PERFIL DE RESISTÊNCIA } & \multirow{2}{*}{$\begin{array}{c}\text { CEPA } \\
13\end{array}$} & \multirow{2}{*}{$\begin{array}{l}\text { AMOSTRA } \\
\text { / ANIMAL } \\
\text { Ca I/ } 10\end{array}$} & \multirow{2}{*}{$\begin{array}{c}\text { SOROVAR } \\
\text { S. Give }\end{array}$} \\
\hline CEP & CFX & CL SX & TMP & EST & NAL AMP & & & \\
\hline CEP & CFX & CL SX, & TMP & EST & NAL & 10 & Co / 9 & S. Give \\
\hline CEP & CFX & CL SX & TMP & & NAL KAN & 23 & Co / 98 & S. Abaetetuba \\
\hline CEP & & CL SX & TMP & & CLO & 17 & Co / 17 & S. Typhimurium \\
\hline CEP & CFX & CL SX & & & & 9 & Ca II / 8 & S. Give \\
\hline CEP & CFX & CL SX & & & & 11 & $\mathrm{Cal} / 9$ & S. enterica* \\
\hline \multirow[t]{2}{*}{ CEP } & & CL SX & TMP & & & 14 & Ca II / 11 & S. Typhimurium \\
\hline & CFX & CL SX & & EST & & 19 & Ca II / 19 & S. Give \\
\hline CEP & CFX & CL SX & & EST & & 8 & Ca I/ 8 & S. Give \\
\hline CEP & & $C L S X$ & & & & 18 & $\mathrm{Ca} \mathrm{I/} 17$ & S. Give \\
\hline CEP & & CL SX & & & & 2 & Co / 5 & S. Give \\
\hline CEP & & $C L S X$ & & & & 3 & Co $/ 6$ & S. Give \\
\hline CEP & & CL SX & & & & 4 & Co $/ 7$ & S. Give \\
\hline CEP & CFX & CL SX & & & & 6 & Co $/ 8$ & S. Give \\
\hline CEP & CFX & CL SX & & & & 12 & Co $/ 10$ & S. Give \\
\hline CEP & CFX & $C L S X$ & & & & 15 & Co / 14 & S. Give \\
\hline \multirow[t]{9}{*}{ CEP } & & $C L S X$ & & & & 25 & Co / 107 & S. Abaetetuba \\
\hline & CFX & & & & NAL & 21 & Co / 84 & S. Dublin \\
\hline & & CL SX & & & & 1 & Ca II / 3 & S. Give \\
\hline & & CL SX & & & & 22 & $\mathrm{Ca} \mathrm{I} / 90$ & S. Abaetetuba \\
\hline & & CL SX & & & & 20 & Co / 34 & S. Agona \\
\hline & & CL SX & & & & 4 & $\mathrm{Co} / 7$ & S. enterica* \\
\hline & & CL SX & & & & 7 & Co / 8 & S. enterica* \\
\hline & & CL SX & & & & 16 & Co $/ 16$ & S. enterica* \\
\hline & & SX & & & & 24 & Co / 103 & S. Abaetetuba \\
\hline
\end{tabular}

Legenda: Co - Couro; Ca I - Carcaça I; Ca II - Carcaça II; S - sensível; R - resistente; * - S. enterica subsp. enterica cepa rugosa; AMP - Ampicilina; CEP - Cefalotina CFX - Cefuroxima; EST Estreptomicina; KAN - Kanamicina; GEN - Gentamicina; TET - Tetraciclina; CLO Cloranfenicol; NAL - Ácido Nalidíxico; CL - Colistina; SX - Sulfametoxazol; TMP Trimetoprim 
Tabela 6. Correlação entre origem das cepas de Salmonella spp, perfil genético, perfil de resistência aos antimicrobianos, sorovares e Eficiência de Invasão de células Caco-2.

\begin{tabular}{|c|c|c|c|c|c|}
\hline $\begin{array}{l}\text { Animal / } \\
\text { Amostra }\end{array}$ & Fazenda & Perfil Genético & Perfil de resistência & Sorovar & IE \\
\hline $7 \mathrm{Co}$ & $\mathrm{B}$ & $\mathrm{A}$ & CL-SX & enterica* $^{*}$ & $0,25 \%$ \\
\hline $8 \mathrm{Co}$ & $\mathrm{B}$ & $A$ & CL-SX & enterica* & $0,16 \%$ \\
\hline $10 \mathrm{Ca} I$ & B & A & CEP-CFX-CL-SX-TMP-EST-NAL-AMP & Give & $0,25 \%$ \\
\hline $17 \mathrm{Ca} \mathrm{I}$ & C & A & CEP-CL-SX & Give & $0,20 \%$ \\
\hline $8 \mathrm{Ca} \mathrm{I}$ & B & A & CEP-CFX-CL-SX-EST & Give & $0,51 \%$ \\
\hline $8 \mathrm{Ca}$ II & B & A & CEP-CFX-CL-SX & Give & $0,57 \%$ \\
\hline 9 Co & B & A & CEP-CFX-CL-SX-TMP-EST-NAL & Give & $0,20 \%$ \\
\hline $98 \mathrm{Co}$ & $\mathrm{L}$ & B & CEP-CFX-CL-SX-TMP-NAL & Abaetetuba & $0,47 \%$ \\
\hline $9 \mathrm{Ca} \mathrm{I}$ & $\mathrm{B}$ & B & CEP-CFX-CL-SX & enterica* & $0,13 \%$ \\
\hline $10 \mathrm{Co}$ & $\mathrm{B}$ & B & CEP-CFX-CL-SX & Give & $0,35 \%$ \\
\hline $3 \mathrm{Ca} I \mathrm{I}$ & A & B & CL-SX & Give & $0,07 \%$ \\
\hline 5 Co & B & $\mathrm{B}$ & CEP-CL-SX & Give & $0,23 \%$ \\
\hline 6 Co & B & B & CEP-CL-SX & Give & $0,19 \%$ \\
\hline 7 Co & B & B & CEP-CL-SX & Give & $0,60 \%$ \\
\hline 8 Co & B & B & CEP-CFX-CL-SX & Give & $0,27 \%$ \\
\hline $11 \mathrm{Ca} I I$ & C & C & CEP-CL-SX-TMP & Typhimurium & $0,32 \%$ \\
\hline $17 \mathrm{Co}$ & $\mathrm{C}$ & $\mathrm{D}$ & CEP-CL-SX-TMP-CLO & Typhimurium & $0,36 \%$ \\
\hline $34 \mathrm{Co}$ & G & $E$ & CL-SX & Agona & $0,75 \%$ \\
\hline 16 Co & C & $\mathrm{F}$ & CL-SX & enterica* & $6,09 \%$ \\
\hline $90 \mathrm{Ca} I$ & $\mathrm{~L}$ & G & CL-SX & Abaetetuba & $1,99 \%$ \\
\hline $19 \mathrm{Ca}$ II & C & $\mathrm{H}$ & CFX-CL-SX-EST & Give & $0,64 \%$ \\
\hline $84 \mathrm{Co}$ & $\mathrm{K}$ & I & CFX-NAL & Dublin & $0,53 \%$ \\
\hline 103 Co & L & $J$ & SX & Abaetetuba & $0,59 \%$ \\
\hline 107 Co & $\mathrm{L}$ & $\mathrm{K}$ & CEP-CL-SX & Abaetetuba & $0,52 \%$ \\
\hline $14 \mathrm{Co}$ & $\bar{C}$ & 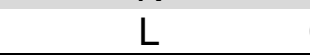 & CEP-CFX-CL-SX & Give & $0,87 \%$ \\
\hline
\end{tabular}


5. DISCUSSÃO 
A contaminação microbiana mais importante da carne bovina é de origem externa, uma vez que, em condições normais, a massa interna (músculo) da carne não contém microrganismos, ou estes são muito escassos. A contaminação externa depende de uma série de fatores, tais como quantidade, variedade e condições fisiológicas dos microrganismos da microbiota intestinal do animal, método de sacrifício a que o animal foi submetido, condições higiênico-sanitárias durante e após o abate e processamento, e das condições do resfriamento da carne após o processamento (XAVIER e JOELE 2004).

Outro fator muito importante que influencia os tipos e quantidade de microrganismos detectados na carne está relacionado ao método de amostragem e a metodologia analítica laboratorial adotada. As variações nos resultados obtidos em diferentes pesquisas são, em grande parte, decorrentes do uso de diferentes métodos de amostragem e delineamento experimental (RANSOM et al., 2002 e GHAFIR et al., 2005).

Os resultados obtidos neste estudo em relação à positividade de carcaças para Salmonella spp foram bastante semelhantes aos reportados por Ghafir et al. (2005), em Ghent, Bélgica, que verificaram 2,5\% de positividade nas carcaças analisadas entre 1997 a 1999 e 1,1\% naquelas analisadas entre 2000 e 2003. Os autores consideraram que esse índice de positividade era baixo. No entanto, dois estudos realizados na Austrália, indicaram que essa positividade pode ser bem mais baixa: Vanderlinde et al. (1998) reportaram $0,1 \%$ de positividade e Phillips et al. (2001) verificaram que $0,2 \%$ das amostras analisadas foram positivas. Stevens et al. (2006) consideraram que variações na positividade podem ser explicadas por diferenças na etapa do processamento em que as amostras foram obtidas e nos métodos e meios de cultura empregados na detecção e identificação das salmonelas (STEVENS et al., 2006).

Comprando positividade de Salmonella spp em carcaças bovinas antes da etapa de evisceração, verifica-se que a positividade detectada neste estudo $(2,5 \%)$ foi bem inferior ao detectado em outros estudos. Rivera-Betancourt et al. (2004), no Colorado, EUA, detectaram este patógeno em 23,0 a 27,0\% das carcaças na etapa de pré-evisceração. Por outro lado, Small et al. (2006), em Londres, Reino Unido, relataram uma positividade de $20,0 \%$ para carcaças de bezerros com menos de 14 dias de idade e $12,7 \%$ para carcaças de novilho com menos de um ano, mas não 
detectaram Salmonella spp em nenhuma das 330 amostras de carcaças de bovinos adultos. Molla et al. (2003), pesquisando Salmonella spp em amostras de carcaças bovinas de abatedouros da Etiópia detectaram 5,2\% de amostras positivas, com prevalência dos sorovares $S$. Braenderup (18,9\%), S. Dublin (17,2\%), S. SaintPaul (15,0\%) e $S$. Typhimurium (6,8\%).

Agrupando os animais por lotes, neste estudo foi constatado que dentre os 16 lotes de animais analisados, compostos de 10 ou 15 bovinos cada, cinco $(31,2 \%)$ apresentaram resultado positivo ao menos para uma amostra de couro, enquanto que três $(18,7 \%)$ lotes foram positivos para uma ou mais amostras de carcaça, esse resultado é inferior ao reportado em outros estudos, em outros países. Ransom et al. (2002) verificaram que nos 30 lotes compostos de 5 animais, abatidos num frigorífico no Colorado, EUA, 21 (70,0\%) tinham ao menos uma amostra de couro (depois do atordoamento) positiva para Salmonella spp, enquanto que dois $(6,7 \%)$ apresentavam pelo menos uma amostra de carcaça (antes da toalete) positiva. Além disso, cinco $(16,7 \%)$ lotes apresentaram pelo menos uma amostra fecal positiva para esta bactéria.

Molla et al. (2003), pesquisando Salmonella spp em 1.116 amostras de carcaças bovinas de abatedouros da Etiópia (de acordo com ISO 6579) detectaram $63(5,2 \%)$ amostras positivas e uma prevalência dos sorovares S. Braenderup (78 cepas, 18,9\%), $S$. Dublin (71 cepas, 17,2\%), $S$. SaintPaul (62 cepas, 15,0\%) e $S$. Typhimurium ( 28 cepas, $6,8 \%$ ) nas amostras positivas.

Devido às condições de aglomeração de animais nos setores de produção, transporte, comercialização e abate, nem sempre é possível obter produtos de origem animal livres de Salmonella spp. Quanto à adoção de medidas, que previnam a contaminação da carne, deve-se atentar para as possibilidades de contaminação do animal, bem como de contaminação cruzada, durante o transporte e/ou confinamento, antes do abate. Medidas de higiene devem ser aplicadas a partir dos currais, pois as fezes, a água e os alimentos estão entre os principais veiculadores de disseminação de patógenos Sistemas de limpeza dos animais antes do abate minimizam o risco de contaminação do couro pela microbiota presente (SMALL et al., 2006).

Comparando os resultados de positividade de Salmonella spp obtidos neste estudo (Figura 5) com os observados por outros autores que empregaram o mesmo 
método de amostragem (técnica de amostragem de superfície empregando esponjas), verifica-se que a positividade detectada nas amostras de couro dos animais analisados foi bastante inferior ao reportado em outros países. Barham et al. (2002), Kansas, EUA, observaram que a incidência de Salmonella spp no couro dos animais no campo foi baixa, da ordem de $6,0 \%$ que aumentou para $86,9 \%$, nos mesmos animais após um confinamento de 14 dias em currais. Também Ransom et al. (2002), Colorado, EUA, observaram elevada freqüência de Salmonella spp nos animais, tendo detectado $45,3 \%$ de positividade quando foi considerado o total de amostras de superfície analisadas e $70,0 \%$ de positividade em pelo menos uma amostra dos 30 lotes, de 5 animais cada, examinados.

É sabido que Salmonella spp pode persistir por vários dias no ambiente. Assim, além da transferência do couro ou pele de um único animal para os demais animais no curral, pode ocorrer a contaminação do ambiente do abatedouro (estábulo, boxes de confinamento e/ou atordoamento), que pode ser uma forma adicional de transferência do patógeno para animais que entram neste abatedouro (COLLIS et al., 2004; GHAFIR et al., 2005; SMALL et al., 2006; FLUCKEY et al., 2007).

A utilização de práticas adequadas na etapa de remoção do couro e das vísceras pode diminuir a importância desta etapa na transmissão horizontal de patógenos para as carcaças, durante o processo de abate. Na pesquisa realizada por Ransom et al. (2002), E.coli 0157:H7 foi detectada em 18,0\% das amostras de couro mas em nenhuma das carcaças estudadas, assim como somente $1,7 \%$ das carcaças foram positivas para Salmonella spp, enquanto que $45,3 \%$ das amostras de couro foram positivas. Este relato está em concordância com os resultados obtidos neste estudo, onde foi verificado que a positividade para Salmonella spp nas couro foi de $7,0 \%$, enquanto nas carcaças $\mathrm{Ca}$ I e Ca II a positividade foi mais baixa (2,5\% e 2,0\%, respectivamente).

Entre as práticas adequadas na etapa da remoção do couro e vísceras, Roça e Serrano (1994) destacam a importância da utilização de duas facas de sangria, uma para incisão da barbela e outra para o corte dos vasos sanguíneos, e de sua esterilização após a sangria de cada animal, através de sua imersão na caixa de esterilização. Além disso, a esfola, que é a remoção do couro por separação do tecido subcutâneo, quando realizada pelo sistema aéreo, ou seja, com o bovino 
suspenso no trilho, traz vantagens do ponto de vista higiênico-sanitário e tecnológico (ROÇA e SERRANO, 1994). Todas essas práticas eram utilizadas no abatedouro estudado, sendo mais uma justificativa para a baixa transmissão horizontal de Salmonella spp observada.

Em relação aos sorovares de Salmonella detectados neste estudo (Tabela 2 ), as 25 cepas detectadas pertenceram a apenas cinco sorovares diferentes, com uma prevalência de cepas pertencentes ao sorovar S. Give (52,0\%). Quatro cepas não puderam ser sorotipadas por estarem na forma rugosa. Não foi encontrada na literatura nenhuma referência de estudo sobre prevalência de sorovares de Salmonella spp em carne bovina brasileira. Além disso, a prevalência do sorovar $\mathrm{S}$. Give, observada neste estudo, não foi observada em nenhum outro estudo envolvendo carne bovina, no Brasil ou em outros países. Ghafir et al. (2005) constataram que $40,6 \%$ das cepas de Salmonella spp isoladas das carcaças bovinas coletadas entre 2000 e 2003 na Bélgica pertenceram ao sorovar S. Typhimurium, seguido por $S$. Enteritidis e S. Derby (12,5\% cada). No Senegal, Stevens et al. (2006) verificaram que o sorovar mais prevalente em amostras de carne bovina, provenientes de abatedouros e varejo, foi $S$. Bredeney $(25,0 \%)$. Estes autores observaram uma maior diversidade de sorovares entre as cepas isoladas do varejo, com sorovares não encontrados nas amostras obtidas nos abatedouros, sugerindo que a contaminação tenha sido causada por manipulação inadequada pósprocessamento. Fluckey et al. (2007), no Texas, EUA, observaram uma prevalência semelhante de diferentes sorovares nas amostras de fezes, couro e carcaças de bovinos analisadas, onde foram detectados os seguintes sorovares: $S$. Muenster $(27,5 \%)$, S. Cerro (18,6\%), S. Montevideo (13,7\%), S. Kentucky (13,7\%) e S. Meleagridis (12,7\%), além de outros sorovares com positividade entre zero e 5,0\%.

É interessante notar que os sorovares $S$. Dublin e $S$. Abaetetuba detectados neste estudo foram também detectados em carne bovina por Molla et al. (2003) e Stevens et al. (2006), na Etiópia e no Senegal, respectivamente.

Considerando os sorovares encontrados nas amostras analisadas neste estudo, com exceção de S. Typhimurium, detectada no couro de um único animal (animal 17, da Fazenda C), mas não detectada na carcaça derivada deste animal (Ca I e/ou Ca II), os demais sorovares tem pouca importância quanto à sua relação com aqueles detectados em fontes humanas. Conforme o relatório do CDC (2006a), 
durante o ano de 2006 o sorovar de Salmonella spp mais frequentemente detectado de fontes humanas nos EUA foi $S$. Typhimurium (16,9\%), seguido de $S$. Enteritidis $(16,6 \%), S$. Newport $(8,3 \%)$, S. Heidelberg $(3,7 \%)$ e $S$. Javiana (3,5\%), e outros sorovares com freqüência inferior a 3,0\%.

Ainda segundo o CDC, os sorovares de Salmonella spp mais frequentemente isolados em 2006 de fontes não humanas (bovinos, suínos, equinos e outros animais domésticos, além de aves e do ambiente) foram $S$. Typhimurium $(19,9 \%), S$. Heidelberg (11,5\%), S. Newport (8,1\%) e S. Kentucky (10,9\%), entre outros. Segundo o CDC, os sorovares S. Agona (3,0\%) e S. Give (1,6\%), detectadas no presente estudo em várias das amostras de bovinos estudadas, foram isoladas somente das fontes não humanas (CDC, 2006a).

A análise do dendrograma apresentado na Figura 6 permite verificar que as 25 cepas de Salmonella analisadas por PFGE foram agrupadas em 12 perfis genéticos distintos, sendo que 10 perfis foram compostos por uma única cepa. Resultados similares foram observados por Kérouanton et al. (2007), que ao subtipificar por PFGE cepas isoladas da França, obtiveram 452 perfis distintos, sendo que 305 $(67,5 \%)$ perfis eram constituídos por uma única cepa e $54(11,9 \%)$ por somente duas cepas.

Stevens et al. (2008), objetivando efetuar uma análise epidemiológica de cepas Salmonella spp detectadas na cadeia produtiva de carne bovina em Dakar, Senegal, efetuaram a genotipagem (PFGE), para identificar as relações clonais e a sua potencial transmissão na cadeia produtiva. Foi observada a prevalência de seis sorovares (S. Bredeney, S. Muenster, S. Waycross, S. Corvallis. S. Kentucky e S. Brandenburg), e as cepas puderam ser agrupadas em 17 genótipos, com cepas de um mesmo sorovar apresentando até seis genótipos diferentes. A correlação entre os perfis genéticos e a origem das amostras bovinas revelou uma gama extensa de fontes de contaminação dentro da cadeia produtiva. A comparação entre o perfil genético e o perfil de resistência aos antimicrobianos mostrou que o abatedouro e o varejo apresentavam o mesmo papel como fontes de contaminação da carne analisada.

A Figura 6 mostra também que 15 das 25 cepas $(60,0 \%)$ de Salmonella spp isoladas apresentaram apenas dois perfis genéticos distintos ( $\mathrm{p} 1$ e p2), mas com elevado grau de similaridade entre si $(91,7 \%)$. Outra cepa, isolada do animal 19 
(carcaça II), apresentou similaridade de $87,0 \%$ com os outros dois perfis (p1 e p2), enquanto aquela isolada do couro do animal 84 apresentou similaridade de $82,3 \%$ com o perfil p2. Considerando essas cepas em conjunto, verifica-se que $68,0 \%$ das cepas de Salmonella spp isoladas no estudo apresentaram perfis genéticos com elevado grau de similaridade, no mínimo $82,3 \%$.

Por outro lado, verificou-se que as cepas de Salmonella spp isoladas nos três animais da fazenda $L$ (animais 98, 103 e 107) foram agrupadas em dois perfis genéticos diferentes, e apresentaram três perfis de resistência a antimicrobianos. No entanto, a três cepas pertenceram ao mesmo sorovar $S$. Abaetetuba.

As 15 cepas que apresentaram perfis genéticos de similaridade elevada pertenceram a apenas dois sorovares distintos, enquanto três eram não tipáveis. Os dois sorovares detectados nestes dois grupos foram S. Give, com onze das doze cepas tipadas e $S$. Abaetetuba, com apenas uma das cepas tipadas. Foram isoladas outras cepas do sorovar $S$. Give, mas foram pertencentes a outros grupos genéticos. Outras duas cepas do sorovar Abaetetuba, isoladas do couro de dois animais (animais 103 e 107) apresentaram perfis genéticos com grau de similaridade de $75,9 \%$ entre si, mas a similaridade com as demais cepas desse sorovar isoladas dos animais 90 (carcaça I) e 98 (couro) foi baixa.

Em relação às quatro cepas de Salmonella spp que não puderam ser tipadas por estarem na forma rugosa ( $S$. enterica subsp. enterica cepa rugosa), os resultados da tipagem molecular (Figura 6) e dos testes de sensibilidade aos antimicrobianos (Tabela 4), além de sua origem (Quadro 1), indicam que é bastante provável que três delas sejam pertencentes ao sorovar S. Give. A cepa 5, proveniente do animal 7, apresentou o mesmo perfil genético que a cepa 4 , isolada deste mesmo animal, pertencente ao sorovar S. Give. A cepa 7, isolada do couro do animal 8, apresentou o mesmo perfil genético da quatro outras cepas isoladas deste animal (cepas 6, 8, 9 e 10), todas pertencentes ao sorovar S. Give. Também a cepa 11, isolada da carcaça I do animal 9, apresentou o mesmo perfil genético que a outra cepa de $S$. Give isolada deste animal. Como a quarta cepa não tipável (cepa 16, do couro do animal 16) apresentou um perfil genético diferente de todas as demais cepas isoladas em todo o trabalho, e como foi a única cepa isolada deste animal, não é possível inferir a qual sorovar pertence. 
Em relação à patogenicidade das cepas isoladas (Tabela 3), verificou-se que, com exceção de uma, todas apresentaram Eficiência de Invasão de células Caco-2 inferior a 1,0\%, independentemente do animal de onde foram isoladas, do sorovar, do perfil genético e do perfil de resistência aos antimicrobianos. A Eficiência de Invasão de células Caco-2 apresentada pelas cepas foi inferior à apresentada pelo controle negativo, constituído por uma linhagem de E.coli $\mathrm{K} 12$, indicando que estas cepas apresentam baixo potencial de virulência. Xia et al. (2009), também empregaram células Caco-2 para avaliar a patogenicidade de cepas de Salmonella spp isoladas de diversos tipos de alimentos no Estados Unidos no período entre 2000 e 2003, e verificaram que todas as cepas apresentaram baixo índice de internalização, independentemente do sorovar, perfil genético e alimento do qual haviam sido isoladas. Resultados similares já haviam sido relatados por Kim e Wei (2007).

Deve-se ressaltar, no entanto, que o teste de invasão de células Caco-2 é apenas um dos testes propostos para avaliação da patogenicidade de Salmonella spp. Outros testes, como pesquisa e avaliação da expressão dos genes relacionados com virulência e, testes com outras linhagens celulares são necessários para se determinar de maneira mais precisa o risco associado a estas cepas.

Em relação à resistência aos antimicrobianos (Tabela 4), verificou-se uma frequência preocupante de cepas de Salmonella spp resistentes a vários dos antibióticos testados. Segundo vários estudos, o uso indiscriminado de produtos farmacêuticos na Medicina Veterinária é a principal causa da emergência de bactérias resistentes aos antimicrobianos (GUERRA et al., 2000; THRELFALL et al., 2006). O uso em larga escala de certos antibióticos pode causar a disseminação dos microrganismos resistentes, via seleção (WELLS et al., 2001; JONES et al., 2002; van DUIJKEREN et al., 2003; FITZGERALD et al., 2003; JOHNSON et al., 2005; ZHAO et al., 2005), gerando questionamentos sobre o uso dos antimicrobianos e seu vínculo, se houver, com a emergência de cepas de Salmonella spp multiresistentes.

Os resultados de resistência a antimicrobianos detectada no presente estudo são diferentes aos obtidos por Graziani et al. (2008), que avaliaram cepas de Salmonella Typhimurium, isoladas de amostras clínicas de humanos e de animais 
em abatedouros, no período de 2002 a 2004, com resultado similar apenas para antimicrobiano do grupo das sulfonamidas. A multiresistência detectada por eles foi devida, principalmente, à circulação de dois fenótipos - o perfil tetra-resistente AMPEST-SUL-TET (20,9\%) e o penta-resistente AMP-CLO-EST-SUL-TET (19,2\%), que apresentaram resistência adicional ao ácido nalidíxico-NAL ou ao sulfametoxazoltrimetoprim-SXT. Além disso, esses dois fenótipos e suas variantes representaram $88,6 \%$ das cepas multiresistente isoladas de humanos e de animais.

Bacon et al. (2002) verificaram que, dentre as 53 amostras de couro e carcaça positivas, das quais foram isoladas pelo menos uma cepa resistente a um dos antimicrobianos, foram detectadas S. Typhimurium var. Copenhagen DT104 (11 cepas), resistentes a pelo menos 6 antibióticos, com os seguintes perfis de resistência: (AMP-CLO-EST-SUL-TET+SXT), (AMP-CLO-EST-SUL-TET+AMO/AcAMP/SUB); (AMP-CLO-EST-SUL-TET+SXT-AMO/Ac-SXT). Das 8 amostras positivas, foram isoladas 61 cepas de $S$. Agona, 52 das quais foram sensíveis a todos os antibióticos testados e 9 foram resistentes a sulfonamidas e a tetraciclina, simultaneamente.

Small et al. (2006), avaliando a resistência a antimicrobianos pelo método do disco, verificaram que, das 137 cepas Salmonella spp isoladas do meio ambiente e de carcaças de carne vermelha, processadas em abatedouros de pequeno, médio e grande porte em Londres, UK, 90 (65,7\%) foram sensíveis aos 16 antimicrobianos $24(17,5 \%)$ foram resistentes ao ácido nalidíxico, 11 (8,0 \%) à tetraciclina, 8 (5,8\%) aos componentes do grupo sulfonamidas e ao sulfametoxazol + trimetoprim, e 4 $(3,0 \%)$ ao cloranfenicol. Estes resultados são semelhantes aos que foram encontrados nesse estudo para a resistência ao ácido nalidíxico (16,0\%) e ao cloranfenicol (4,0\%), mas diferentes quanto à resistência às sulfonamidas $(96,0 \%) \mathrm{e}$ à tetraciclina, para a qual todas as cepas foram sensíveis. Neste estudo não foram encontradas cepas de Salmonella spp sensíveis a todos os antimicrobianos testados, o que contraria resultados de outros estudos, indicando que o perfil de resistência ou sensibilidade pode variar de estudo para estudo, de acordo com o sorovar das cepas, práticas de manejo dos bovinos, idade e da dieta alimentar dos animais, e, principalmente, tratamento médico veterinário, que tem pressão seletiva de microrganismos resistentes (DARGATZ et al., 2000). 
Quanto à sensibilidade de Salmonella spp à gentamicina, Zhao et al. (2005) e Khaitsa et al. (2007), nos EUA, verificaram resistência entre 9,0\% e 3,6\%, das cepas testadas, respectivamente, o que contraria dados do presente estudo, em que todas as cepas foram sensíveis a esse antibiótico.

Embora a estreptomicina não tenha nenhum papel na terapêutica de infecções por Salmonella, o teste de resistência a esse antibiótico é extensamente usado como um marcador epidemiológico. Por exemplo, resistência à estreptomicina faz parte da caracterização fenotípica de Salmonella enterica sorovar Typhimurium DT104, sabidamente resistente à ampicilina, sulfonamidas, tetraciclinas e ao cloranfenicol (DORAN et al., 2006).

Biedenbach et al. (2006) verificaram que cepas ácido nalidíxico resistentes foram detectadas em diversas regiões geográficas, inclusive na Argentina, Brasil, Chile, México e Venezuela, entre os países Latinos Americanos. Cepas resistentes também foram detectadas nos EUA (Califórnia, Colorado, Delaware, lowa, Indiana, Nova lorque, Carolina do Norte e Utah) e nas províncias do Canadá (Alberta e Ontario). Resistência ao ácido nalidíxico foi mais alta na América Latina $(15,0 \%)$ comparada com a América do Norte (6,3\%), com taxas bastante variáveis entre os países. Por exemplo, a taxa de resistência ao ácido nalidíxico foi de $50,0 \%$ no México e 33,6\% no Brasil, enquanto em outros países latino-americanos esta freqüência variou entre 1,8\% e 5,6\%. A taxa de resistência ao ácido nalidíxico foi de 6,0\% e 7,0\% nos EUA e Canadá, respectivamente. Entre os quatro centros médicos geograficamente distintos, que enviaram amostras do Brasil, foi observada resistência ao ácido nalidíxico, com as seguintes taxas - 22,2\% (Brasília), 27,8\% (Porto Alegre), 28,8\% (São Paulo) e 46,3\% (Florianópolis).

Também neste estudo foi detectada uma taxa elevada de resistência a ácido nalidíxico (16,0\%) e cefalotina (60,0\%). Estes dados são preocupantes, pois de acordo com Biedenbach et al. (2006) as quinolonas são drogas escolhidas para o tratamento de infecções gastrointestinais invasivas, e a resistência a elas poderia levar a um fracasso terapêutico.

A melhor medida para controlar o desenvolvimento e a disseminação de microrganismos resistentes é o uso criterioso de antimicrobianos. Medidas de controle efetivas, envolvendo os possíveis reservatórios e vias de disseminação dos agentes de infecção, devem se adotadas, para que a propagação dos patógenos e o 
uso abusivo de antimicrobianos sejam evitados (FILE, 1999; GUERRA et al., 2000; THRELFALL, et al., 2006).

Analisando os resultados de sorotipagem, perfil genético conforme a PFGE e perfil de resistência a antimicrobianos de todas as cepas de Salmonella spp isoladas no estudo (Tabela 6), é possível imaginar que ocorreu uma contaminação cruzada horizontal nas fazendas A e B com uma única cepa de Salmonella Give, ocorrida durante o processamento na linha de abate. Embora as cepas isoladas nos animais destas duas fazendas tenham apresentado dois perfis genéticos distintos, o grau de semelhança entre eles foi muito elevado $(91,7 \%)$, com bastante semelhança entre os perfis de resistência a antibióticos também. As pequenas diferenças observadas nestas cepas podem ser decorrentes de problemas laboratoriais na execução do Etest, bem como na leitura e interpretação de resultados. Chama a atenção o fato de três das quatro cepas não tipáveis apresentarem o mesmo perfil genético que as cepas de $S$. Give, o que permite inferir que as cepas não tipáveis pertençam a este mesmo sorovar. Chama atenção também o fato de haver uma $S$. Abaetetuba com perfil genético idêntico ao de cinco cepas de $S$. Give isoladas em diferentes animais da Fazenda $B$, indicando que cepas de sorovares diferentes podem apresentar 0 mesmo perfil genético determinado pela PFGE, ou então, que tenha ocorrido um erro na tipagem desta cepa. Essa última hipótese, embora possível, é pouco provável, considerando que a sorotipagem completa das cepas foi realizada em laboratório nacional de referência de tipagem de enterobactérias.

Os resultados deste trabalho indicam que a incidência de Salmonella spp nas amostras analisadas foi baixa, mas foi possível detectar a ocorrência de cepas resistentes a vários antimicrobianos. Verificou-se também que animais diferentes, provenientes de uma mesma fazenda, apresentaram salmonelas de um mesmo sorovar e com o mesmo perfil genético e de resistência a drogas, comprovando a ocorrência de contaminação cruzada durante o processamento da carne bovina. Comprova-se uma vez mais que o uso de boas práticas de higiene no abate dos animais é uma medida importante para se evitar a contaminação de carcaças com esse patógeno. 
6. CONCLUSÖES 
Em função dos resultados obtidos neste estudo, é possível concluir que:

A prevalência de Salmonella spp nas amostras analisadas foi baixa. Embora $7,0 \%$ das amostras de couro analisadas tenham sido positivas para Salmonella spp, o patógeno foi detectado em somente $2,5 \%$ das carcaças após a esfola e em 2,0\% das carcaças após o toalete e antes da refrigeração;

> Entre as cepas de Salmonella spp isoladas, observou-se predominância daquelas pertencentes ao sorovar $S$. Give (52,0\%). Outros sorovares detectados foram S. Abaetetuba (16,0\%), S. Typhimurium (8,0\%), S. Agona (4,0\%), $S$. Dublin (4,0\%) e 16,0\% eram rugosas e foram classificadas como Salmonella enterica subespécie enterica cepa rugosa (não tipada);

$>$ A tipagem molecular, feita por PFGE, mostrou que as salmonelas expressaram 12 perfis genéticos distintos, sendo que 65,0\% pertenceram a dois perfis genéticos apenas, que apresentaram $91,7 \%$ de similaridade;

$>$ Os resultados do teste de invasão das células Caco-2 sugerem que a maioria das cepas de Salmonella spp isoladas apresentou baixo potencial de patogenicidade, pois apenas uma das 25 cepas testadas apresentou Eficiência de Invasão próxima daquela apresentada pelo controle positivo (Salmonella Typhimurium ATCC 14028), sendo necessários testes complementares para a confirmação destes resultados.

A freqüência de cepas resistentes a antimicrobianos foi elevada, sendo que $100,0 \%$ delas foram resistentes a pelo menos um antimicrobiano. Destas, 68,0\% apresentaram multiresistência a pelo menos três antimicrobianos;

$>$ Cepas de Salmonella, com o mesmo sorovar, perfil genético e perfil de resistência, detectadas em amostras de animais de determinada fazenda, confirmam a contaminação cruzada durante o processamento da carne bovina;

> Mesmo que a incidência de Salmonella spp nas amostras analisadas tenha sido baixa, o uso de boas práticas de higiene no abate dos animais é uma medida importante para se evitar a contaminação de carcaças com esse patógeno. 
7. REFER EANCIAS BIBLIOGRÁFICAS 
ALMEIDA, A.S.; GONÇALVES, P.M.R.; FRANCO, R.M. Salmonella em cortes de carne bovina inteiro e moído. Revista Higiene Alimentar, v.16, n.96, p.77-81, 2002.

AQUINO, J.S. de. Estudo microbiológico da carne moída comercializada na cidade de Manaus-Amazonas, análise de contaminação por bactéria do gênero Salmonella. 1991. 45p. Mestrado. Instituto Nacional de pesquisas da Amazônia Tecnologia de alimentos e nutrição.

ABIEC 2008 - ASSOCIAÇÃO BRASILEIRA DAS INDÚSTRIAS EXPORTADORAS DE CARNE. Exportação de carne bovina brasileira por país importador: Período de janeiro a outubro de 2008.2 Disponível em: http://www.abiec.com.br/tabela.asp?id_periodo=7. Acesso em: junho 2008

ABIEC 2009 - ASSOCIAÇÃO BRASILEIRA DAS INDÚSTRIAS EXPORTADORAS DE CARNE. Exportação de carne bovina brasileira por país importador: Período de janeiro a julho de 2009. Disponível em: http://www.abiec.com.br/download/EXP\%20JANJUL\%2009.pdf. Acesso em: agosto de 2009.

BACON, R.T.; SOFOS, J.N.; BELK, K.E.; HYATT, D.R.; SMITH, G.C. Prevalence and Antibiotic Susceptibility of Salmonella Isolated from Beef Animal Hides and Carcasses, Journal of Food Protection, v.65,p.284-290, 2002.

BARHAM, A.R.; BARHAM, B.L.; JOHNSON, A.K.; ALLEN, D.M.; BLANTON, J.R.; MILLER, M.F. Effects of the transportation of beef cattle from the feedyard to the packing plant on prevalence levels of Escherichia coli 0157 and Salmonella spp. Journal of Food Protection, v. 65, n. 2, p. 280-283, 2002.

BEACH, J.C.; MURANO, E.A.; ACUFF, G.R. Serotyping and Antibiotic Resistance Profiling of Salmonella in Feedlot and Nonfeedlot Beef Cattle. Journal of Food Protection, v.65, n.11, p.1694-99, 2002 
BERCHIERI, A.; FERNANDES, S.A.; IRINO, K.; QUINTANA, J.L.; SANTOS, A.J. Salmonella in poultry feeds in Brazil. Revista de Microbiologia, v.24, n.1, p.22-25, 1993.

BESSA, M.C.; MICHAEL, G.B.; CANU, N.; CANAL, C.W.; CARDOSO, M.; RABSCH, W.; RUBINO, S. Phenotypic and genetic characterization of Salmonella enterica subsp. enterica serovar Typhimurium isolated from pigs in Rio Grande do Sul, Brazil. Research in Veterinary Science, v.83, n.3, p.302-10, 2007.

BIEDENBACH, D.J.; TOLEMAN, M.; WALSH, T.K.; JONES, R.N. Analysis of Salmonella spp. with resistance to extended-spectrum cephalosporins and fluoroquinolones isolated in North America and Latin America: report from the SENTRY Antimicrobial Surveillance Program (1997-2004). Diagnostic Microbiology and Infectious Disease, v.54, p.13-21, 2006.

BRASIL 1998 - Portaria do Ministério da Agricultura, Pecuária e Abastecimento, no 193 de 12 de maio de 1998. Aprova o Regulamento Técnico para o licenciamento e a renovação de licença de antimicrobianos de uso veterinário, anexo, elaborado pela Secretaria de Defesa Agropecuária. D.O.U. de 13 / 05 / 1998.

BRASIL 1999 - Instrução Normativa do Ministério da Agricultura, Pecuária e Abastecimento, № 42 de 20 de dezembro de 1999. Altera o Plano Nacional de Controle de Resíduos em Produtos de Origem Animal - PNCR e os Programas de Controle de Resíduos em Carne - PCRC, Leite - PCRL e Pescado - PCRP. D.O.U. de 22 / 12 / 1999.

BRASIL 2001 - Resolução no 12 de 02 de janeiro de 2001, do Ministério da Saúde. Secretaria de Vigilância Sanitária. Regulamento técnico sobre padrões microbiológicos para alimentos. Diário Oficial da União, Brasília, DF, p. 45 - 53, 10 de janeiro de 2001, Secção I. Fica revogada / invalidada a portaria SVS / MS 451, de 19 de setembro de 1997. D.O.U. de 2 de junho de 1998. 
BRASIL 2003 - Ministério da Agricultura Pecuária e Abastecimento. Instrução Normativa $n^{\circ}$ 9, de 27 de junho de 2003. Proíbe a fabricação, a importação, a comercialização e o uso da substância química denominada Olaquindox, como aditivo promotor de crescimento em animais produtores de alimentos. D.O.U. 30 de junho de 2003.

BRASIL 2005 - Secretaria de Vigilância em Saúde. Vigilância epidemiológica das doenças transmitidas por alimentos no Brasil, 1999-2004. Boletim Eletrônico Epidemiológico ano $05 \quad$ n.06 p.2-7, 2005. Disponível em http://portal.saude.gov.br/portal/arquivos/pdf/apresentacao_dta.pdf (acesso em 28/04/2008)

BREAKWELL, G.M. Risk communication: factors affecting impact. British Medical Bulletin, v.56, n.1, p.110-20, 2000.

CARDOSO, M.O.; RIBEIRO, A.R.; SANTOS, L.R.; PILOTTO, F.; MORAES, H.L.S.; SALLE, C.T.P; ROCHA, S.L.S.; NASCIMENTO, V.P. Antibiotic resistance in Salmonella Enteritidis isolated from broiler carcasses. Brazilian Journal of Microbiology, v.37, n.3, p.368-71, 2006.

CASTANON, J.I. History of the use of antibiotic as growth promoters in European poultry feeds. Poultry Science, v.86, n.11, p.2466-71, 2007.

CDC 2000 - CENTERS FOR DISEASE CONTROL. One-Day (24-28 h) Standardized Laboratory Protocol for Molecular Subtyping of Escherichia coli O157:H7, nontyphoidal Salmonella serotypes, and Shigella sonnei by Pulsed Field Gel Electrophoresis (PFGE). In: PulseNet: The national molecular subtyping network for foodborne disease surveillance. Atlanta: Centers for Disease Control. Section, v.5, n.11, p.1-14 2000 .

CDC 2002 - CENTER OF DISEASE CONTROL AND PREVENTION. Salmonella Surveillance Summary, 2002. Atlanta, Georgia: US Department of Health and Human Services, 
http://www.cdc.gov/ncidod/dbmd/phlisdata/salmtab/2002/SalmonellaAnnualSummary 2002.pdf. Acesso em: 13 de dezembro de 2008.

CDC 2006a - CENTER OF DISEASE CONTROL AND PREVENTION. Salmonella Surveillance Summary, 2006. Atlanta, Georgia: US Department of Health and Human Services Disponível em: http://www.cdc.gov/ncidod/dbmd/phlisdata/salmtab/2006/SalmonellaAnnualSummary2006 .pdf. Acesso em: 13 de dezembro de 2008.

CDC, 2006b - CENTER OF DISEASE CONTROL AND PREVENTION. National antimicrobial Resistance monitoring system for Enteric Bacteria (NARMS): 2002 Human Isolates Final Report. Atlanta, Georgia: U.S. Department of Health and Human Services, CDC, 2006.

CVE - SP 2008 - CENTRO DE VIGILANCIA EPIDEMIOLÓGICA. Dados estatísticos de doenças transmitidas por alimentos no estado de São Paulo. Disponível em http://www.cve.saude.sp.gov.br/htm/hidrica/hidri_estat.html. Acesso em: 13 de dezembro de 2008.

CHEN, S.; ZHAO, S.; WHITE, D.G.; SCHROEDER, C.M.; LU, R.; YANG, H.; MCDERMOTT, P.F.; AYERS, S.; MENG1, J. Characterization of MultipleAntimicrobial-Resistant Salmonella Serovars Isolated from Retail Meats. Applied and Environmental Microbiology, v.70, p.1-7, 2004.

CIPARS 2005 - Canadian Integrated Program for Antimicrobial Resistance Surveillance. Disponível em: http://www.phac-aspc.gc.ca/cipars-picra/2005_e.html. Acesso em: abril 2008.

CLSI 2005 - CLINICAL AND LABORATORY STANDARDS INSTITUTE (CLSI)/NCCLS. Antimicrobial susceptibility testing standards M2-A8 and M7-A6. Performance standards for antimicrobial susceptibility testing; Fifteenth Informational Supplement. Villanova, Pa; 2005 
COBURN, B.; SEKIROV, I.; FINLAY, B.B. Type III secretion systems and disease. Clinical Microbiology Reviews, v.20, n.4, p.535-49, 2007.

COLLIGHAN, R.J.; WOODWARD, M.J. The SEF14 fimbrial antigen of Salmonella enterica serovar Enteritidis is encoded within a pathogenicity islet. Veterinary Microbiology, v.80, n.3, p.235-45, 2001.

COLLIS, V.J.; REID, C.A.; HUTCHISON, M.L.; DAVIES, M.H.; WHEELER, K.P.A.; SMALL, A.; BUNCIC, S. Hide contamination with marker bacteria on beef cattle in a simulated market and at an abattoir. EU-RAIN: farm-to-fork food safety. The Agricultural University of Athens, 2004.

D'AOUST, J. Y., MAURER, J. Salmonella species. In: Food Microbiology. Fundamentals and frontiers, $3^{\text {rd }}$ Ed. Edited by Doyle, M.P.; Beuchat, L.R., ASM Press, Washington, D.C., 2007, p. 187-236.

DARGATZ, D.A., FEDORKA-CRAY, P.J., LADELY, S.R. AND FERRIS, K.E. Survey of Salmonella serotypes in feces of beef cows and their antimicrobial susceptibility patterns. Journal of Food Protection v.63, p.1648-1653, 2000.

de LUNA, M.G.; SCOTT-TUCKER, A.; DESVAUX, M.; FERGUSON, P.; MORIN, N.P.; DUDLEY, E.G.; TURNER, S.; NATARO, J.P.; OWEN, P.; HENDERSON, I.R. The Escherichia coli biofilm-promoting protein antigen 43 does not contribute to intestinal colonization. FEMS Microbial. Lett. v.284, p.237-246, 2008.

DORAN, G.; NICHULAIN, M.; DELAPPE, N.; O'HARE, C.; CORBETT-FEENEY, G.; CORMICAN, M. Interpreting streptomycin susceptibility test results for Salmonella enterica serovar Typhimurium. International Journal of Antimicrobial Agents, v.27, p.538-540, 2006.

EDWARDS, R.A.; OLSEN, G.J.; MALOY, S.R. Comparative genomics of closely related Salmonellae. Trends in Microbiology , v.10, n.2, p.94-9, 2002. 
FEDORKA-CRAY, P.J.; DARGATZ, D.A.; THOMAS, L.A.; GRAY, J.T. Survey of Salmonella serotypes in feedlot cattle. Journal of Food Protection. v.61, p.525530, 1998.

FERNANDES, S.A.; GHILARDI, A.C.; TAVECHIO, A.T.; MACHADO, A.M.O.; PIGNATARI, A.C.C. Phenotypic and molecular characterization of Salmonella Enteritidis strains isolated in São Paulo, Brazil. Revista do Instituto de Medicina Tropical. São Paulo, v. 45, n.2, p.59-63, 2003.

FILE J.R.T.M. Overview of resistance in the 1990s. Chest, v.115, p.3-8, 1999.

FITZGERALD, A.C.; EDRINGTON, T.S.; LOOPER, M.L.; CALLOWAY, T.R.; GENOVESE, K.J.; BISCHOFF, K.M.; MCREYNOLDS, J.L.; THOMAS, J.D.; ANDERSON, R.C.; NESBET, D.J. Antimicrobial susceptibility and factors affecting the shedding of E. coli O157:H7 and Salmonella in dairy cattle. Letters in Applied Microbiology, v.37, p.392-398, 2003.

FOLEY, S.L.; ZHAO, S.; WALKER, R.D. Comparison of Molecular Typing Methods for the Differentiation of Salmonella Foodborne Pathogens. Foodborne Pathogens and Disease, v.4, p.253-276, 2007

FLUCKEY, W.M.; LONERAGAN, G.H.; WARNER, R.; BRASHEARS, M.M. Antimicrobial Drug Resistance of Salmonella and Escherichia coli Isolates from Cattle Feces, Hides, and Carcasses. Journal of Food Protection, v.70, n.3, p.551-556, 2007.

FLUIT, A.C. Towards more virulent and antibiotic-resistant Salmonella? FEMS Immunology and Medical Microbiology, v.43, n.1, p.1-11, 2005.

FONSECA, E.L.; MYKYTCZUK, O.L.; ASENSI, M.D.; REIS, E.M.; FERRAZ, L.R.; PAULA, F.L.; NG, L.K.; RODRIGUES, D.P. Clonality and antimicrobial resistance gene profiles of multidrug-resistant Salmonella enterica serovar Infantis isolates from 
four public hospitals in Rio de Janeiro, Brazil. Journal of Clinical Microbiology, v.44, n.8, p.2767-72, 2006.

FAO 2006 - FOOD AND AGRICULTURE ORGANIZATION OF THE UNITED NATIONS. Food and Nutrition Papers. Food safety risk analysis - A guide for national food safety authorities. Disponível em: ftp://ftp.fao.org/docrep/fao/009/a0822e/a0822e00.pdf. Acesso em: Fevereiro 2006.

FDA 2005 - FOOD AND DRUG ADMINISTRATION. Final decision of the commissione. Docket $n^{\circ} 2000 \mathrm{~N}-1571$. Withdrawal of approval of the new animal drug application for enrofloxacin in poultry. Disponível em: http://www.fda.gov/oc/antimicrobial/baytril.html. Acesso em: 15 abril 2008.

FDA / CFSAN 2008 - FOOD AND DRUG ADMINISTRATION, CENTER FOR FOOD SAFETY \& APPLIED NUTRITION. Foodborne pathogenic microorganisms and natural toxins handbook. "Bad Bug Book". http://www.cfsan.fda.gov/ mow/chap1.html. Acesso em: Maio de 2008.

FRANCO, B.D.G.M.; LANDGRAF, M. Microbiologia dos alimentos. São Paulo: Atheneu, 2005. 182p.

GHAFIR, Y.; CHINA, B.; KORSAK, N.; DIERICK, K.; COLLARD, J.M.; GODARD, C.; ZUTTER, L.; DAUBE, G. Belgian Surveillance Plans To Assess Changes in Salmonella Prevalence in Meat at Different Production Stages. Journal of Food Protection, v.68, n.11, p.2269-77, 2005.

GHILARDI, A.C.; TAVECHIO, A.T.; FERNANDES, S.A. Antimicrobial susceptibility, phage types, and pulsetypes of Salmonella Typhimurium, in São Paulo, Brazil. Mem. Inst. Oswaldo Cruz, v.101, n.3, p.281-6, 2006.

GIOMBELLI, A.; LOPES DA SILVA, N. Avaliação do método tradicional para detecção de Salmonella spp em carnes in natura. Revista Higiene Alimentar, v. 15, p.63-66, 2001. 
GRAZIANI, C.;BUSANI, L.; DIONISI, A.M.; LUCARELLI, C.; OWCZAREK, S.; RICCI, A.; MANCIN, M.; CAPRIOLI, A.; LUZZI, I. Antimicrobial resistance in Salmonella enterica serovar Typhimurium from human and animal sources in Italy. Veterinary Microbiology, v.128, p.414-418, 2008.

GUERRA, B.; SOTO, S.; CAL, S.; MENDOZA, M.C. Antimicrobial resistance and spread of class 1 integrons among Salmonella serotypes. Antimicrobial Agents and Chemotherapy, v. 44, p.2166-2169, 2000.

HELMS, M.; VASTRUP, P.; GEMER-SMIDT, P.; MOLBAK, K. Excess mortality associated with antimicrobial drug-resistant Salmonella Typhimurium. Journal Emerging Infectious Diseases, v.8, p.490-495, 2002.

HOLT, G.J.; KRIEG, R.N.; SNEATH, P.H.A.; STALEY, J.T.; WILLIAMS, S.T. Bergey's Manual of Determinative Bacteriology. 9 Ed. Willians \& Wilkins: Baltmore. 1994, 787p.

HUANG, X.Z.; TALL, B.; SCHWAN, W.R.; KOPECKO, D.J. Physical Limitations on Salmonella typhi Entry into Cultured Human Intestinal Epithelial Cells. Infection and Immunity, v.66, p. 2928-2937, 1998.

HUNTER, S.B.; VAUTERIN, P.; LAMBERT-FAIR, M.A.; VAN DUYNE, M.S.; KUBOTA, K.; GRAVES, L.; WRIGLEY, D.; BARETT, T.; RIBOT, E.M. Establishment of a universal size standard strain for use with the PulseNet standardized pulsedfield gel electrophoresis protocols: converting the national databases to the new size standard. Journal Clinical Microbiology, v.43, p.1045-1050, 2005.

HURLEY, B.P.; MCCORMICK, B.A. Translating tissue culture results into animal models: the case of Salmonella Typhimurium. Trends in Microbiology, v.11, p.562 - 569, 2003. 
ICMSF 2005 - INTERNATIONAL COMMISSION ON MICROBIOLOGICAL SPECIFICATIONS FOR FOODS. Microorganisms in Foods. 6. Microbial Ecology of Food Commodities. Kluwer Academic/Plenum Publishers.

ISO 2002 - INTERNATIONAL ORGANIZATION FOR STANDARDIZATION. ISO 6579. Microbiology of food and animal feeding stuffs - Horizontal method for the detection of Salmonella spp., $4^{\text {th }}$ ed, 2002

JAKABI, M.J. et al. Observações laboratoriais sobre surtos alimentares de Salmonella spp ocorridos na grande São Paulo, no período de 1994 a 1997. Revista do Instituto Adolfo Lutz, São Paulo, v.58, n.1, p.47-51, 1999.

JAY, J. M. Modern Food Microbiology. Maryland: Aspen, 6 ed, 2005. 679p.

JOHNSON, J. M., A. RAJIC, AND L. M. MCMULLEN. Antimicrobial resistance of selected Salmonella isolates from food animals and food in Alberta. Canadian Veterinary Journal, v.46, p.141-146, 2005.

JONES, Y. E., S. CHAPPELL, I. M. MCLAREN, R. H. DAVIES, AND C. WRAY. Antimicrobial resistance in Salmonella isolated from animals and their environment in England and Wales from 1988 to 1999. Veterinary Record, v.150, p.649-654, 2002.

KÉROUANTON, A.; MARAULT, M.; LAILLER, R.; WEILL, F.X.; FEURER, C.; ESPIÉ, E.; BRISABOIS, A. Pulsed-Field Gel Electrophoresis Subtyping Database for Foodborne Salmonella enterica Serotype Discrimination. Foodborne Pathogens and Disease, v.4, p.293-303, 2007.

KHAITSA, M.L.; KEGODE, R.B.; BAUER, M.L.; GIBBS, P.S.; LARDY, G.P.; DOETKOTT, D.K. A Longitudinal Study of Salmonella Shedding and Antimicrobial Resistance Patterns in North Dakota Feedlot Cattle. Journal of Food Protection, v.70, n.2, p.476-481, 2007. 
KIM, S.H.; WEI, C.I. Invasiveness and intracellular growth of multidrug-resistant Salmonella and other pathogens in Caco-2 cells. Journal of Food Science, v.72, p.M72 - M78, 2007.

KONEMAN, E. W.; STEPHEN, D. A.; WILLIAM, M. J. Diagnóstico Microbiológico. Texto e atlas colorido. 5 $5^{\text {a }}$ Ed. MEDSI - Editora Médica e Científica. Rio de Janeiro - RJ. 2001, 1465p.

MAIJALA, R.; JOHANSON, T.; HIRN, J. Growth of Salmonella and competing flora in five commercial Rappaport-Vassiliadis (RV) media. International Journal of Food Microbiology, v.17, p.1-8, 1992.

MALORNY, B.; HOORFARB, J.; HUGASC, M.; HEUVELINKD, A.; FACHE, P.; ELLERBROEKA, L.; BUNGEA, C.; DORNA, C.; HELMUTHA, R. Interlaboratory diagnostic accuracy of a Salmonella specific PCR-based method. International Journal of Food Microbiology, v.89, p.241-249, 2003.

MARCUS, S.L.; BRUMELL, J.H.; PFEIFER, C.G.; FINLAY, B.B. Salmonella pathogenicity islands: big virulence in small packages. Microbes Infections., v.2, n.2, p.145-56, 2000.

MEAKINS, S.; FISHER, I.S.; BERGHOLD, C.; GERNER-SMIDT, P.; TSCHÄPE, H.; CORMICAN, M.; LUZZI, I.; SCHNEIDER, F.; WANNETT, W.; COIA, J.; ECHEITA, A.; THRELFALL, E.J. Antimicrobial Drug Resistance in Human Nontyphoidal Salmonella Isolates in Europe 2000-2004: A Report from the Enter-net International Surveillance Network. Microbial Drug Resistance, v.14, p.31-35, 2008.

MENDES, L.M. Avaliação das condições higiênico - sanitárias da carne bovina in natura comercializada na cidade de Belém - PA. Belém: UFPA, 1996. Trabalho de conclusão de curso (Pós-graduação em tecnologia de alimentos). Departamento de Engenharia Química. Univ. Fed. Do Pará. 
MICHAEL, G.B.; CARDOSO, M.; SCHWARZ, S. Class 1 integron-associated gene cassettes in Salmonella enterica subsp. enterica serovar Agona isolated from pig carcasses in Brazil. Journal of Antimicrobial Chemotherapy, v.55, n.5, p.776-9, 2005.

MICHAEL, G.B.; CARDOSO, M.; RABSCH, W.; SCHWARZ, S. Phenotypic and genotypic differentiation of porcine Salmonella enterica subsp. enterica serovar Derby isolates. Veterinary Microbiology, v.118, n.3/4, p. 312-18, 2006.

MIDURA, T.F.; BRYANT, R.G. Sampling plans, sample collection, shipment, and preparation for analysis. In: Compendium of Methods for the microbiological examination of foods. American Public Health Association (APHA), Chap. 2, p.1323. 2001

MDICE 2008 - MINISTÉRIO DO DESENVOLVIMENTO, INDÚSTRIA E COMÉRCIO EXTERIOR. A cadeia produtiva de carnes. Departamento da Indústrias Intensivas em Mão-de-obra e Recursos Naturais. Disponível em: http://www.mdic.gov.br/sitio/interna/interna.php?area=2\&menu=855. Acesso em: junho 2008.

MOLLA, B.,ALEMAYEHU,D., SALAH,W. Sources and distribution of Salmonella serotypes isolated from food animals, slaughterhouse personnel and retail meat product in Ethiopia: 1997-2002. Ethiopia Journal Health Dev., v.17, p.63-70, 2003.

MUSKEN, A.; BIELASZEWSKA, M.; GREUNE, L.; SCHWEPPE, C.H.; MUTHING, J.; SCHMIDT, H.; SCHMIDT, M.A.; KARCH, H.; ZHANG, W. Anaerobic conditions promote expression of Sfp fimbriae and adherence of sorbitol-fermenting enterohemorrhagic Escherichia coli 0157:NM to human intestinal epithelial cells. Applied and Environmental Microbiology, v.74, p.1087-1093, 2008

NEL, S.; LUES, JF.R.; BUYS, E.M.; VENTER, P. Bacterial populations associated with meat from the deboning room of a high throughput red meat abattoir. Meat Science, v.66, p.667-74, 2004. 
OLIVEIRA, S.D.; SIQUEIRA FLORES, F.; DOS SANTOS, L.R.; BRANDELLI, A. Antimicrobial resistance in Salmonella Enteritidis strains isolated from broiler carcasses, food, human and poultry-related samples. International Journal of Food Microbiology, v.97, n.3, p.297- 305, 2005.

PARDI, M.C.; SANTOS, I.F.; SOUZA, E.R.; PARDI, H.S. Ciência e higiene da carne. tecnologia da sua obtenção e transformação. Universidade Federal Fluminense. EDUFF - Editora Universitária, 2001. 623p.

PHILLIPS, D.; SUMNER, J.; ALEXANDER, J.F.; DUTTON, K.M. Microbiological quality of Australian beef. Journal of Food Protection, v.64, p.692- 696, 2001.

PLACHÁ, I.; VENGLOVSKÝ, J.; SASÁKOVAÁ, N.; SVOBODA, I.F. The effect of summer and winter seasons on the survival of Salmonella Typhimurium and indicator micro-organism during the storage of solid fraction of pig slurry. Journal of Applied Microbiology, v.91, p.1036-1043, 2001.

POPOFF M.Y.; BOCKEMÜHL J.; GHEESLING L.L. Supplement 2002 (no. 46) to the Kauffmann-White scheme. Research in Microbiology, n.155 p.568-570, 2004.

POPOFF, M.Y.; LE MINOR, L.E. Genus XXXIII Salmonella. In: BRENNER, D.J., KRIEG, N.R.; STALEY, J.T. (Eds) Bergey's Manual of Sistematic Bacteriology, $2^{\text {nd }}$ Ed. Volume 2. New York: Springer Science + Bussiness Media Inc. p.764-799, 2005.

RANSOM, J.R.; BELK, K.E.; BACON, R.T.; SOFOS,J.N.; SCANGA, J.A.;SMITH, G.C. Comparison of sampling methods for microbiological testing of beef animal rectal / colonal feces hides and carcasses. Journal of Food Protection, v.65 p.621626, 2002.

RASMUSSEN, M.A.; CARLSON, S.A.; FRANKLIN, S.K.; MCCUDDIN, Z.P.; WU, M.T.; SHARMA, V.K. Exposure to rumenprotozoa leads to enhancement of 
pathogenicity of and invasion by multiple-antibiotic-resistant Salmonella enterica bearing SGI1. Infection And Immunity, v.73, p.4668-75, 2005.

RIBEIRO, A.R.; KELLERMANN, A.; DOS SANTOS, L.R.;. FITTÉL, A.P.; DO NASCIMENTO, V.P. Resistência antimicrobiana em Salmonella enterica subsp. enterica sorovar Hadar isoladas de carcaças de frango. Arquivos do Instituto Biológico, v.73, n.3, p.357-60, 2006.

RIVERA-BETANCOURT, M.; SHACKELFORD, S.D.; ARTHUR, T.M.; WESTMORELAND, K.E.; BELLINNGER, G.; ROSSMAN, M.; REAGAN, J.O.; KOOHMARAIE, M. Prevalence of Escherichia coli O157:H7, Listeria monocytogenes and Salmonella in two geographically distant commercial beef processing plants in the United States. Journal of Food Protection, v.67, p.295-302, 2004.

ROÇA, R.O.; SERRANO, A.M. Operações de abate de bovinos. Revista Higiene Alimentar, v.8, n.34, p.14-20, 1994.

ROÇA, R.O.; SERRANO, A.M. Abate de Bovinos: alterações Microbianas da Carcaça. Revista Higiene Alimentar, v.9, n.35, p.8-11, 1995.

SARMAH, A.K.; MEYER, M.T.; BOXALL, A.B. A global perspective on the use, sales, exposure pathways, occurrence, fate and effects of veterinary antibiotics (VAs) in the environment. Chemosphere, v.65, n.5, p. 725-59, 2006.

SCHLUNDT, J. New directions in food borne disease prevention. International Journal of Food Microbiology, v.78, p.3-17, 2002.

SIGARINI, C.O.; OLIVEIRA, L.A.T.; FIGUEIREDO, E.E.S.; CARVALHO, J.C.A.P. Avaliação microbiológica da carne bovina desossada, em estabelecimentos comerciais do município de Cuiabá, MT. Revista Higiene Alimentar, v.20, n.139, p.89-97, 2006. 
SKOV, M.N.; ANDERSEN, J.S.; AABO, S.; ETHELBERG, S.; AARESTRUP, F.M.; SORENSEN, A.H.; SORENSEN, G.; PEDERSEN, K.; NORDENTOFT, K.; OLSEN, K.E.P.; GERNER-SMIDT, P.; BAGGESENT, D.L. Antimicrobial Drug Resistance of Salmonella Isolates from Meat and Humans, Denmark. Emerging Infectious Diseases, v.13, p.638 - 641, 2007.

SILVA, N.; JUNQUEIRA, V.C.A.; SILVEIRA, N.F.A.; TANIWAKI, M.H.; SANTOS, R.F.S.; GOMES, R.A.R. Manual de Métodos de Análise Microbiológica de Alimentos - 3ed. - São Paulo: Varela, 2007, 552p.

SMALL, A.; JAMES, C.; JAMES, S.; DAVIES, R.; LIEBANA, E.; HOWELL, M.; HUTCHISON, M.; BUNCIC, S. Presence of Salmonella in the Red Meat Abattoir Lairage after Routine Cleansing and Disinfection and on Carcasses. Journal of Food Protection, v.69, n.10, p.2342-51, 2006.

SNEATH, P.H.A.; SOKAL, R.R. Numerical Taxonomy. San Francisco: Freeman, $573 p, 1973$.

SORENSEN, O., J. VAN DONKERSGOED, M. MCFALL, K. MANNINEN, G. GENSLER, AND G. OLLIS. Salmonella spp. shedding by Alberta beef cattle and the detection of Salmonella spp. in ground beef. Journal of Food Protection, v.65, p.484-491, 2002.

STEVENS, A.; KABORE, Y.; PERRIER-GROS-CLAUDE, J.D.; MILLEMANN, Y.; BRISABOIS, A.; CATTEAU, M.; CAVIN, J.F.; DUFOUR, B. Prevalence and antibiotic resistance of Salmonella isolated form beef sampled from the slaughterhouse and from retailers in Dakar (Senegal). International Journal of Food Microbiology, v.110, p.178-186, 2006.

STEVENS, A.; KEROUANTON, A.; MARAULT, M.; MILLEMANN, Y.; BRISABOIS, A.; CAVIN, J.F.; DUFOUR, B. Epidemiological analysis of Salmonella enterica from beef sampled in the slaughterhouse and retailers in Dakar (Senegal) using pulsedfield gel electrophoresis and antibiotic susceptibility testing. International Journal of Food Microbiology, v.123, p.191-197, 2008. 
TANCREDI, R.C.P. Prevalência de surtos de toxinfecções alimentares envolvendo alimentos de origem animal, ocorrido no município do Rio de Janeiro durante o período de 1986 a 1988. Niterói, 1990. p.135. Tese (mestrado em Medicina Veterinária) - Universidade Federal Fluminense.

THRELFALL, E.J.; DAY, M.; DE PINNA, E.; CHARLETT, A.; GOODYEAR, K.L. Assessment of factors contributing to changes in the incidence of antimicrobial drug resistance in Salmonella enterica serotypes Enteritidis and Typhimurium from humans in England and Wales in 2000, 2002 and 2004. International Journal of Antimicrobial Agents, v.28, n.5, p.389-95, 2006.

TRABULSI, L.R.; ALTERTHUM, F. Microbiologia - 5ed - São Paulo: Atheneu, 2008, p.579.

TRAVERS, K.; BARZA, M. Morbidity of infections caused by antimicrobial-resistant bacteria. Journal Clinical Infectious Diseases, v.34, p.S131-4, 2002.

VALDEZATE, S., A. VIDAL, S. HERRERA-LEON, et al. Salmonella Derby clonal spread from pork. Journal Emerging Infectious Diseases, v.11, p.694-698, 2005.

van DUIJKEREN, E.; WANNET, W.J.B.; HOUWERS, D.J.; VAN PELT, W. Antimicrobial susceptibilities of Salmonella strains isolated from humans, cattle, pigs, and chickens in The Netherlands. Journal of Clinical Microbiology, v.41, p.35743578, 2003.

VANDERLINDE, P.B.; SHAY, B.; MURRAY, J. Microbiological quality of Australian beef carcass meat and frozen bulk packed beef. Journal of Food Protection, v.61, p.437-643, 1998.

VARMA, J.; MOLBAK, S.; ROSSITER, S.; HAWKINS, M.; JONES, T.; MAUVAIS, S.; RABATSKY- HER, T.; STENZEL, S.; VUGIA, D.; PARK, M.; JOYCE, K.; CHANG, H.; ANGULO, F.; 2002. Antimicrobial resistance in Salmonella is associated with 
increased hospitalization: NARMS 1996-2000. Intl. Conference on Emerging Infectious Diseases, Atlanta, Ga. Disponível em: http://www.cdc.gov/enterics/publications/271Varma_2002.pdf Acesso em agosto de 2009.

WELLS, S.J.; FEDORKA-CRAY, P.J.; DARGATZ, D.A.; FERRIS, K.; GREEN, A. Fecal shedding of Salmonella spp. by dairy cows on farm and at cull cow markets. Journal of Food Protection, v.64, p.3-11, 2001.

WHITE, D.G.; ZHAO, S., SUDLER, R.; AYERS, S.; FRIEDMAN, S.; CHEN, S.; MCDERMOTT, P.F.; MCDERMOTT, S.; WAGNER, D.D.; MENG, J. The isolation of antibiotic resistant Salmonella from retail ground meat. New Engl. Journal of Medicine, v.345, p.1147-1154, 2001.

WOO, Y.K.; S.H. LEE. Genetic diversity of multiresistant Salmonella enterica serotype Typhimurium isolates from animals and humans. Journal Microbiology, v.44, p.106-112, 2006.

XAVIER, R.V.G.; JOELE, M.R.S.P. Avaliação das condições higiênico-sanitárias da carne bovina in natura comercializada na cidade de Belém - PA. Revista Higiene Alimentar, v.18, n.125, p.64-73, 2004.

XIA, X.; ZHAO, S.; SMITH, A.; MCEVOY, J.; MENG, J.; BHAGWAT, A.A. Characterization of Salmonella isolates from retail foods based on serotyping, pulse field gel electrophoresis, antibiotic resistance and other phenotypic properties. Revista International Journal of Food Microbiology, v.129, p.93-98, 2009.

ZHAO, S.; MAURER, J.J.; HUBERT, S.; DE VILLENA, J.F.; MCDERMOTT, P.F.; MENG,J.; AYERS, S.; ENGLISH, L.; WHITE, D.G. Antimicrobial susceptibility and molecular characterization of avian pathogenic Escherichia coli isolates. Veterinary Microbiology, v.107, p.215-224, 2005 
8. ANEXO 


\begin{tabular}{|c|c|c|c|c|c|}
\hline \multicolumn{6}{|c|}{$\begin{array}{l}\text { Anexo } 1 \text { - Distribuição dos Sorovares de Salmonella spp } \\
\text { amostras de bovinos, de acordo com a data de coleta, amc } \\
\text { município. }\end{array}$} \\
\hline \multirow{2}{*}{$\underset{\lambda}{\text { ANIMAL / }}$} & \multirow{2}{*}{$\begin{array}{l}\text { DATA DA } \\
\text { COLETA }^{\ominus}\end{array}$} & \multirow[b]{2}{*}{ AMOSTRA } & \multirow[b]{2}{*}{ SOROVAR } & \multicolumn{2}{|c|}{ PROCEDÊNCIA } \\
\hline & & & & FAZENDA & $\begin{array}{l}\text { ESTADO - } \\
\text { MUNICÍPIO }\end{array}$ \\
\hline 1 & $15 / 1 / 2008$ & Co, Ca I, Ca II & Aus & \multirow[t]{3}{*}{ A } & \multirow[t]{3}{*}{ MS - I } \\
\hline 2 & $15 / 1 / 2008$ & Co, Ca I, Ca II & Aus & & \\
\hline 3 & $15 / 1 / 2008$ & Ca II & S.Give & & \\
\hline 4 & $15 / 1 / 2008$ & Co, Ca I, Ca II & Aus & \multirow[t]{12}{*}{$B$} & \multirow[t]{12}{*}{ MS - II } \\
\hline 5 & $15 / 1 / 2008$ & Co & S.Give & & \\
\hline 6 & $15 / 1 / 2008$ & Co & S.Give & & \\
\hline 7 & $15 / 1 / 2008$ & Co & S.Give e enterica* & & \\
\hline \multirow[t]{3}{*}{8} & \multirow[t]{3}{*}{$15 / 1 / 2008$} & Co & S.Give e enterica* & & \\
\hline & & $\mathrm{Ca} \mathrm{I}$ & S.Give & & \\
\hline & & Ca II & S.Give & & \\
\hline \multirow[t]{2}{*}{9} & \multirow[t]{2}{*}{$15 / 1 / 2008$} & Co & S.Give & & \\
\hline & & $\mathrm{Ca} \mathrm{I}$ & enterica* & & \\
\hline \multirow[t]{3}{*}{10} & \multirow[t]{3}{*}{$15 / 1 / 2008$} & Co & S.Give & & \\
\hline & & Co & S.Typhimurium & & \\
\hline & & $\mathrm{Ca} \mathrm{I}$ & S.Give & & \\
\hline 11 & 20/2/2008 & Ca II & S.Typhimurium & \multirow[t]{10}{*}{$\mathrm{C}$} & \multirow[t]{10}{*}{$\mathrm{MS}-\mathrm{III}$} \\
\hline 12 & $20 / 2 / 2008$ & Co, Ca I, Ca II & Aus & & \\
\hline 13 & $20 / 2 / 2008$ & Co, Ca I, Ca II & Aus & & \\
\hline 14 & $20 / 2 / 2008$ & Co & S.Give & & \\
\hline 15 & $20 / 2 / 2008$ & Co, Ca I, Ca II & Aus & & \\
\hline 16 & $20 / 2 / 2008$ & Co & enterica* & & \\
\hline 17 & $20 / 2 / 2008$ & Co & S.Typhimurium & & \\
\hline 18 & $20 / 2 / 2008$ & Co, Ca I, Ca II & Aus & & \\
\hline 19 & $20 / 2 / 2008$ & Ca II & S.Give & & \\
\hline 20 & $20 / 2 / 2008$ & Co, Ca I, Ca II & Aus & & \\
\hline 21 & $5 / 3 / 2008$ & Co, Ca I, Ca II & Aus & \multirow[t]{5}{*}{ D } & \multirow[t]{5}{*}{ MS - IV } \\
\hline 22 & $5 / 3 / 2008$ & Co, Ca I, Ca II & Aus & & \\
\hline 23 & $5 / 3 / 2008$ & Co, Ca I, Ca II & Aus & & \\
\hline 24 & $5 / 3 / 2008$ & Co, Ca I, Ca II & Aus & & \\
\hline 25 & $5 / 3 / 2008$ & Co, Ca I, Ca II & Aus & & \\
\hline 26 & $5 / 3 / 2008$ & Co, Ca I, Ca II & Aus & \multirow[t]{3}{*}{$E$} & \multirow[t]{3}{*}{ PR-I } \\
\hline 27 & $5 / 3 / 2008$ & Co, Ca I, Ca II & Aus & & \\
\hline 28 & $5 / 3 / 2008$ & Co, Ca I, Ca II & Aus & & \\
\hline 29 & $5 / 3 / 2008$ & Co, Ca I, Ca II & Aus & \multirow[t]{2}{*}{$F$} & \multirow[t]{2}{*}{$\mathrm{MS}-\mathrm{V}$} \\
\hline 30 & $5 / 3 / 2008$ & Co, Ca I, Ca II & Aus & & \\
\hline 31 & $25 / 3 / 2008$ & Co, Ca I, Ca II & Aus & $G$ & $\mathrm{MS}-\mathrm{VI}$ \\
\hline 32 & $25 / 3 / 2008$ & Co, Ca I, Ca II & Aus & & \\
\hline 33 & $25 / 3 / 2008$ & Co, Ca I, Ca II & Aus & & \\
\hline 34 & $25 / 3 / 2008$ & Co & S.Agona & & \\
\hline 35 & $25 / 3 / 2008$ & Co, Ca I, Ca II & Aus & & \\
\hline 36 & $25 / 3 / 2008$ & Co, Ca I, Ca II & Aus & & \\
\hline
\end{tabular}




\begin{tabular}{|c|c|c|c|c|c|}
\hline \multicolumn{6}{|c|}{$\begin{array}{l}\text { Anexo } 1 \text { - Distribuição dos Sorovares de Salmonella spp em diferentes } \\
\text { amostras de bovinos, de acordo com a data de coleta, amostra, fazenda e } \\
\text { município (cont.). }\end{array}$} \\
\hline \multirow{2}{*}{$\underset{\delta}{\text { ANIMAL / }}$} & \multirow{2}{*}{$\begin{array}{l}\text { DATA DA } \\
\text { COLETA }^{\ominus}\end{array}$} & \multirow[b]{2}{*}{ AMOSTRA } & \multirow[b]{2}{*}{ SOROVAR } & \multicolumn{2}{|c|}{ PROCEDÊNCIA } \\
\hline & & & & FAZENDA & $\begin{array}{l}\text { ESTADO - } \\
\text { MUNICÍPIO }\end{array}$ \\
\hline 37 & $25 / 3 / 2008$ & Co, Ca I, Ca II & Aus & \multirow[t]{4}{*}{ G } & \multirow[t]{4}{*}{$\mathrm{MS}-\mathrm{VI}$} \\
\hline 38 & $25 / 3 / 2008$ & Co, Ca I, Ca II & Aus & & \\
\hline 39 & $25 / 3 / 2008$ & Co, Ca I, Ca II & Aus & & \\
\hline 40 & $25 / 3 / 2008$ & Co, Ca I, Ca II & Aus & & \\
\hline 41 & $14 / 4 / 2008$ & Co, Ca I, Ca II & Aus & \multirow[t]{15}{*}{$\mathrm{H}$} & \multirow[t]{15}{*}{ MS -II } \\
\hline 42 & $14 / 4 / 2008$ & Co, Ca I, Ca II & Aus & & \\
\hline 43 & $14 / 4 / 2008$ & Co, Ca I, Ca II & Aus & & \\
\hline 44 & $14 / 4 / 2008$ & Co, Ca I, Ca II & Aus & & \\
\hline 45 & $14 / 4 / 2008$ & Co, Ca I, Ca II & Aus & & \\
\hline 46 & $14 / 4 / 2008$ & Co, Ca I, Ca II & Aus & & \\
\hline 47 & $14 / 4 / 2008$ & Co, Ca I, Ca II & Aus & & \\
\hline 48 & $14 / 4 / 2008$ & Co, Ca I, Ca II & Aus & & \\
\hline 49 & $14 / 4 / 2008$ & Co, Ca I, Ca II & Aus & & \\
\hline 50 & $14 / 4 / 2008$ & Co, Ca I, Ca II & Aus & & \\
\hline 51 & $14 / 4 / 2008$ & Co, Ca I, Ca II & Aus & & \\
\hline 52 & $14 / 4 / 2008$ & Co, Ca I, Ca II & Aus & & \\
\hline 53 & $14 / 4 / 2008$ & Co, Ca I, Ca II & Aus & & \\
\hline 54 & $14 / 4 / 2008$ & Co, Ca I, Ca II & Aus & & \\
\hline 55 & $14 / 4 / 2008$ & Co, Ca I, Ca II & Aus & & \\
\hline 56 & $16 / 5 / 2008$ & Co, Ca I, Ca II & Aus & \multirow[t]{13}{*}{ I } & \multirow[t]{13}{*}{$S P-I$} \\
\hline 57 & $16 / 5 / 2008$ & Co, Ca I, Ca II & Aus & & \\
\hline 58 & $16 / 5 / 2008$ & Co, Ca I, Ca II & Aus & & \\
\hline 59 & $16 / 5 / 2008$ & Co, Ca I, Ca II & Aus & & \\
\hline 60 & $16 / 5 / 2008$ & Co, Ca I, Ca II & Aus & & \\
\hline 61 & $16 / 5 / 2008$ & Co, Ca I, Ca II & Aus & & \\
\hline 62 & $16 / 5 / 2008$ & Co, Ca I, Ca II & Aus & & \\
\hline 63 & $16 / 5 / 2008$ & Co, Ca I, Ca II & Aus & & \\
\hline 64 & $16 / 5 / 2008$ & Co, Ca I, Ca II & Aus & & \\
\hline 65 & $16 / 5 / 2008$ & Co, Ca I, Ca II & Aus & & \\
\hline 66 & $16 / 5 / 2008$ & Co, Ca I, Ca II & Aus & & \\
\hline 67 & $16 / 5 / 2008$ & Co, Ca I, Ca II & Aus & & \\
\hline 68 & $16 / 5 / 2008$ & Co, Ca I, Ca II & Aus & & \\
\hline 69 & $16 / 5 / 2008$ & Co, Ca I, Ca II & Aus & \multirow[t]{2}{*}{$J$} & \multirow[t]{2}{*}{$\mathrm{MS}-\mathrm{III}$} \\
\hline 70 & $16 / 5 / 2008$ & Co, Ca I, Ca II & Aus & & \\
\hline 71 & $5 / 6 / 2008$ & Co, Ca I, Ca II & Aus & \multirow[t]{8}{*}{$\mathrm{K}$} & \multirow[t]{8}{*}{ GO - I } \\
\hline 72 & $5 / 6 / 2008$ & Co, Ca I, Ca II & Aus & & \\
\hline 73 & $5 / 6 / 2008$ & Co, Ca I, Ca II & Aus & & \\
\hline 74 & $5 / 6 / 2008$ & Co, Ca I, Ca II & Aus & & \\
\hline 75 & $5 / 6 / 2008$ & Co, Ca I, Ca II & Aus & & \\
\hline 76 & $5 / 6 / 2008$ & Co, Ca I, Ca II & Aus & & \\
\hline 77 & $5 / 6 / 2008$ & Co, Ca I, Ca II & Aus & & \\
\hline 78 & $5 / 6 / 2008$ & Co, Ca I, Ca II & Aus & & \\
\hline
\end{tabular}




\begin{tabular}{|c|c|c|c|c|c|}
\hline \multicolumn{6}{|c|}{$\begin{array}{l}\text { Anexo } 1 \text { - Distribuição dos Sorovares de Salmonella spp em diferente } \\
\text { amostras de bovinos, de acordo com a data de coleta, amostra, fazenda } \\
\text { município. }\end{array}$} \\
\hline \multirow{2}{*}{$\underset{\delta}{\operatorname{ANIMAL} /}$} & \multirow{2}{*}{$\begin{array}{l}\text { DATA DA } \\
\text { COLETA }\end{array}$} & \multirow[b]{2}{*}{ AMOSTRA } & \multirow[b]{2}{*}{ SOROVAR } & \multicolumn{2}{|c|}{ PROCEDÊNCIA } \\
\hline & & & & FAZENDA & $\begin{array}{l}\text { ESTADO - } \\
\text { MUNICÍPIO }\end{array}$ \\
\hline 79 & $5 / 6 / 2008$ & Co, Ca I, Ca II & Aus & \multirow[t]{8}{*}{$\mathrm{K}$} & \multirow[t]{8}{*}{ GO - I } \\
\hline 80 & $5 / 6 / 2008$ & Co, Ca I, Ca II & Aus & & \\
\hline 81 & $5 / 6 / 2008$ & Co, Ca I, Ca II & Aus & & \\
\hline 82 & $5 / 6 / 2008$ & Co, Ca I, Ca II & Aus & & \\
\hline 83 & $5 / 6 / 2008$ & Co, Ca I, Ca II & Aus & & \\
\hline \multirow[t]{2}{*}{84} & $5 / 6 / 2008$ & Co & Agona & & \\
\hline & $5 / 6 / 2008$ & $\mathrm{Ca}$ I, Ca II & Aus & & \\
\hline 85 & $5 / 6 / 2008$ & Co, Ca I, Ca II & Aus & & \\
\hline 86 & $13 / 8 / 2008$ & Co, Ca I, Ca II & Aus & \multirow[t]{26}{*}{ L } & \multirow[t]{26}{*}{$\mathrm{SP}-\mathrm{II}$} \\
\hline 87 & $13 / 8 / 2008$ & Co, Ca I, Ca II & Aus & & \\
\hline 88 & $13 / 8 / 2008$ & Co, Ca I, Ca II & Aus & & \\
\hline 89 & $13 / 8 / 2008$ & Co, Ca I, Ca II & Aus & & \\
\hline \multirow[t]{2}{*}{90} & $13 / 8 / 2008$ & $\mathrm{CaI}$ & Abaetetuba & & \\
\hline & $13 / 8 / 2008$ & Co, Ca II & Aus & & \\
\hline 91 & $13 / 8 / 2008$ & Co, Ca I, Ca II & Aus & & \\
\hline 92 & $13 / 8 / 2008$ & Co, Ca I, Ca II & Aus & & \\
\hline 93 & $13 / 8 / 2008$ & Co, Ca I, Ca II & Aus & & \\
\hline 94 & $13 / 8 / 2008$ & Co, Ca I, Ca II & Aus & & \\
\hline 95 & $13 / 8 / 2008$ & Co, Ca I, Ca II & Aus & & \\
\hline 96 & 13/8/2008 & Co, Ca I, Ca II & Aus & & \\
\hline 97 & $13 / 8 / 2008$ & Co, Ca I, Ca II & Aus & & \\
\hline \multirow[t]{2}{*}{98} & 13/8/2008 & Co & Abaetetuba & & \\
\hline & $13 / 8 / 2008$ & Ca I, Ca II & Aus & & \\
\hline 99 & $13 / 8 / 2008$ & Co, Ca I, Ca II & Aus & & \\
\hline 100 & $13 / 8 / 2008$ & Co, Ca I, Ca II & Aus & & \\
\hline 101 & $13 / 8 / 2008$ & Co, Ca I, Ca II & Aus & & \\
\hline 102 & $13 / 8 / 2008$ & Co, Ca I, Ca II & Aus & & \\
\hline 103 & $13 / 8 / 2008$ & Co, Ca I, Ca II & Aus & & \\
\hline 104 & 13/8/2008 & Co, Ca I, Ca II & Aus & & \\
\hline 105 & $13 / 8 / 2008$ & Co, Ca I, Ca II & Aus & & \\
\hline 106 & $13 / 8 / 2008$ & Co, Ca I, Ca II & Aus & & \\
\hline \multirow[t]{2}{*}{107} & $13 / 8 / 2008$ & Co & Abaetetuba & & \\
\hline & $13 / 8 / 2008$ & Ca I, Ca II & Aus & & \\
\hline 108 & $13 / 8 / 2008$ & Co, Ca I, Ca II & Aus & & \\
\hline 109 & $24 / 9 / 2008$ & Co, Ca I, Ca II & Aus & \multirow[t]{8}{*}{$\mathrm{M}$} & \multirow[t]{8}{*}{ SP - III } \\
\hline 110 & $24 / 9 / 2008$ & Co, Ca I, Ca II & Aus & & \\
\hline 111 & $24 / 9 / 2008$ & Co, Ca I, Ca II & Aus & & \\
\hline 112 & $24 / 9 / 2008$ & Co, Ca I, Ca II & Aus & & \\
\hline 113 & $24 / 9 / 2008$ & Co, Ca I, Ca II & Aus & & \\
\hline 114 & $24 / 9 / 2008$ & Co, Ca I, Ca II & Aus & & \\
\hline 115 & $24 / 9 / 2008$ & Co, Ca I, Ca II & Aus & & \\
\hline 116 & $24 / 9 / 2008$ & Co, Ca I, Ca II & Aus & & \\
\hline
\end{tabular}




\begin{tabular}{|c|c|c|c|c|c|}
\hline $\begin{array}{l}\text { Anexo } 1 \\
\text { amostras } \\
\text { municípic }\end{array}$ & $\begin{array}{l}\text { Distribuiçá } \\
\text { bovinos, } \\
\text { ont.). }\end{array}$ & $\begin{array}{l}\text { Jos Sorova } \\
\text { acordo con }\end{array}$ & $\begin{array}{l}\text { de Sall } \\
\text { data de }\end{array}$ & $\begin{array}{l}\text { nella sp } \\
\text { bleta, am }\end{array}$ & $\begin{array}{l}\text { m diferer } \\
\text { a, fazend }\end{array}$ \\
\hline & & & & PRC & DÊNCIA \\
\hline$\underset{0}{0}$ & COLETA & AMOSTRA & SOROVAR & FAZENDA & $\begin{array}{l}\text { ESTADO - } \\
\text { MUNICÍPIO }\end{array}$ \\
\hline 117 & 24/9/2008 & Co, Ca I, Ca II & Aus & $M$ & SP - III \\
\hline 118 & $24 / 9 / 2008$ & Co, Ca I, Ca II & Aus & & \\
\hline 119 & $24 / 9 / 2008$ & Co, Ca I, Ca II & Aus & & \\
\hline 120 & $24 / 9 / 2008$ & Co, Ca I, Ca II & Aus & & \\
\hline 121 & $24 / 9 / 2008$ & Co, Ca I, Ca II & Aus & & \\
\hline 122 & $24 / 9 / 2008$ & Co, Ca I, Ca II & Aus & & \\
\hline 123 & $24 / 9 / 2008$ & Co, Ca I, Ca II & Aus & & \\
\hline 124 & $24 / 9 / 2008$ & Co, Ca I, Ca II & Aus & & \\
\hline 125 & $24 / 9 / 2008$ & Co, Ca I, Ca II & Aus & & \\
\hline 126 & $24 / 9 / 2008$ & Co, Ca I, Ca II & Aus & & \\
\hline 127 & 24/9/2008 & Co, Ca I, Ca II & Aus & & \\
\hline 128 & $24 / 9 / 2008$ & Co, Ca I, Ca II & Aus & & \\
\hline 129 & 24/9/2008 & Co, Ca I, Ca II & Aus & & \\
\hline 130 & $24 / 9 / 2008$ & Co, Ca I, Ca II & Aus & & \\
\hline 131 & $24 / 9 / 2008$ & Co, Ca I, Ca II & Aus & & \\
\hline 132 & $15 / 10 / 2008$ & Co, Ca I, Ca II & Aus & $\mathrm{N}$ & $\mathrm{SP}-\mathrm{IV}$ \\
\hline 133 & $15 / 10 / 2008$ & Co, Ca I, Ca II & Aus & & \\
\hline 134 & $15 / 10 / 2008$ & Co, Ca I, Ca II & Aus & & \\
\hline 135 & $15 / 10 / 2008$ & Co, Ca I, Ca II & Aus & & \\
\hline 136 & $15 / 10 / 2008$ & Co, Ca I, Ca II & Aus & & \\
\hline 137 & $15 / 10 / 2008$ & Co, Ca I, Ca II & Aus & & \\
\hline 138 & $15 / 10 / 2008$ & Co, Ca I, Ca II & Aus & & \\
\hline 139 & $15 / 10 / 2008$ & Co, Ca I, Ca II & Aus & & \\
\hline 140 & $15 / 10 / 2008$ & Co, Ca I, Ca II & Aus & & \\
\hline 141 & $15 / 10 / 2008$ & Co, Ca I, Ca II & Aus & & \\
\hline 142 & $15 / 10 / 2008$ & Co, Ca I, Ca II & Aus & & \\
\hline 143 & $15 / 10 / 2008$ & Co, Ca I, Ca II & Aus & & \\
\hline 144 & $15 / 10 / 2008$ & Co, Ca I, Ca II & Aus & & \\
\hline 145 & $15 / 10 / 2008$ & Co, Ca I, Ca II & Aus & & \\
\hline 146 & $15 / 10 / 2008$ & Co, Ca I, Ca II & Aus & & \\
\hline 147 & $15 / 10 / 2008$ & Co, Ca I, Ca II & Aus & & \\
\hline 148 & $15 / 10 / 2008$ & Co, Ca I, Ca II & Aus & & \\
\hline 149 & $15 / 10 / 2008$ & Co, Ca I, Ca II & Aus & $\mathrm{O}$ & GO - II \\
\hline 150 & $15 / 10 / 2008$ & Co, Ca I, Ca II & Aus & & \\
\hline 151 & $15 / 10 / 2008$ & Co, Ca I, Ca II & Aus & & \\
\hline 152 & $15 / 10 / 2008$ & Co, Ca I, Ca II & Aus & & \\
\hline 153 & $15 / 10 / 2008$ & Co, Ca I, Ca II & Aus & & \\
\hline 154 & $15 / 10 / 2008$ & Co, Ca I, Ca II & Aus & & \\
\hline 155 & $4 / 11 / 2008$ & Co, Ca I, Ca II & Aus & $P$ & $S P-V$ \\
\hline 156 & $4 / 11 / 2008$ & Co, Ca I, Ca II & Aus & & \\
\hline 157 & $4 / 11 / 2008$ & Co, Ca I, Ca II & Aus & & \\
\hline 158 & 4/11/2008 & Co, Ca I, Ca II & Aus & & \\
\hline
\end{tabular}




\begin{tabular}{|c|c|c|c|c|c|}
\hline \multicolumn{6}{|c|}{$\begin{array}{l}\text { Anexo } 1 \text { - Distribuição dos Sorovares de Salmonella spp em diferentes } \\
\text { amostras de bovinos, de acordo com a data de coleta, amostra, fazenda e } \\
\text { município. }\end{array}$} \\
\hline \multirow{2}{*}{$\underset{\delta}{\operatorname{ANIMAL} /}$} & \multirow{2}{*}{$\begin{array}{l}\text { DATA DA } \\
\text { COLETA }\end{array}$} & \multirow[b]{2}{*}{ AMOSTRA } & \multirow[b]{2}{*}{ SOROVAR } & \multicolumn{2}{|c|}{ PROCEDÊNCIA } \\
\hline & & & & FAZENDA & $\begin{array}{l}\text { ESTADO - } \\
\text { MUNICÍPIO }\end{array}$ \\
\hline 159 & $4 / 11 / 2008$ & Co, Ca I, Ca II & Aus & \multirow[t]{19}{*}{$P$} & \multirow[t]{19}{*}{$\mathrm{SP}-\mathrm{V}$} \\
\hline 160 & $4 / 11 / 2008$ & Co, Ca I, Ca II & Aus & & \\
\hline 161 & $4 / 11 / 2008$ & Co, Ca I, Ca II & Aus & & \\
\hline 162 & $4 / 11 / 2008$ & Co, Ca I, Ca II & Aus & & \\
\hline 163 & $4 / 11 / 2008$ & Co, Ca I, Ca II & Aus & & \\
\hline 164 & $4 / 11 / 2008$ & Co, Ca I, Ca II & Aus & & \\
\hline 165 & $4 / 11 / 2008$ & Co, Ca I, Ca II & Aus & & \\
\hline 166 & $4 / 11 / 2008$ & Co, Ca I, Ca II & Aus & & \\
\hline 167 & $4 / 11 / 2008$ & Co, Ca I, Ca II & Aus & & \\
\hline 168 & $4 / 11 / 2008$ & $\mathrm{Co}, \mathrm{Ca}$ I, Ca II & Aus & & \\
\hline 169 & $4 / 11 / 2008$ & Co, Ca I, Ca II & Aus & & \\
\hline 170 & $4 / 11 / 2008$ & Co, Ca I, Ca II & Aus & & \\
\hline 171 & $4 / 11 / 2008$ & Co, Ca I, Ca II & Aus & & \\
\hline 172 & $4 / 11 / 2008$ & Co, Ca I, Ca II & Aus & & \\
\hline 173 & $4 / 11 / 2008$ & Co, Ca I, Ca II & Aus & & \\
\hline 174 & $4 / 11 / 2008$ & Co, Ca I, Ca II & Aus & & \\
\hline 175 & $4 / 11 / 2008$ & Co, Ca I, Ca II & Aus & & \\
\hline 176 & $4 / 11 / 2008$ & $\mathrm{Co}, \mathrm{Ca}$ I, Ca II & Aus & & \\
\hline 177 & $4 / 11 / 2008$ & Co, Ca I, Ca II & Aus & & \\
\hline 178 & $5 / 12 / 2008$ & Co, Ca I, Ca II & Aus & \multirow[t]{21}{*}{ Q } & \multirow[t]{21}{*}{$\mathrm{SP}-\mathrm{VI}$} \\
\hline 179 & $5 / 12 / 2008$ & Co, Ca I, Ca II & Aus & & \\
\hline 180 & $5 / 12 / 2008$ & Co, Ca I, Ca II & Aus & & \\
\hline 181 & $5 / 12 / 2008$ & Co, Ca I, Ca II & Aus & & \\
\hline 182 & $5 / 12 / 2008$ & Co, Ca I, Ca II & Aus & & \\
\hline 183 & $5 / 12 / 2008$ & Co, Ca I, Ca II & Aus & & \\
\hline 184 & $5 / 12 / 2008$ & Co, Ca I, Ca II & Aus & & \\
\hline 185 & $5 / 12 / 2008$ & Co, Ca I, Ca II & Aus & & \\
\hline 186 & $5 / 12 / 2008$ & Co, Ca I, Ca II & Aus & & \\
\hline 187 & $5 / 12 / 2008$ & Co, Ca I, Ca II & Aus & & \\
\hline 188 & $5 / 12 / 2008$ & Co, Ca I, Ca II & Aus & & \\
\hline 189 & $5 / 12 / 2008$ & Co, Ca I, Ca II & Aus & & \\
\hline 190 & $5 / 12 / 2008$ & Co, Ca I, Ca II & Aus & & \\
\hline 191 & $5 / 12 / 2008$ & Co, Ca I, Ca II & Aus & & \\
\hline 192 & $5 / 12 / 2008$ & Co, Ca I, Ca II & Aus & & \\
\hline 193 & $5 / 12 / 2008$ & Co, Ca I, Ca II & Aus & & \\
\hline 194 & $5 / 12 / 2008$ & Co, Ca I, Ca II & Aus & & \\
\hline 195 & $5 / 12 / 2008$ & Co, Ca I, Ca II & Aus & & \\
\hline 196 & $5 / 12 / 2008$ & Co, Ca I, Ca II & Aus & & \\
\hline 197 & $5 / 12 / 2008$ & Co, Ca I, Ca II & Aus & & \\
\hline 198 & $5 / 12 / 2008$ & Co, Ca I, Ca II & Aus & & \\
\hline $199 q$ & $5 / 1 / 2009$ & Co, Ca I, Ca II & Aus & \multirow[t]{2}{*}{$\mathrm{R}$} & \multirow[t]{2}{*}{$\mathrm{MS}-\mathrm{VII}$} \\
\hline $200 q$ & $5 / 1 / 2009$ & Co, Ca I, Ca II & Aus & & \\
\hline
\end{tabular}


